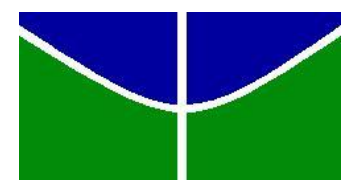

UNIVERSIDADE DE BRASÍLIA

INSTITUTO DE CIÊNCIAS HUMANAS

DEPARTAMENTO DE GEOGRAFIA

PROGRAMA DE PÓS-GRADUAÇÃO EM GEOGRAFIA

ANÁLISE ESPACIAL DA HANTAVIROSE POR MEIO DO USO DE SISTEMAS DE INFORMAÇÕES GEOGRÁFICAS E DE MODELAGEM DE NICHO ECOLÓGICO NO ESTADO DE GOIÁS E NO DISTRITO FEDERAL.

JANDUHY PEREIRA DOS SANTOS

Tese de Doutorado 
UNIVERSIDADE DE BRASÍLIA

INSTITUTO DE CIÊNCIAS HUMANAS

DEPARTAMENTO DE GEOGRAFIA

PROGRAMA DE PÓS-GRADUAÇÃO EM GEOGRAFIA

\title{
ANÁLISE ESPACIAL DA HANTA VIROSE POR MEIO DO USO DE SISTEMAS DE INFORMAÇÕES GEOGRÁFICAS E DE MODELAGEM DE NICHO ECOLÓGICO NO ESTADO DE GOIÁS E NO DISTRITO FEDERAL.
}

\author{
JANDUHY PEREIRA DOS SANTOS
}

Tese apresentada como requisito parcial à obtenção do grau de Doutor, pelo curso de Pós-Graduação em Geografia, Instituto de Ciências Humanas, da Universidade de Brasília.

Orientador: Prof. Dr. Valdir Adilson Steinke

Brasília-DF: Abril/ 2015 


\section{ANÁliSE ESPACIAL DA HANTAVIROSE POR MEIO DO USO DE SISTEMAS DE INFORMAÇÕES GEOGRÁFICAS E DE MODELAGEM DE NICHO ECOLÓGICO NO ESTADO DE GOIÁS E NO DISTRITO FEDERAL.}

\section{JANDUHY PEREIRA DOS SANTOS}

Tese de Doutorado submetida ao Departamento de Geografia da Universidade de Brasília, como parte dos requisitos necessários para a obtenção do Grau de Doutor em Geografia, área de concentração Gestão Ambiental e Territorial, opção Acadêmica.

Aprovado por:

Orientador:

Prof. Dr. Valdir Adilson Steinke

Departamento de Geografia, GEA/IH/UnB.

Membro externo:

Profa. Dra. Ruth Elias de Paula Laranja

Departamento de Geografia, GEA/IH/UnB.

Membro externo:

Prof. Dr. Mario Diniz de Araújo Neto

Departamento de Geografia, GEA/IH/UnB.

Membro externo:

Prof. Dr. Carlos Hiroo Saito

Departamento de Ecologia, ECL/CDS/UnB.

Membro externo:

Profa. Dra. Maria Margarita Urdaneta Gutierrez

Faculdade de Ciências da Saúde, DSC/FS/UnB.

Brasília, 10 de abril de 2015. 


\section{FICHA CATALOGRÁFICA}

SANTOS, JANDUHY PEREIRA DOS.

Análise espacial da Hantavirose por meio do uso de sistemas de informações geográficas e de Modelagem de Nicho Ecológico no Estado de Goiás e no Distrito Federal, 148 p., $75 \mathrm{~g} / \mathrm{m}^{2}$ (GEA/IH/UnB, Doutor, Geografia, 2015). Tese de Doutorado - Universidade de Brasília. Instituto de Ciências Humanas. Departamento de Geografia.

1. Hantavirose

3. Análise espacial

I. GEA/IH/UnB
2. Modelagem de Nicho Ecológico

4. Sistemas de Informações Geográficas

II.Título (Série)

\section{REFERÊNCIA BIBLIOGRÁFICA}

SANTOS, J. P. Análise espacial da Hantavirose por meio do uso de sistemas de informações geográficas e de Modelagem de Nicho Ecológico no Estado de Goiás e no Distrito Federal. Tese (Doutorado), publicação GEA. TD, Departamento de Geografia, Universidade de Brasília, Brasília, DF, 148 p.

\section{CESSÃO DE DIREITOS}

NOME DO AUTOR: Janduhy Pereira dos Santos

TÍTULO DA TESE DE DOUTORADO: Análise espacial da Hantavirose por meio do uso de sistemas de informações geográficas e de Modelagem de Nicho Ecológico no Estado de Goiás e no Distrito Federal.

\section{GRAU/ANO: Doutor/2015}

É concedida à Universidade de Brasília permissão para produzir cópias desta tese de doutorado e para emprestar ou vender tais cópias somente para propósitos acadêmicos ou científicos. O autor reserva outros direitos de publicação e nenhuma parte desta tese de doutorado pode ser reproduzida sem autorização por escrito do autor.

Janduhy Pereira dos Santos 


\section{DEDICATÓRIA}

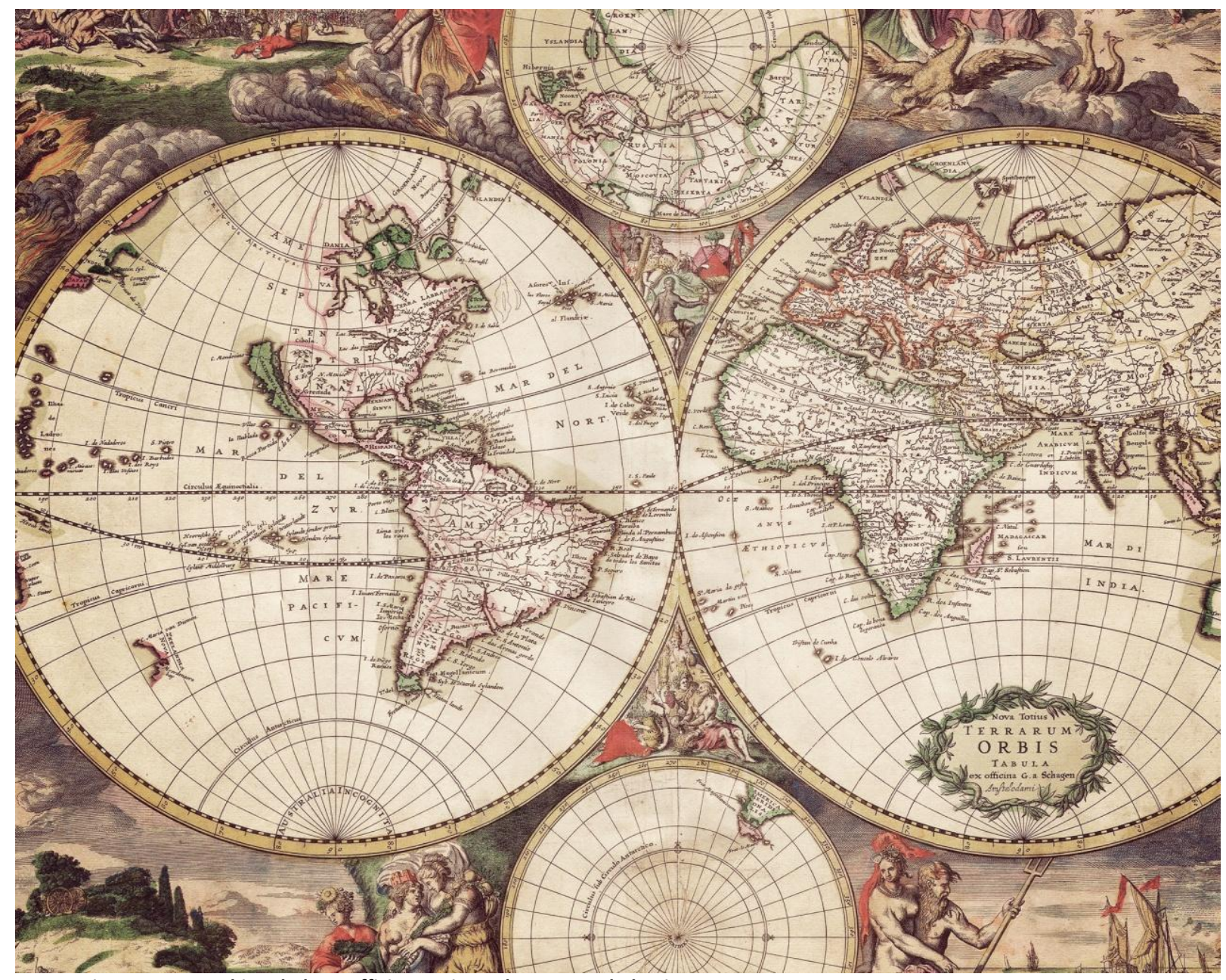

Nova Totius Terrarum Orbis Tabula ex officina lusti Danckerts Amstelodami, 1680.

"O segredo do sucesso é a constância do propósito"

Para Ceiça:

"Á quem merece o meu amor hoje e sempre" 


\section{AGRADECIMENTOS}

A Deus, pois, o que seria dos meus passos sem a fé que n'Ele deposito.

À minha esposa Conceição, pela sua sensibilidade e pelo seu apoio à minha jornada.

O apoio maravilhoso recebido de meus pais, Jurandi e Maria das Neves, e dos meus irmãos, João Bosco e Patrícia, aos quais sempre lembrarei com muita estima e gratidão.

Ao meu orientador, professor Doutor Valdir Adilson Steinke: muito obrigado por ter aceitado ser meu orientador e pela condução nos trabalhos que permitiram, com êxito, a elaboração do presente estudo.

Ao professor Doutor Marco Túlio Antônio García-Zapata, pela sua paciência e por acreditar em minha potencialidade para os trabalhos acadêmicos desde a minha graduação até o Doutorado.

À professora Doutora Ercília Steinke, pelos incentivos em todas as etapas da minha formação acadêmica no Departamento de Geografia (GEA) do Instituto de Ciências Humanas (IH) da Universidade de Brasília (UnB).

Aos professores Doutor Carlos Saito, Doutora Helen Gurgel e Doutor Mário Diniz, pelas contribuições na banca de qualificação e por aceitarem em participar da banca de exame final.

Aos funcionários da Secretaria do GEA, pela atenção dispensada durante esta jornada.

Sou muito grato aos técnicos do Ministério da Saúde (MS): Eduardo Caldas e Stefan Vilges de Oliveira, pelo atendimento prestado e pelas informações fornecidas sobre a Hantavirose.

Às professoras Dra. Marinez Ferreira de Siqueira da Fundação Jardim Botânico do Rio de Janeiro e Dra. Silvana Amaral do Instituto Nacional de Pesquisas Espaciais pelas sugestões e os auxílios na composição dos dados ambientais e antropogênicos da Modelagem de Nicho Ecológico. Muito obrigado!

Aos colegas e amigos da Gerência de Geoprocessamento do Departamento de Estradas de Rodagem do Distrito Federal (DER/DF), pelo apoio constante e pela compreensão nos momentos em que precisei me afastar das atividades na instituição, a fim de constituir a minha tese e as demais atividades acadêmicas.

À Diretora de Gestão de Pessoas do DER/DF, Maria Antônia, pelo empenho no meu processo de afastamento para esta etapa essencial de elaboração da presente tese.

Por fim, agradeço a todos aqueles que, de alguma forma, contribuíram para a conclusão da presente etapa de minha carreira acadêmica. 


\section{RESUMO}

O presente estudo tem como objetivo analisar a distribuição espacial da Hantavirose no Estado de Goiás e no Distrito Federal. O hantavírus Araraquara (ARAV) é o agente causador de mais de $50 \%$ dos casos relatados de hantavirose no Brasil, e também é o que apresenta maior virulência. O reservatório deste é o roedor silvestre Necromys lasiurus. Neste sentido, com o intuito de alcançar o objetivo proposto, foram realizados procedimentos de análise com a utilização da Modelagem de Nicho Ecológico (MNE) para o roedor reservatório e da análise geoespacial dos casos de hantavirose nas referidas Unidades da Federação (UFs), bem como a correlação destes casos com as formas de uso da terra na Região de Desenvolvimento Integrado do Distrito Federal e Entorno (RIDE-DF). Para o desenvolvimento da pesquisa fez-se uso de ferramentas de análise espacial, como, por exemplo, a MNE, que utilizou o algoritmo MAXENT (Maximum Entropy) e os sistemas de informações geográficas. Os resultados obtidos apontaram uma ampla distribuição potencial do Necromys lasiurus, e também a espacialidade da incidência dos casos de hantavirose nas UFs aqui em destaque. Ademais, os impactos trazidos pelo uso da terra na RIDE-DF apresentaram consequências na dispersão do agravo na região. Assim, buscou-se resgatar a importância do espaço geográfico no estudo das doenças contagiosas transmitidas por animais que são vetores e reservatórios de patógenos de interesse à saúde pública, uma vez que estas possuem um elo com as atividades humanas e carecem de análise mediante uma abordagem interdisciplinar.

Palavras-chave: Hantavirose. Modelagem de Nicho Ecológico. Uso da terra. 


\begin{abstract}
The research aimed to analyze the spatial distribution of hantavirus in the state of Goiás and the Federal District. Hantavirus Araraquara (ARAV) is the causative agent of more than 50\% of reported cases of hantavirus in Brazil and is also the one with greater virulence. The reservoir for Hantavirus is the wild rodent Necromys lasiurus. Based on this information and in order also to achieve the proposed objective analysis procedures were performed with the use of the Ecological Niche Modeling (ENM) for the rodent reservoir and geospatial analysis of cases of hantavirus in federal units of Goiás and the Federal District and also the correlation of these findings with the forms of land use in the Integrated Development Region of the Federal District and Goiás. Research development of spatial analysis tools were used as the ecological niche modeling that used the MAXENT algorithm (Maximum Entropy) and geographic information systems. The results showed a wide distribution of potential Necromys lasiurus and also the spatiality of the incidence of cases of hantavirus in Goiás and the Federal District. Moreover, the impacts brought by the land use in the RIDE-DF had consequences in the dispersion of the disease in the region. Thus, we sought to redeem the importance of geographical space in the study of diseases transmitted by animals that are vectors and reservoirs of pathogens of interest to public health, since these diseases have a link with human activities and therefore, need be analyzed with an interdisciplinary approach.
\end{abstract}

Keywords: Hantavirus, Ecological Niche Modeling, Land use. 


\section{SUMÁRIO}

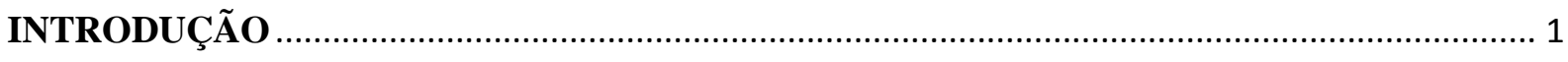

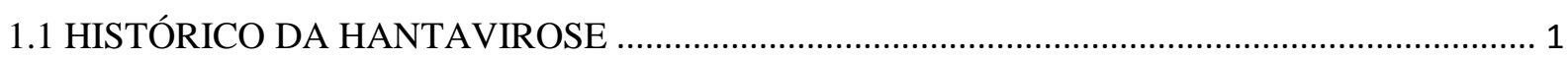

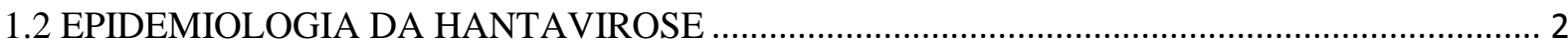

1.3 SITUAÇÃO EPIDEMIOLÓGICA DA SÍNDROME CARDIOPULMONAR POR HANTAVÍRUS

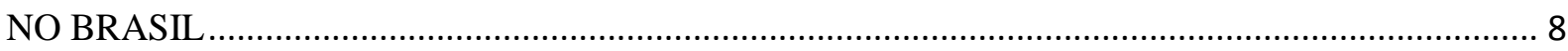

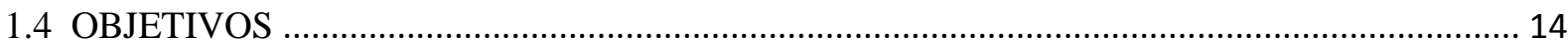

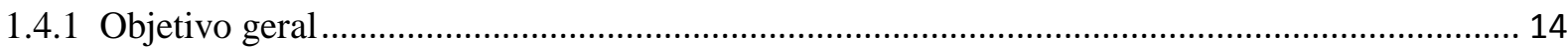

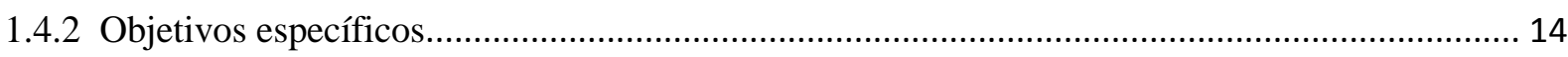

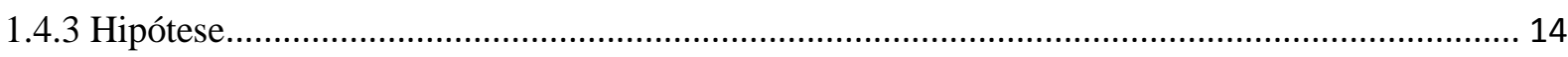

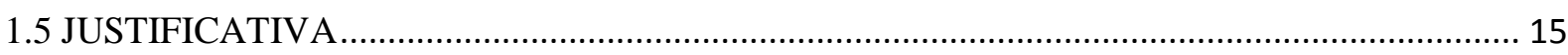

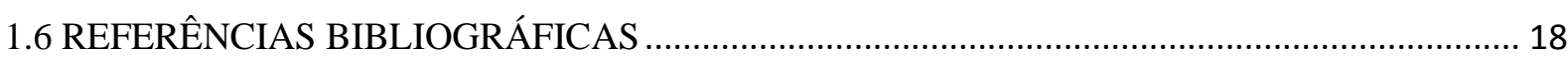

CAPÍtUlO 2 - ARTIGO 1: ESPAÇO E DOENÇA: MUDANÇAS ANTRÓPICAS E A

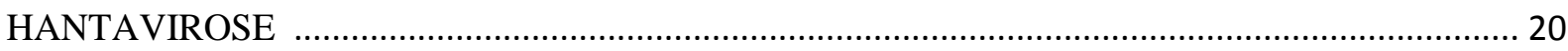

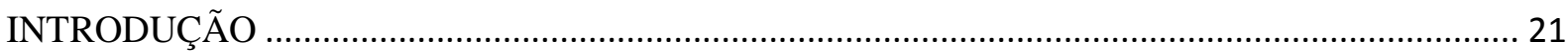

2.1 A DIMENSÃO DO ESPAÇO NA GEOGRAFIA DA SAÚDE: CONTEXTO HISTÓRICO ....... 22

2.2 A TEORIA DOS FOCOS NATURAIS E A EPIDEMIOLOGIA PAISAGÍSTICA ...................... 25

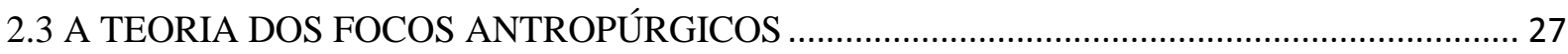

2.4 A HANTAVIROSE SEGUNDO A TEORIA DOS FOCOS ANTROPÚRGICOS ....................... 29

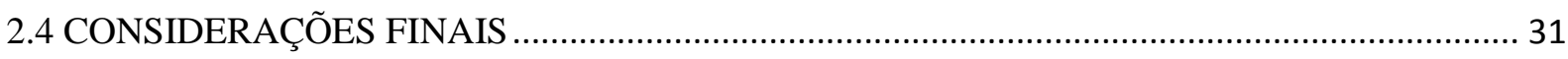

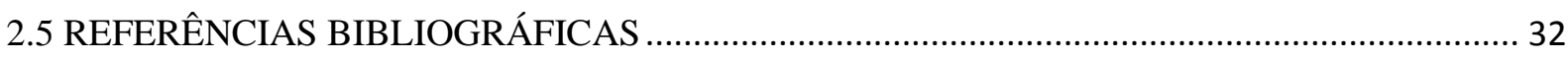

CAPÍTULO 3 - ARTIGO 2: MODELAGEM DE NICHO ECOLÓGICO DO Necromys lasiurus (LUND, 1841): CONTRIBUIÇÕES À ECOEPIDEMIOLOGIA DA HANTAVIROSE..................... 34

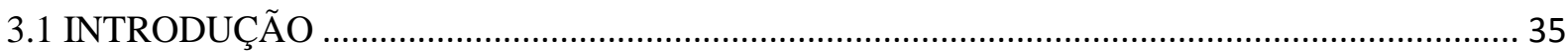

3.1.1 Pressupostos da Modelagem de Nicho Ecológico e sua aplicabilidade à Hantavirose ................ 37

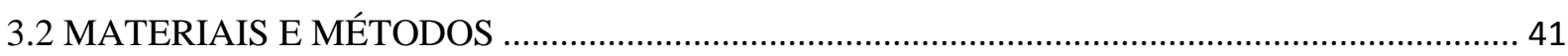

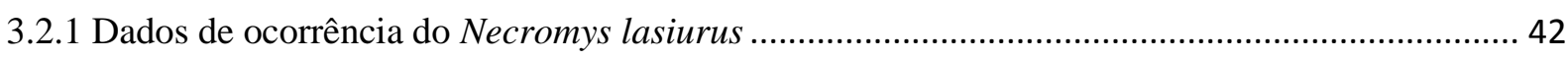

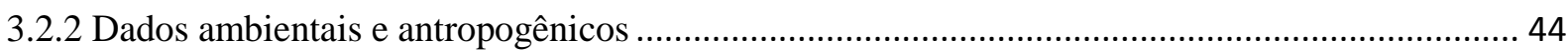

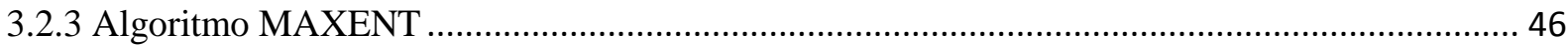

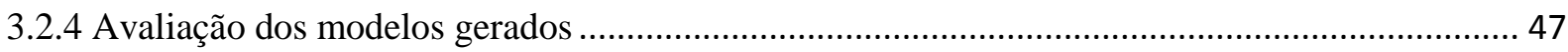

3.3 RESULTADOS

3.4 DISCUSSÃO

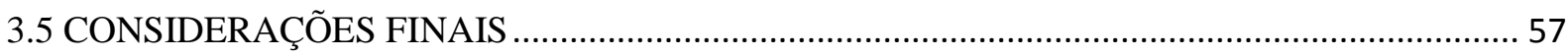

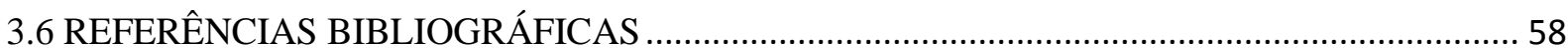

CAPÍTULO 4 - ARTIGO 3: ANÁLISE DE DEPENDÊNCIA ESPACIAL DE CASOS DE HANTAVIROSE NO ESTADO DE GOIÁS E NO DISTRITO FEDERAL, 2003-2010.................... 62 


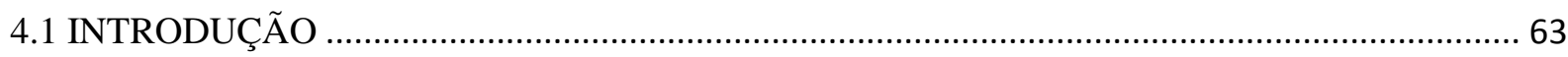

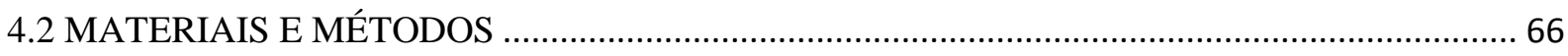

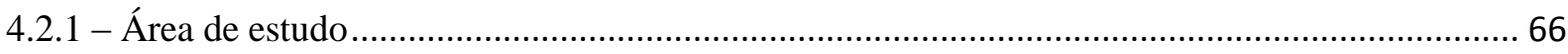

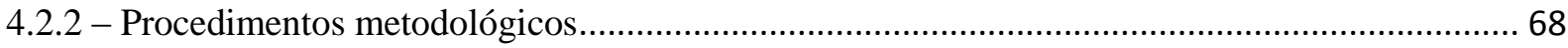

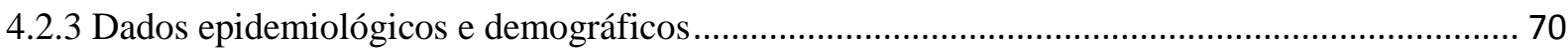

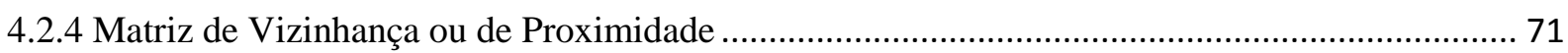

4.2.5 Indicadores Globais de Autocorrelação Espacial: Índices de Moran Global e Local .................. 71

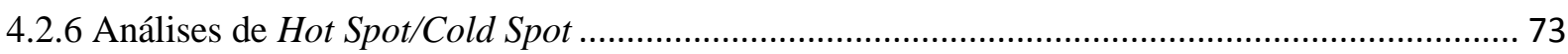

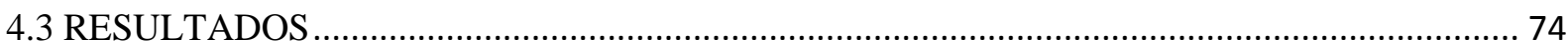

4.3.1 Análise da distribuição espacial da hantavirose em Goiás ............................................................ 74

4.3.2 Análise da distribuição espacial da Hantavirose no Distrito Federal ........................................... 79

4.4 DISCUSSÃO

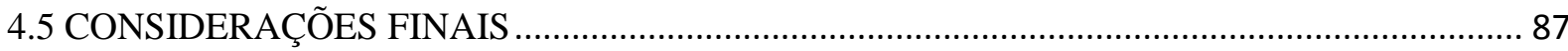

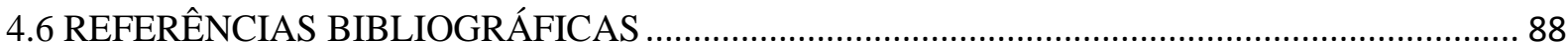

CAPÍTULO 5 - ARTIGO 4: A DINÂMICA DO USO E DA COBERTURA DA TERRA NA REGIÃO INTEGRADA DE DESENVOLVIMENTO DO DISTRITO FEDERAL E GOIÁS (RIDE-

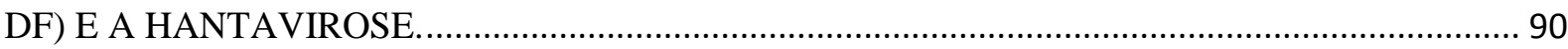

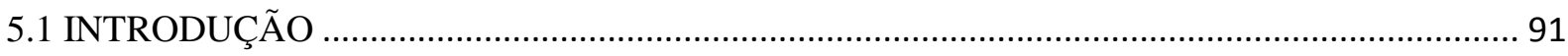

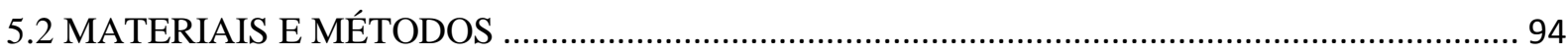

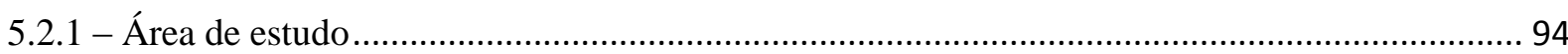

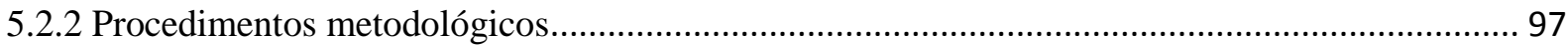

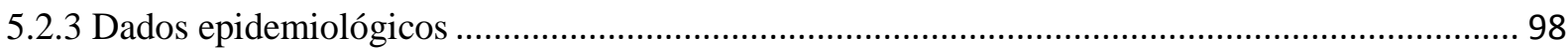

5.2.4 Base cartográfica do uso e cobertura da Terra da Região Integrada de Desenvolvimento do

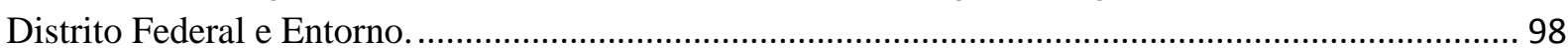

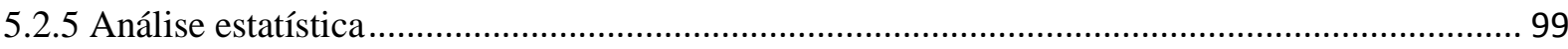

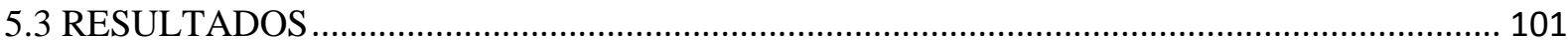

5.4 DISCUSSÃO

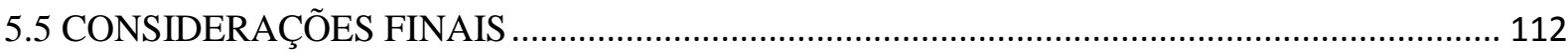

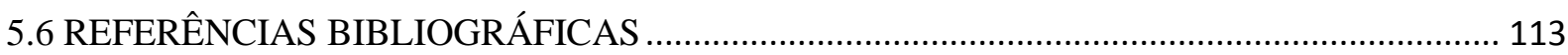

CAPÍTULO 6 - CONSIDERAÇÕES FINAIS E RECOMENDAÇÕES.......................................... 116

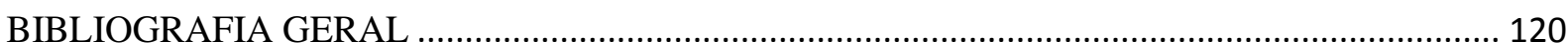

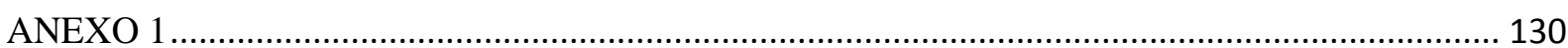

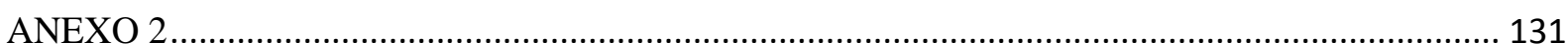

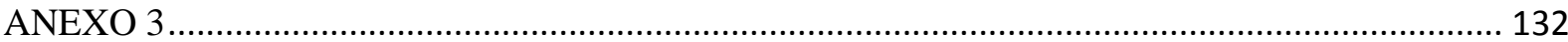




\section{LISTA DE FIGURAS}

\section{FIGURAS DO CAPÍTULO 1 - INTRODUÇÃO}

Figura 1: Microfotografia do hantavírus.

Figura 2: Ciclo de transmissão da Hantavirose

Figura 3: Distribuição mundial dos casos de Hantavirose.

Figura 4: Casos confirmados de Hantavirose por região geográfica.

Figura 5: Distribuição das variantes de hantavírus e os seus reservatórios no território brasileiro.

Figura 6: Necromys lasiurus (rato Pixuna)

FIGURAS DO CAPITULO 2 - ESPAÇO E DOENÇA: MUDANÇAS ANTRÓPICAS E A HANTAVIROSE

Figura 1: Esquematização da formação de "paisagens de doenças" - Exemplo: Hantavirose

FIGURAS DO CAPITULO 3 - MODELAGEM DE NICHO ECOLÓGICO DO Necromys lasiurus (LUND, 1841): CONTRIBUIÇÕES À ECOEPIDEMIOLOGIA DA HANTAVIROSE

Figura 1: Diagrama BAM (Biótico, Abiótico e Movimento) representando os fatores que afetam a distribuição das espécies

Figura 2: Diagrama dos procedimentos metodológicos

Figura 3: Distribuição geográfica do Necromys lasiurus. 49

Figura 4: Mapa de adequabilidade ambiental do Necromys lasiurus com a influência do uso da terra......

Figura 5: Mapa de adequabilidade ambiental do Necromys lasiurus sem a influência do uso da terra. 
FIGURAS DO CAPITULO 4 - ANÁLISE DE DEPENDÊNCIA ESPACIAL DE CASOS DE HANTAVIROSE NO ESTADO DE GOIÁS E NO DISTRITO FEDERAL, 2003-2010.

Figura 1: Mapa de localização do Estado de Goiás e do Distrito Federal 67

Figura 2: Fluxograma dos procedimentos metodológicos da análise espacial da Hantavirose no Goiás e no Distrito Federal. 69

Figura 3: Diagrama de Espalhamento de Moran 72

Figura 4: Mapa da distribuição espacial da incidência de Hantavirose no Estado de Goiás e no Distrito Federal - 2003 a 2010 75

Figura 5: Diagrama de espalhamento de Moran da incidência de Hantavirose no Estado de Goiás 76

Figura 6: Mapa de análise espacial com o indicador Getis-ord $G i^{*}$ da incidência de Hantavirose no Estado de Goiás.

Figura 7: Mapa da distribuição espacial da incidência de Hantavirose nas Regiões Administrativas do Distrito Federal - período 2003-2010 80

Figura 8: Diagrama de espalhamento de Moran da incidência de Hantavirose no Distrito Federal.

Figura 9: Box Map do índice global de Moran da incidência de Hantavirose no Distrito Federal. 82

Figura 10: Mapa de análise espacial com o indicador Getis-ord $G i^{*}$ da incidência de Hantavirose no Distrito Federal. 84 
FIGURAS DO CAPITULO 5 - A DINÂMICA DO USO E DA COBERTURA DA TERRA NA REGIÃO INTEGRADA DE DESENVOLVIMENTO ECONÔMICO DO DISTRITO FEDERAL E ENTORNO (RIDE-DF) E A HANTAVIROSE.

Figura 1: Mapa de localização da Região Integrada de Desenvolvimento do Distrito Federal e Entorno (RIDE-DF) 95

Figura 2: Fluxograma dos procedimentos metodológicos do estudo. 97

Figura 3: Mapa de uso e cobertura da terra da Região Integrada de Desenvolvimento do Distrito Federal e Entorno (RIDE-DF) e os casos de Hantavirose, período 20042010 102

Figura 4: Mapa de uso e cobertura da terra do Distrito Federal e os casos de Hantavirose, período 2004-2010. 107 


\section{LISTA DE TABELAS}

\section{TABELA DO CAPÍTULO 1 - INTRODUÇÃO}

TABELA 1: Distribuição geográfica das espécies de hantavírus no mundo 05

TABELAS DO CAPITULO 3 - MODELAGEM DE NICHO ECOLÓGICO DO Necromys lasiurus (LUND, 1841): CONTRIBUIÇÕES À ECOEPIDEMIOLOGIA DA HANTAVIROSE

TABELA 1: Dados utilizados na modelagem de distribuição potencial do Necromys lasiurus.

TABELA 2: Desempenho dos modelos de distribuição potencial do Necromys lasiurus 54

TABELA 3: Contribuição (\%) das variáveis ecogeográficas com e sem a camada 'uso da terra' 55

TABElaS do CAPITULO 4 - A DINÂMICA dO USO E DA COBERTURA DA TERRA NA REGIÃO INTEGRADA DE DESENVOLVIMENTO ECONÔMICO DO DISTRITO FEDERAL E ENTORNO (RIDE-DF) E A HANTAVIROSE

TABELA 1: Área total das classes de uso e cobertura da terra da Região Integrada de Desenvolvimento do Distrito Federal e Entorno (RIDE-DF) e os casos de Hantavirose, período 2004-2010. 103

TABELA 2: Área total das classes de uso e cobertura da terra no Distrito Federal e os casos de Hantavirose, período 2004-2010. 108

TABELA 3: Resultados da análise da relação do uso da terra e a ocorrência de Hantavirose na Região Integrada de Desenvolvimento do Distrito Federal e Entorno (RIDE-DF) e no Distrito Federal, período 2007-2010. 109

TABELA 4: Resultados do teste do qui-quadrado $\left(\chi^{2}\right)$ para a Região Integrada de Desenvolvimento do Distrito Federal e Entorno (RIDE-DF) e o Distrito Federal. 110 


\section{LISTA DE ABREVIATURAS E SIGLAS}

ANDV

ARAV

DOBV

DZUP

HANV

IAL

IBGE

ICMBio

IMEB

IPEA

MAXENT

MHNCI

MMA

MZUEL

OPAS

PUUV

RIDE-DF

UNEMAT

UNICAMP

ZUEC-MAM
Hantavírus Andes

Hantavírus Araraquara

Hantavírus Dobrava

Departamento de Zoologia da Universidade Federal do Paraná

Hantavírus Haatan

Instituto Adolfo Lutz

Instituto Brasileiro de Geografia e Estatística

Instituto Chico Mendes de Conservação da Biodiversidade

Instituo Mauro Borges de Estatísticas e Estudos Socioeconômicos

Instituto de Pesquisas Econômicas Aplicadas

Maximum Entropy

Museu de História Natural Capão da Imbuia

Ministério do Meio Ambiente

Museu de Zoologia da Universidade Estadual de Londrina

Organização Pan-Americana de Saúde

Hantavírus Puumala

Região Integrada de Desenvolvimento Econômico do Distrito Federal e Entorno

Universidade do Estado do Mato Grosso

Universidade de Campinas

Coleção de Mamíferos do Museu de Zoologia da UNICAMP 


\section{INTRODUÇÃO}

\subsection{HISTÓRICO DA HANTAVIROSE}

O primeiro surto de Hantavirose se deu durante a Guerra da Coréia (1950 a 1953), onde mais de 3.000 soldados da Organização das Nações Unidas adoeceram, sendo que 400 destes morreram com uma síndrome febril e hemorrágica, que posteriormente foi chamada de Febre Hemorrágica com Síndrome Renal (FHSR). No início dos anos 1940, a etiologia viral para a Hantavirose já tinha sido sugerida por pesquisadores russos e japoneses, que também deram as primeiras pistas para um possível reservatório natural daquele tipo de enfermidade (JONSSON et al, 2010).

Em 1976, um cientista coreano isolou um vírus do roedor Apodemus agrarius às margens do rio Hantaan na Coréia do Norte e, no ano seguinte, isolou o mesmo vírus em um ser humano, onde o patógeno recebeu o nome de Hantavírus (HANV) (LEE et al., 1978).

Jonsson et al. (2010) destacaram também que os esforços dos serviços de vigilância epidemiológica encontraram a presença do vírus Hantaan nos reservatórios Apodemus agrarius (rato listado) e A. peninsulae (rato do campo coreano), bem como em roedores na Rússia, China e Coréia do Sul. E ainda, relataram a descoberta de outros genótipos de Hantavírus no continente europeu, a saber: os vírus Dobrava (DOBV) e Puumala (PUUV), presentes em 04 (quatro) roedores hospedeiros da Europa Central e dos Balcãs, conforme se segue: Apodemus flavicollis, A. agrarius, A. ponticus e Clethrionomys glareous.

No final do século XX, muitos casos de hantavirose foram diagnosticados em áreas urbanas na China e em alguns países europeus. Schmaljohn e Hjelle (1997) destacam que além de alguns países do Extremo Oriente (China, as Coreias, Japão e Rússia), outros casos de hantavirose foram detectados em grande quantidade (centenas) na Finlândia, Suécia, Bulgária, Grécia, Hungria, França e na região dos Balcãs. Dependendo do país em que o hantavírus é responsável pela doença, as manifestações clínicas podem aparecer de forma leve, moderada ou grave.

Faz-se importante ainda destacar que em maio de 1993, um hantavírus desconhecido emergiu em 04 (quatro) Estados do sudoeste dos Estados Unidos da América (EUA) (Novo México, Arizona, Colorado e Utah), causando uma epidemia de uma doença respiratória aguda denominada Síndrome Pulmonar por Hantavírus (SPH) (NICHOL et al., 1993). Consequentemente, a SPH recebe uma nova nomenclatura em razão do comprometimento 
cardíaco, passando a ser denominada por Síndrome Cardiopulmonar por Hantavírus (SCPH) (OPAS, 1999). O agente etiológico da SCPH nos EUA foi isolado no roedor silvestre Peromyscus maniculatus, sendo inicialmente denominado de Four Corners e Muerto Canyon, e, finalmente, recebeu o nome de vírus Sin Nombre (SNV) (CHILDS et al. 1994).

Ao mesmo tempo em que eram diagnosticados os primeiros casos de Hantaviroses nos EUA (em 1993), surgiam casos da doença em diversos países do continente americano Brasil, Argentina, Paraguai, Panamá e Chile começaram a notificar as ocorrências de Hantavirose em seus territórios (OPAS, 1999; UJVARI, 2004). A subfamília Murinae tem até o momento uma espécie-reservatório para os hantavírus encontrados nas referidas áreas (NUNES et al., 2011).

O primeiro hantavírus identificado no continente africano - o Sangassou - foi encontrado nas vísceras do roedor Hylomyscus simus na Guiné (WEISS et al., 2012). Meheretu et al. (2012) também relatam que naquele país, pacientes com uma febre de origem desconhecida apresentavam anticorpos do hantavírus Sangassou. A mesma situação também foi relatada na República Centro-Africana, o que demonstra que o problema da Hantavirose merece uma atenção especial no referido continente em razão da enorme diversidade de pequenos mamíferos que podem ser reservatórios destes patógenos.

\subsection{EPIDEMIOLOGIA DA HANTAVIROSE}

O gênero Hantavírus é composto por vírus RNA (Figura 1) pertencente à família Bunyaviridae, com mais de 300 vírus que infectam animais, plantas e humanos. De acordo com Deareing e Dizney (2010) tais patógenos são antropozoonoses virais agudas, cujas infecções em humanos podem se manifestar sob várias formas clínicas - desde o modo inaparente ou como enfermidade subclínica, cuja suspeita diagnóstica fundamenta-se nos antecedentes epidemiológicos, até quadros mais graves e característicos, como, por exemplo, a Febre Hemorrágica com Síndrome Renal (FHSR) (típica da Europa e da Ásia) e a SCPH (detectada somente nas Américas). 


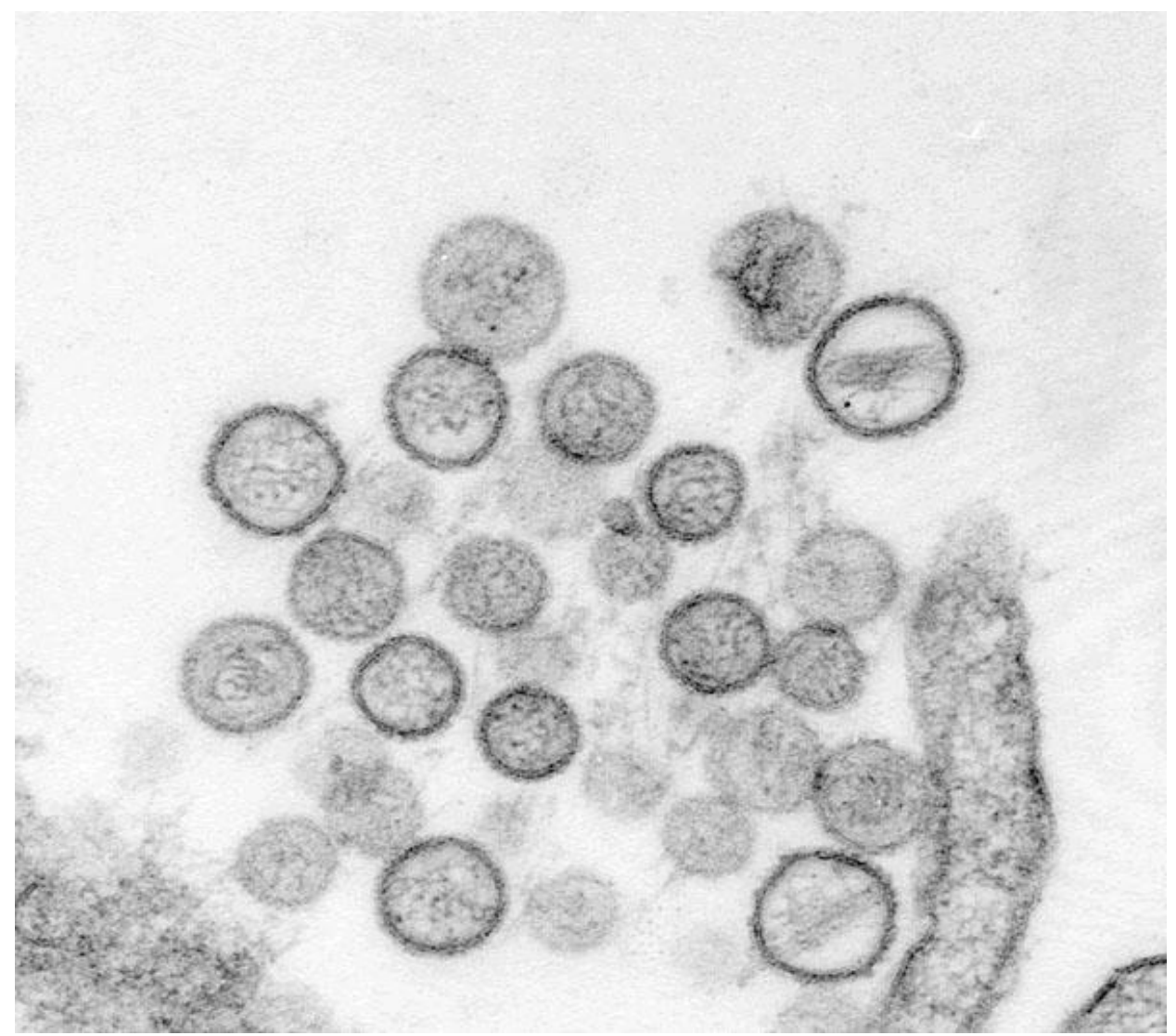

Figura 1- Microfotografia do hantavírus. Fonte: Centro de Controle de Doenças, 2013.

A infecção humana ocorre mais frequentemente pela inalação de aerossóis, formados a partir da urina, fezes e saliva de roedores infectados (Figura 2). Outras formas de transmissão, para a espécie humana, foram também descritas, conforme se segue: a) percutânea, por meio de escoriações cutâneas ou mordedura de roedores; b) contato do vírus com mucosa (conjuntival, da boca ou do nariz), por meio de mãos contaminadas com excretas de roedores; c) transmissão pessoa a pessoa (), relatada, de forma esporádica, na Argentina e Chile, sempre associada ao hantavírus Andes (ANDV) (MINISTÉRIO DA SAÚDE, 2013).

Os roedores reservatórios, apesar de apresentarem anticorpos séricos, podem eliminar o vírus por meio de suas excretas durante semanas, meses ou por toda a vida (em torno de 02 (dois) anos), sendo que tal eliminação é muito maior nas primeiras 03 (três) a 08 (oito) semanas pós-infecção. 


\section{Transmissão}

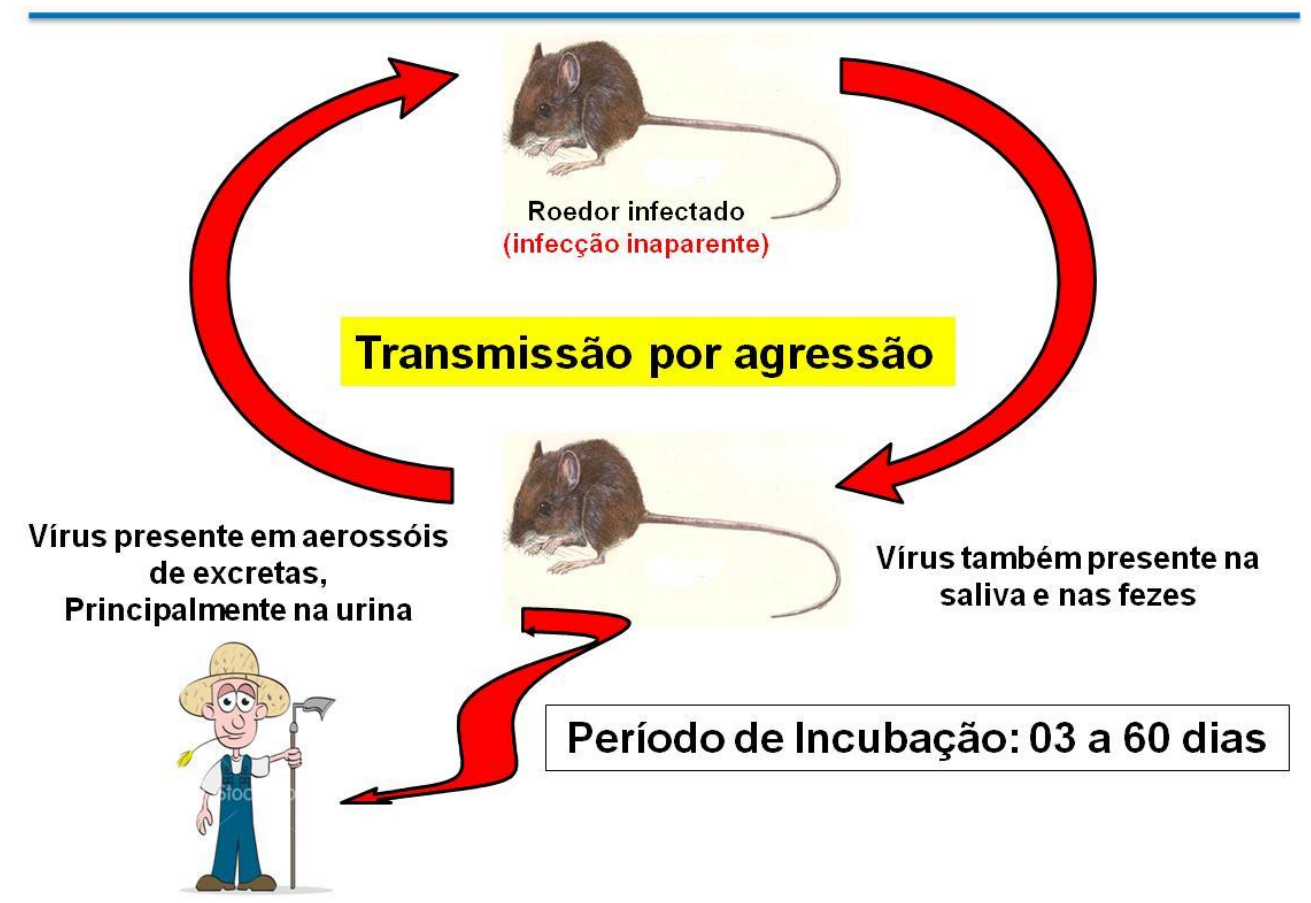

Figura 2 - Ciclo de transmissão da Hantavirose. Fonte: Secretaria de Vigilância em Saúde, 2010.

A maior parte dos casos apresenta os primeiros sinais da doença em torno de 02 (duas) semanas após a exposição (YOUNG et al., 2000). As manifestações sintomáticas da SCPH ocorrem de maneira aguda e grave por meio de febre, mialgia, dor dorso-lombar e abdominal, cefaleia intensa, náuseas, vômitos e diarreia, e sempre associadas à insuficiência respiratória e choque cardiogênico (MINISTÉRIO DA SAÚDE, 2013). A duração média da enfermidade desde o início dos sintomas até a cura ou óbito é de cerca de 07 (sete) a 10 dias (MINISTÉRIO DA SAÚDE, 2013).

O gênero Hantavírus possui mais de 20 espécies descritas, relatadas, em sua maioria, há poucos anos. Atualmente, existem 03 (três) grupos principais de espécies de hantavírus, quais sejam: 1) 04 (quatro) espécies que estão associadas à FHSR; 2) mais de uma dezena de espécies que produzem a SCPH; e, 3) as espécies que, apesar de confirmadas em roedores capturados, não tiveram até o presente momento sua patogenia para o homem determinada (JONSSON et al., 2010). Em geral, as espécies de hantavírus recebem o nome do local onde foram detectados pela primeira vez (Tabela 1). 
Tabela 1 - Distribuição geográfica das espécies de hantavírus no mundo.

\begin{tabular}{llll}
\hline $\begin{array}{l}\text { Subfamília } \\
\text { de roedores }\end{array}$ & Roedor hospedeiro & Vírus isolado & Distribuição \\
& & Geográfica
\end{tabular}

$\begin{array}{clc}\text { Murinae } & \text { Hantaan } & \text { China, Coréia do Sul e Rússia } \\ \text { Apodemus flavicollis } & \text { Dobrava } & \text { Balcãs } \\ \text { Rattus sp. } & \text { Seoul } & \text { Mundial } \\ \text { Apodemus agrarius } & \text { Saaremaa } & \text { Europa } \\ \text { Apodemus peninsulae } & \text { Amur } & \text { Rússia } \\ \text { Apodemus peninsulae } & \text { Soochong } & \text { Coréia do Sul }\end{array}$

Arvicolinae

$\begin{array}{clc}\text { Clethrionomys glareolus } & \text { Puumala } & \text { Europa, Ásia e América } \\ \text { Microtus fortis } & \text { Khabarovsk } & \text { Rússia (Sibéria) } \\ \text { Myodes regulus } & \text { Muju } & \text { Coréia do Sul } \\ \text { Microtus arvalis } & \text { Tula } & \text { Europa Oriental } \\ \text { Microtus californicus } & \text { Isla Vista } & \text { América do Norte } \\ \text { Lemmus sibericus } & \text { Topografov } & \text { Rússia (Sibéria) }\end{array}$

\section{Sigmodontinae}

$\begin{array}{clc}\text { Peromyscus maniculatus } & \text { Sin Nombre } & \text { América do Norte } \\ \text { Peromyscus leucopus } & \text { Monongahela } & \text { América do Norte } \\ \text { Peromyscus leucopus } & \text { New York } & \text { América do Norte } \\ \text { Sigmodon hispidus } & \text { Black Creek Canal } & \text { América do Norte } \\ \text { Oryzomys palustris } & \text { Bayou } & \text { América do Norte } \\ \text { Peromyscus boylii } & \text { Limestone Canyon } & \text { América do Norte } \\ \text { Oryzomys couesi } & \text { Playa de Oro } & \text { México } \\ \text { Oryzomys couesi } & \text { Catacamas } & \text { Honduras } \\ \text { Oligoryzomys fulvescens } & \text { Choclo } & \text { Panamá } \\ \text { Zygodontomys brevicauda } & \text { Calabazo } & \text { Panamá } \\ \text { Reithrodontomys mexicanus } & \text { Rio Segundo } & \text { Costa Rica }\end{array}$




$\begin{array}{clc}\text { Oligoryzomys longicaudatus } & \text { Andes } & \text { Argentina e Chile } \\ \text { Oligoryzomys chocoensis } & \text { Bermejo } & \text { Argentina } \\ \text { Akodon azarae } & \text { Pergamino } & \text { Argentina } \\ \text { Oligoryzomys flavescens } & \text { Lechiguanas } & \text { Argentina } \\ \text { Bolomys obscurus } & \text { Maciel } & \text { Argentina } \\ \text { Oligoryzomys longicaudatus } & \text { Oran } & \text { Argentina } \\ \text { Calomys laucha } & \text { Laguna Negra } & \text { Paraguai, Bolivia e Argentina } \\ \text { Holochilus chacoensis } & \text { Alto Paraguay } & \text { Paraguai } \\ \text { Akodon montensis } & \text { Ape Aime } & \text { Paraguai } \\ \text { Oligoryzomys nigripes } & \text { Itapúa } & \text { Paraguai } \\ \text { Oligoryzomys microtis } & \text { Rio Mamore } & \text { Bolivia e Peru } \\ \text { Necromys lasiurus } & \text { Araraquara } & \text { Brasil } \\ \text { Oligoryzomys nigripes } & \text { Juquitiba } & \text { Brasil } \\ \text { Akodon montensis } & \text { Jaborá } & \text { Brasil, Paraguai }\end{array}$

Elaboração: Janduhy Santos. Fonte: Jonsson et al. (2010)

Em geral, para os epidemiologistas, as Hantaviroses são distribuídas de acordo com as subfamílias de roedores. Neste sentido, conforme observado anteriormente na Tabela 1, e na Figura 3, a seguir, possuem uma ampla distribuição geográfica. A descoberta destes hantavírus permitiu o aperfeiçoamento de novas técnicas moleculares que têm ajudado no diagnóstico da Hantavirose em todo mundo. Dearing e Dizney (2010) relatam que no mundo são diagnosticados 150.000 casos de Hantavirose por ano, e mais da metade destes ocorrem na China. A distribuição geográfica e a Epidemiologia de casos humanos da doença causada pela Hantavirose têm sido consideradas como uma consequência da difusão e da história natural dos hospedeiros naturais. 


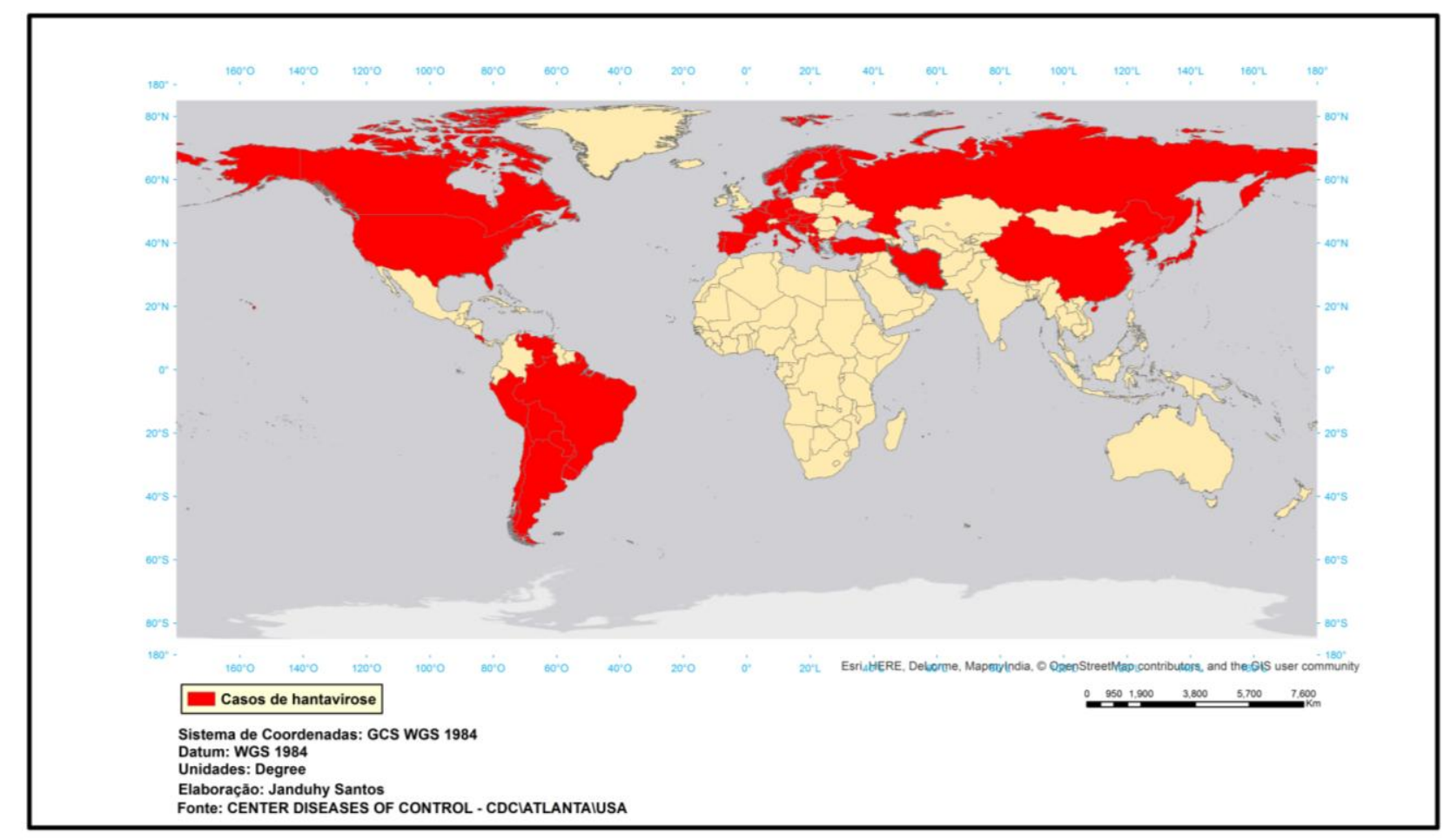

Figura 3 - Distribuição mundial dos casos de Hantavirose.

Jonsson et al. (2010) e Zeir et al. (2005) detalham notícias recentes sobre a detecção de anticorpos específicos de hantavírus em animais domésticos e em outros animais silvestres das ordens Rodentia, Insectivora, Lagomorpha e Carnívora. E ainda, a presença de antígenos de hantavírus em outras espécies de roedores em países e regiões sem casos confirmados de Hantavirose, como, por exemplo, Grã-Bretanha, Tailândia, México, Honduras, Índia, Irã, África Central, no Alasca e na Bolívia.

A questão de novos genótipos de hantavírus e hospedeiros expõe uma questão de suma importância no surgimento de doenças zoonóticas que são particularmente sensíveis às alterações ecológicas, aos movimentos migratórios e à introdução de animais domésticos em ambientes silvestres, uma vez que os fatores antropogênicos (como, por exemplo, o desmatamento, a expansão agrícola e a urbanização) têm cada vez mais exposto pessoas e animais domésticos a doenças transmitidas por vetores e reservatórios. Neste sentido, Mills (2005) apontam 05 (cinco) variáveis que regulam a prevalência de hantavírus, quais sejam: (1) fatores ambientais (clima e vegetação), que afetam as taxas de transmissão através do seu efeito no sucesso reprodutivo e nas densidades populacionais; (2) fatores antropogênicos, como, por exemplo, uma perturbação, que impacta a complexidade do ecossistema; (3) fatores genéticos, que poderiam influenciar na dispersão; (4) fatores comportamentais nos roedores e 
em humanos (como, por exemplo, disputas territoriais e trabalhos agrícolas); e (5) controle dos fatores fisiológicos do hospedeiro que dão uma melhor resposta à infecção.

\subsection{SITUAÇÃO EPIDEMIOLÓGICA DA SÍNDROME CARDIOPULMONAR POR HANTAVÍRUS NO BRASIL}

A hantavirose é doença de notificação compulsória (DNC) no Brasil, sendo obrigação dos serviços de saúde a comunicação imediata de casos suspeitos. Todo caso de hantavirose deve ser investigado em até 48 horas após a notificação, avaliando a necessidade de adoção de medidas de controle pertinentes (SECRETARIA DE VIGILÂNCIA EM SAÚDE, 2010).

A SCPH por hantavírus foi detectada no Brasil pela primeira vez em 1993, no Município de Juquitiba, Estado de São Paulo. Posteriormente, Pará (1995), Bahia (1996), Minas Gerais, Mato Grosso e Rio Grande do Sul (1998), Paraná e Santa Catarina (1999), Goiás e Maranhão (2000) e, por último, Distrito Federal, Rondônia e Amazonas (2004) também detectaram a referida Síndrome.

De acordo com o Ministério da Saúde (MS) (2014), de 1993 a 2013 foram confirmados $1.771 \operatorname{casos}^{1}$ de hantavirose, apontando o total de 666 óbitos, e a taxa de letalidade de 37,6\%. Todas as 05 (cinco) regiões brasileiras apresentam casos de hantavirose e, conforme apresentado na Figura 4, as regiões Sul (gráfico D), Centro-Oeste (gráfico E) e Sudeste (gráfico C) registraram 602 casos (34\%), 448 casos (25\%) e 440 casos (25\%), respectivamente, enquanto que a região Norte (gráfico A) registrou 94 casos, e a região Nordeste (gráfico B), 15 casos, onde, juntos, detectaram apenas $6 \%$ dos casos no Brasil. A região que apresentou a maior quantidade de óbitos de Hantavirose foi a região Sudeste (com 209 casos - 31,3\%). O sexo masculino representou a maioria dos casos com 79,6\%, e o ambiente com a maior exposição foi o local de trabalho, sendo a agricultura a principal ocupação dos pacientes com a doença. A faixa etária da maioria dos pacientes se dá entre os 20 a 39 anos, com 55,4\% dos casos de Hantavirose.

\footnotetext{
${ }^{1}$ Dados preliminares, segundo UF de Infecção.
} 

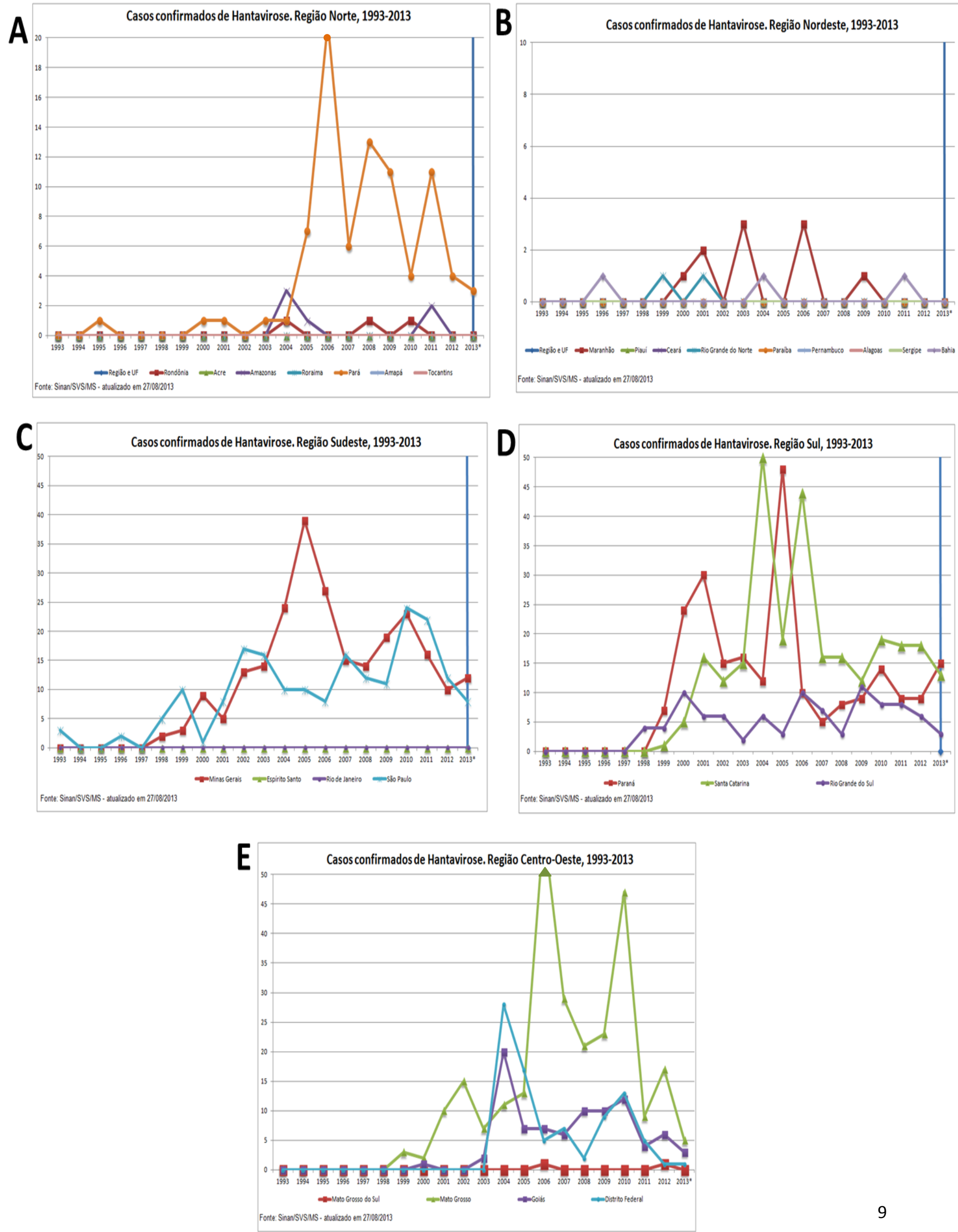

Figura 4 - Casos confirmados de Hantavirose por região, período 1993-2013. Fonte: Ministério da Saúde, 2013. 
Apesar da ocorrência da Hantavirose em todas as regiões brasileiras, apenas 14 Estados registraram casos, dos quais 74\% destes encontra-se em Santa Catarina (274 casos - 15,4\%), Mato Grosso (270 casos - 15,2\%), Minas Gerais (245 casos - 13,8\%), Paraná (231 casos - 13\%), São Paulo (195 casos - 11\%) e o Rio Grande do Sul (97 casos - 5,4\%). O Distrito Federal e o Estado de Goiás registraram cada um 88 casos, enquanto que os Estados do Pará (85 casos), Maranhão (10 casos), Amazonas (06 (seis) casos), Rondônia (03 (três) casos), Bahia (03 (três) casos), Mato Grosso do Sul (02 (dois) casos) e o Rio Grande do Norte (02 (dois) casos) notificaram, em conjunto, 6,6\% dos casos nos últimos 20 anos. As UFs que apresentaram maior quantitativo de óbitos de Hantavirose foram Minas Gerais (105 óbitos - 15,7\%) e São Paulo (104 óbitos $-15,6 \%$ ). Os casos de Hantavirose de origem indeterminada ou ignorada somam 166 casos (9,3\%). A quantidade de municípios com transmissão e que apresentaram algum caso de hantavirose foi de 372 dos 5.563 municípios do território nacional.

Os casos aqui registrados estão distribuídos em todas as regiões, identificados em 03 (três) dos 06 (seis) grandes biomas brasileiros, quais sejam: Cerrado, Mata Atlântica e Floresta Amazônica. E também em áreas de transição entre estes biomas (NUNES et al., 2011). Existem diversos estudos sobre a distribuição das variantes do vírus e que proporcionam o estabelecimento de uma associação-espécie específica, responsável pela manutenção da circulação do vírus em cada bioma. Apesar de Zeir et al. (2005) apontarem que é de opinião geral que os roedores não são a única fonte de infecção para os seres humanos, tal fato tem por base uma série de estudos sorológicos ali descritos (encontrados nos últimos anos - anticorpos de hantavírus presentes em alguns animais não roedores silvestres (como, por exemplo, mussaranhos, morcegos e outros) e domésticos).

Neste sentido, se faz necessária a realização de outros estudos epidemiológicos, moleculares e ecológicos que permitam identificar demais variantes e reservatórios em razão da biodiversidade do território brasileiro. Assim, o cartograma (Figura 5) que se segue sintetiza a distribuição de variantes de hantavírus existentes no Brasil. 


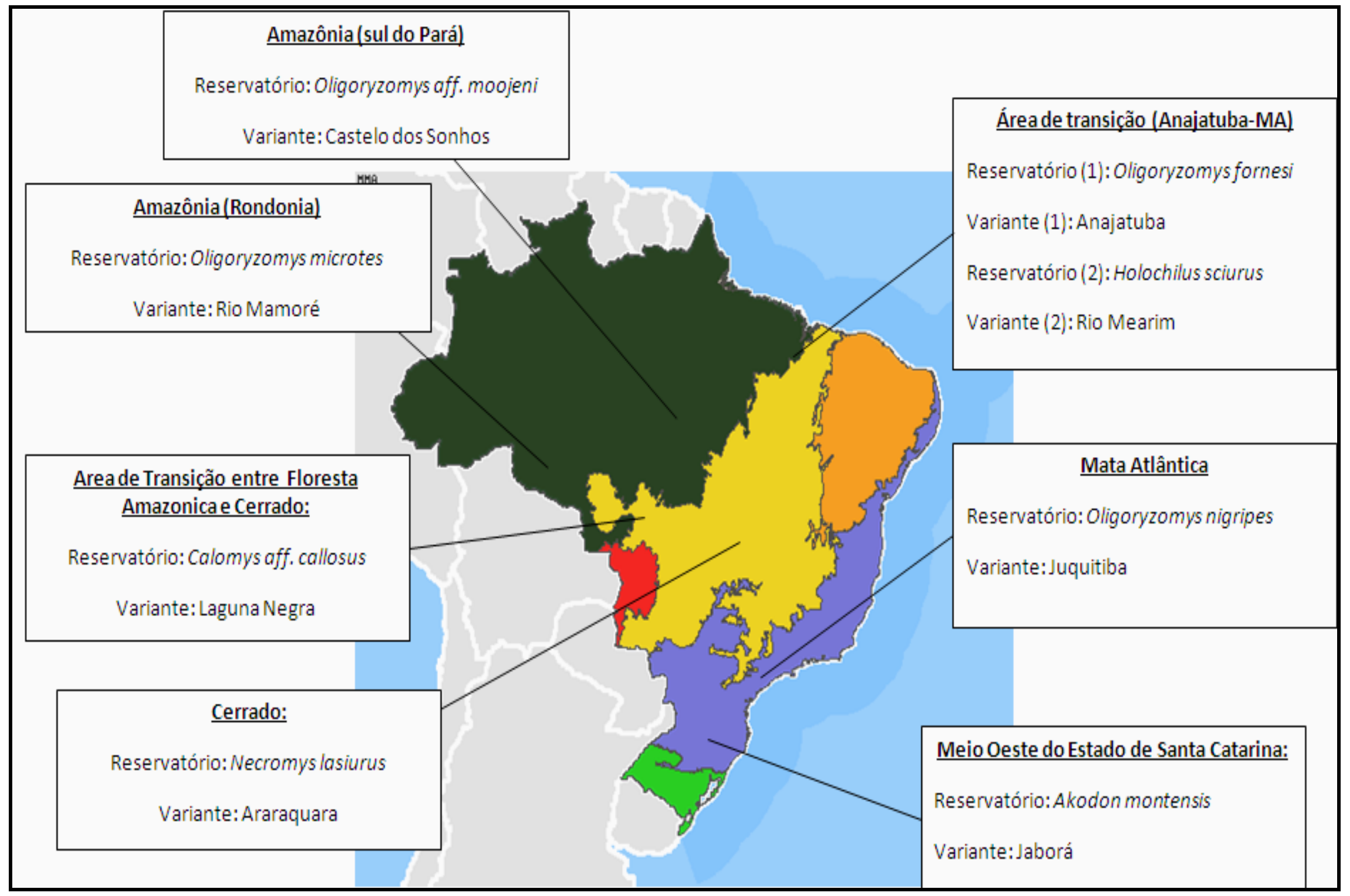

Figura 5 - Distribuição das variantes de hantavírus e os seus reservatórios no território brasileiro. Fonte: Secretaria de Vigilância em Saúde, 2010. 
É importante ainda destacar as variantes e os reservatórios de hantavírus existentes no Brasil, quais sejam: Juquitiba (variante) - Oligorizomys nigripis (reservatório); Araraquara (variante) - Necromys lasiurus (reservatório); Castelos dos Sonhos (variante) - Oligoryzomys aff. Moojeni (reservatório); Anajatuba (variante) - Oligoryzomys fornesis (reservatório); Laguna Negra (variante) - Calomys aff. callosus (reservatório); Rio Mearim (variante) Holochilus sciurus (reservatório); Rio Marmoré (variante) - Oligoryzomys microtes (reservatório); e, Jaburá (variante) - Akondon montensis (reservatório). Neste sentido, Nunes et al. (2011) reforça que a variante Rio Marmoré encontrada no Oligoryzomys microtis não foi, até o momento, identificada em casos humanos.

Dentro dos reservatórios silvestres de hantavírus no Brasil, o roedor Necromys lasiurus (Figura 6) possui uma particularidade interessante, pois, até o presente momento, é o portador do vírus Araraquara que, segundo Figueiredo et al. (2009), é o agente causador de mais de $50 \%$ dos casos notificados de Hantavirose no Brasil.

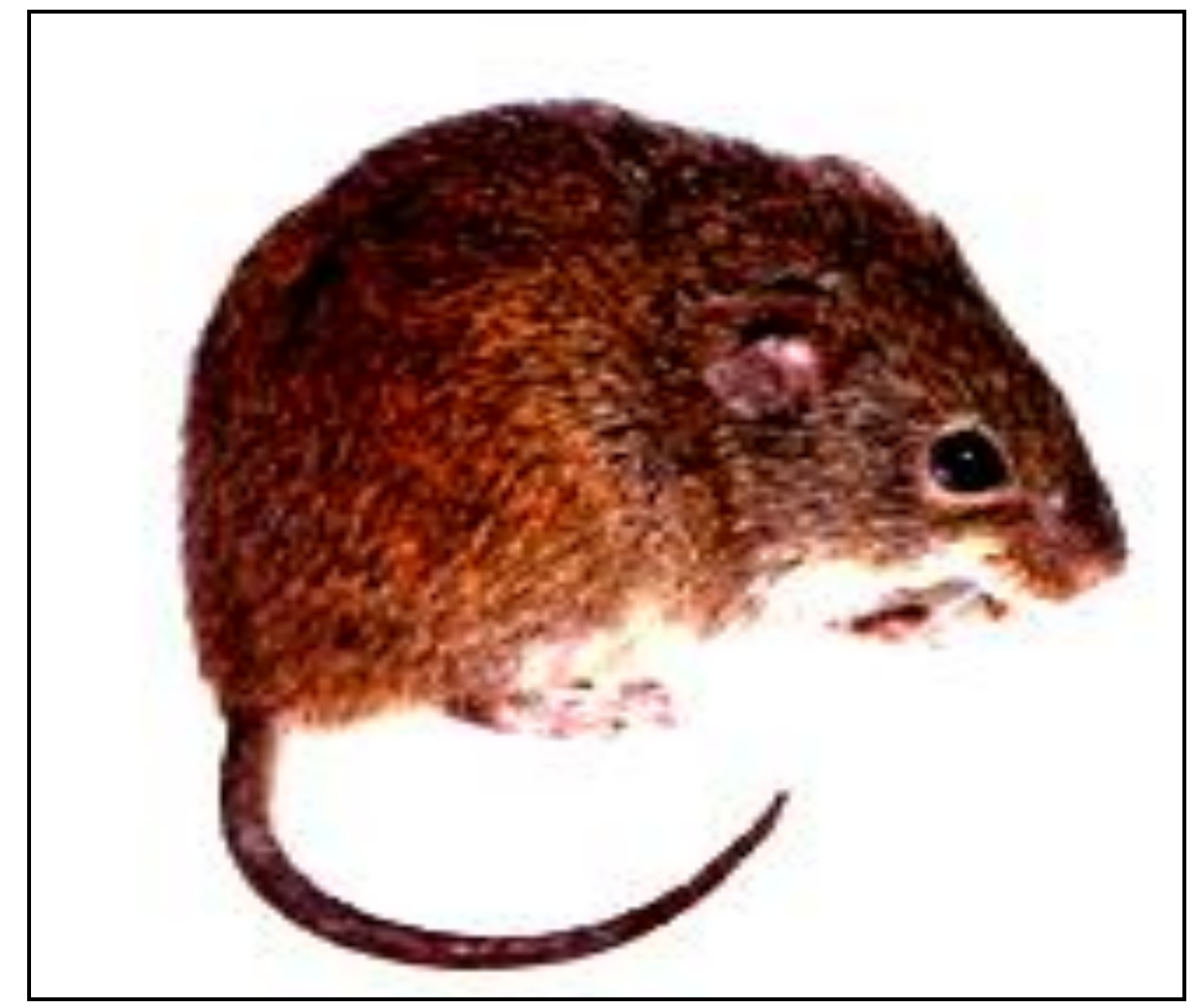

Figura 6 - Necromys lasiurus (rato Pixuna). Fonte: Secretaria de Vigilância em Saúde, 2010. 
Segundo Suzuki et al. (2004), o roedor Necromys lasiurus se dá em uma distribuição geográfica que inclui as áreas originais dos biomas Cerrado e Caatinga. Também se tem registros deste em áreas de campos no ecossistema amazônico (LAYME et al., 2004). Aquele roedor possui uma alimentação onívora (grãos e insetos) e dois picos de atividade - um crepuscular e outro pela manhã (ALHO, 1982; REIS et al., 2006). Sua reprodução ocorre principalmente entre abril e junho, com mais de uma ninhada por ano. A distribuição do roedor demonstra uma habilidade de adaptação em ambientes antrópicos, especialmente em áreas agrícolas, como, por exemplo, as pastagens que possuem capim do tipo Brachiaria sp., as lavouras de cana-de-açúcar e soja e a expansão sem planejamento de assentamentos nas periferias das cidades.

O roedor possui um comportamento territorialista e agressivo, o que o torna oportunista, invadindo, assim, as moradias em áreas antropicamente modificadas. Neste contexto, Alho (1982) descreve que em uma determinada coleta de roedores, a densidade de Necromys lasiurus chegou a 187 indivíduos por hectare no município de Exu, Pernambuco. Estudos realizados em áreas abertas do cerrado do Distrito Federal apontam uma densidade máxima de 14,3 a 27 indivíduos por hectare para a referida espécie (BECKER et al., 2007). Apesar da densidade de captura no Cerrado ser menor do que na Caatinga, Becker et al. (2007) salientam que o Necromys lasiurus representa mais de 30\% dos indivíduos capturados em tal bioma.

Diante do exposto, as referidas informações são de grande valia para a vigilância epidemiológica, pois, em alguns Estados das regiões Sudeste e Centro-Oeste, observam-se o aumento dos casos de Hantavirose, apresentando alguma correlação com as alterações ambientais que ocorrem no espaço geográfico, advindas de modelos de uso e ocupação da terra e que, por sua vez, vêm reduzindo o habitat do roedor (FIGUEIREDO et al., 2009; NUNES et al., 2011; SANTOS, 2011). 


\subsection{OBJETIVOS}

\subsubsection{Objetivo geral}

A presente pesquisa tem como objetivo realizar a análise espacial da dispersão do Necromys lasiurus - reservatório do hantavírus Araraquara (ARAV), bem como avaliar a dependência espacial e a correlação dos casos de Hantavirose com a cobertura e o uso da terra no Estado de Goiás e no Distrito Federal entre 2003 e 2010.

\subsubsection{Objetivos específicos}

1. Realizar a revisão teórica da Geografia da Saúde e suas contribuições nos aspectos ecológicos dos focos de Hantavirose (Epidemiologia Paisagística).

2. Predizer as áreas de maior adequabilidade ambiental para o roedor silvestre Necromys lasiurus.

3. Elaborar mapas preditivos de ocorrência do roedor Necromys lasiurus.

4. Avaliar a dependência espacial da Hantavirose no Estado de Goiás e no Distrito Federal.

5. Associar e analisar espacialmente o tipo de cobertura e uso da terra e a prevalência do hantavírus Araraquara (ARAV) na Região Integrada de Desenvolvimento do Distrito Federal e Entorno (RIDE-DF).

\subsubsection{Hipótese}

A dinamização dos padrões do uso da terra permitiu a expansão do roedor silvestre Necromys lasiurus contribuindo, assim, para a emergência e a distribuição dos casos de Síndrome Cardiopulmonar por Hantavírus (SCPH) no Estado de Goiás e no Distrito Federal. 


\subsection{JUSTIFICATIVA}

Para Oliveira (2013), o roedor Necromys lasiurus - reservatório do hantavírus Araraquara - tem como seu ecossistema o bioma Cerrado; é adaptado a viver no interior do pasto de braquiária, alimentando-se das sementes e extraindo água de suas raízes, o que permite a manutenção de população com alta densidade; é reconhecido como portador do vírus Araraquara, que, segundo Figueiredo et al. (2009), é o agente causador de mais de 50\% dos casos relatados de Hantavirose no Brasil, e também o que apresenta maior virulência.

Neste sentido, o interesse em utilizar a Modelagem de Nicho Ecológico (MNE) para o Necromys lasiurus se dá em decorrência do agravamento da Hantavirose em áreas onde circula o vírus Araraquara. Tal agravamento tem sido ocasionado por alterações de origem antropogênica em áreas que são habitat do roedor (DONALÍSIO et al., 2008; SANTOS, 2011;). Estas se encontram inseridas dentro do bioma Cerrado, que, nos últimos 50 anos, vêm passando por alterações ambientais relacionadas à expansão das atividades humanas, com a colonização de pequenas áreas e expansão da área de atuação, o que intensifica as consequências do processo de ocupação e uso do ambiente. É preciso salientar que, conforme o Ministério do Meio Ambiente (MMA) (2011), o bioma Cerrado teve uma área suprimida de $43,6 \%$ até o ano de 2002 , e de $47,8 \%$ até o ano de 2008.

Os estudos dos impactos decorrentes do uso do solo estão ganhando cada vez mais espaço junto à comunidade médica em virtude do aumento das zoonoses e, em particular, da Hantavirose. O próprio Ministério da Saúde (MS) brasileiro vem trabalhando nos últimos anos com os possíveis impactos advindos de alterações nos sistemas climáticos no Brasil (Barcellos et al., 2009).

Outro aspecto de grande importância para a realização da presente pesquisa é que através do levantamento bibliográfico realizado, foi possível identificar a não realização, até o momento, de nenhum trabalho de MNE que tenha feito uso de variáveis climáticas e do uso do solo para roedores reservatórios no Brasil. Tal fato demonstra que a realização deste projeto é imprescindível em virtude da urgência do maior conhecimento do agravo aqui apontado para o planejamento de políticas públicas eficazes.

Diante das mudanças que vêm ocorrendo no ambiente e os seus impactos sobre as zoonoses, alguns autores - como, por exemplo, Winters et al. (2009), Eisen et al. (2007) e Zhang et al. (2009), tem sugerido o desenvolvimento de modelos preditivos para análise 
espacial de doenças transmitidas por vetores e animais reservatórios de vírus, bactérias, protozoários e outros. Tais modelos trabalhariam com MNE no intuito de determinar a distribuição geográfica potencial de espécies a partir da utilização de algoritmos.

Além da modelagem preditiva de nicho ecológico, as análises provenientes de recursos provindos da estatística espacial permitem espacializar e quantificar os agrupamentos similares (clusters) e as autocorrelações dos casos de Hantavirose nas áreas investigadas e, assim, encontrar um padrão espacial na distribuição do agravo (Hantavirose).

Para o desenvolvimento do estudo, além da parte introdutória, a pesquisa tem sua divisão em 04 (quatro) abordagens - estruturadas em formato de artigos independentes. $\mathrm{Na}$ introdução, têm-se os aspectos ecoepidemiológicos da Hantavirose e a sua evolução no Brasil. A primeira abordagem trata da relação do espaço geográfico com a saúde pública, com ênfase na Epidemiologia Paisagística da Hantavirose. A abordagem seguinte é a MNE aliada à distribuição potencial do Necromys lasiurus - reservatório do hantavírus Araraquara. Seguiuse a análise através do uso da estatística espacial dos casos de Hantavirose nos municípios inseridos no bioma Cerrado. E, finalmente, o último artigo trata das análises dos padrões de uso e cobertura das terras correlacionando os prováveis locais de infecção por hantavírus Araraquara, e permitindo a obtenção de padrões de distribuição da Hantavirose no Distrito Federal e no Entorno.

\section{Artigo no. 1}

\section{A dimensão do espaço na Geografia da Saúde.}

Tem-se aí uma abordagem teórica a respeito da espacialidade na Geografia da Saúde e suas contribuições na Epidemiologia Paisagística. A revisão crítica do assunto traz à tona a importância da análise dos aspectos ecoepidemiológicos dos focos de Hantavirose sob a visão da Geografia.

As contribuições de Sorre, na Geografia, e de Pavlovsky, na Epidemiologia, endossaram a possibilidade de articular os complexos elementos das sociedades e da natureza com base no conceito de paisagem. Estas ainda permitiram embasar a revisão teórica com o entendimento das inter-relações entre o homem e seu ambiente e, assim, esquematizar a dinâmica das "paisagens de doenças", como, por exemplo, a Hantavirose. 


\section{Artigo $n^{0} .2$}

\section{Modelagem ambiental e a distribuição potencial do Necromys lasiurus.}

Trata-se da MNE para a distribuição potencial de espécies e a sua importância no estudo das possíveis rotas de disseminação de doenças infecciosas. Com base em tais considerações foram construídos modelos de adequabilidade ambiental para o Necromys lasiurus, que, no momento, é o principal reservatório do hantavírus Araraquara presente na região de estudo (Distrito Federal e o Estado de Goiás). Os resultados apontaram as diferenças de distribuição potencial da espécie em razão da inclusão e da exclusão da camada ambiental do uso da terra.

\section{Artigo $n^{\circ} .3$}

\section{Análise espacial dos casos de Hantavirose.}

Através dos recursos da estatística espacial foi possível realizar inferências que permitiram observar a distribuição da incidência de Hantavirose nos Municípios do Estado de Goiás e nas Regiões Administrativas (RAs) do Distrito Federal. Os algoritmos Getis-Ord Gi* e o Índice de Moran utilizados nas inferências geraram padrões de distribuição dos casos de Hantavirose nas áreas estudadas.

\section{Artigo n ${ }^{\circ} 4$}

\section{A dinâmica do uso e da cobertura da terra e a Hantavirose na Região Integrada de Desenvolvimento Econômico do Distrito Federal e Entorno (RIDE-DF).}

Através do uso de sistemas de informações geográficas e de análises estatísticas, este estudo teve por objetivo de identificar os padrões de uso da terra com maior impacto na Hantavirose no Distrito Federal e no Entorno. Neste sentido, foram realizadas correlações espaciais dos locais de ocorrência da Hantavirose com o uso da terra nos locais onde as pessoas contraíram a doença. As análises estatísticas e o mapeamento realizados demonstraram que algumas classes de uso e cobertura da terra, como, por exemplo, áreas urbanizadas, lavouras e pastagens, apresentaram risco elevado para a Hantavirose. 


\subsection{REFERÊNCIAS BIBLIOGRÁFICAS}

ALHO J.R.C, Brazilian rodents: their habitats and habits. Pymatuning Laboratory of Ecology Special Publications. No 06, 1982.

BARCELLOS, C. et al. Mudanças climáticas e ambientais e as doenças infecciosas: cenários e incertezas para o Brasil. Epidemiol. Serv. Saúde, Brasília , v. 18, n. 3, set. 2009

BECKER, R. G. et al. Estrutura de comunidades de pequenos mamíferos e densidade de Necromys lasiurus (Rodentia, Sigmodontinae) em áreas abertas de cerrado no Brasil Central. Mastozool. neotrop., Mendoza, v. 14, n. 2, dic. 2007.

CHILDS, J.E. et al. Serologic and Genetic Identification of Peromyscus maniculatus as the Primary Rodent Reservoir for a New Hantavirus in the Southwestern United States. Journal Infectious Diseases. Vol. 169 (6): 1994. 1271-1280.

DEARING, MD ; DIZNEY, L. Ecology of hantavirus in a changing world. Year in Ecology and Conservation Biology. Vol.1195, 2010. pp.99-112.

DONALÍSIO, M.R et al. Aspectos climáticos em áreas de transmissão de hantavirose no estado de São Paulo, Brasil. Cadernos de Saúde Pública, Rio de Janeiro, 24(5): 2008, pp 1141-1150.

EISEN R. J. et al. A Spatial Model of Shared Risk for Plague and Hantavirus Pulmonary Syndrome in the Southwestern United States. American Journal Tropical Medicine Hygiene. 77(6), 2007, pp. 999-1004.

FIGUEIREDO L.T.M. et al. Hantavirus Pulmonary Syndrome, Central Plateau, Southeastern, and Southern Brazil. Emerging Infectious Diseases. Vol. 15, nº 04, 2009.

JONSSON C.B.; FIGUEIREDO L.T.; VAPALAHTI O. A global perspective on hantavirus ecology, epidemiology and disease. Clin Microbiol Rev. 2010; 23:412-41.

LAYME, V.M.G.; LIMA, A.P.; MAGNUSSON, W.E. Effects of fire, food availability and vegetation on the distribution of the rodent Bolomys lasiurus in an Amazonian savanna. Journal of Tropical Ecology, 20, 2004. pp 183-187.

LEE, H. W.; LEE, P.W.; JOHNSON, K.M. Isolation of the etiologic agent of Korean hemorrhagic fever. Journal Infectious Diseases, 137:298-308. 1978.

MEHERETU Y. et al. High diversity of RNA viruses in rodents, Ethiopia. Emerging Infectious Diseases. Vol. 18, n. 12. 2012.

MILLS J.N. Regulation of rodent-borne viruses in the natural host: implications for human disease. Archives of Virology. Suppl. 2005:45-57. 2005.

MINISTÉRIO DA SAÚDE, Hantaviroses: Situação Epidemiológica - Dados. Disponível em: 〈http://portal.saude.gov.br/>. Acesso em: 09 jan. 2014.

MINISTÉRIO DA SAÚDE. Manual de vigilância, prevenção e controle das hantaviroses. Departamento de Vigilância Epidemiológica. - Brasília : Ministério da Saúde, 2013. 94 p.

MINISTÉRIO DO MEIO AMBIENTE. Relatório técnico de monitoramento do desmatamento no cerrado - Bioma Cerrado, 2002 a 2010: Dados Revisados. Centro de Sensoriamento Remoto - CSR/IBAMA. 2011. 
NICHOL S.T et al. Genetic identification of a hantavirus associated with an outbreak of acute respiratory illness. Science: Vol. 262 (5135), 1993. 914-917.

NUNES, M.L; MAIA-ELKHOURY, A.N.S; PELISSARI, D.M. Caracterização clínica e epidemiológica dos casos confirmados de hantavirose com local provável de infecção no bioma Cerrado Brasileiro, 1996 a 2008. Epidemiol. Serv. Saúde, vol.20, no.4, 2011. p.537545.

OLIVEIRA, S.V. Análise preditiva da distribuição geográfica de hantavírus no Brasil. Dissertação (mestrado) - Universidade de Brasília, Faculdade de medicina, Pós-Graduação em Medicina Tropical, 2013. 129 pp.

ORGANIZAÇÃO PAN-AMERICANA DE SAÚDE. Organización Panamericana de la Salud. Hantavírus en las Americas: guía para el diagnóstico, el tratamiento, la prevención y el control. Cuaderno Técnico. Washington, 1999. 66p.

REIS, N.R.; PERACCHI, A.L.; PEDRO, W.A.; LIMA, I.P. Mamíferos do Brasil. Editora UEL. 2006.

SANTOS, J.P.; STEINKE, E.T.; GARCIA-ZAPATA, M.T.A. Uso e ocupação do solo e a disseminação da hantavirose na região de São Sebastião, Distrito Federal: 2004 - 2008. Rev. Soc. Bras. Med. Trop., Uberaba, v. 44, n. 1, 2011.

SCHMALJOHN, C.; HJELLE, B. Hantaviruses: a global disease problem. Emerg Infect Dis. Vol. 3(2): 1997.

SECRETARIA DE VIGILÂNCIA EM SAÚDE. Guia de Vigilância Epidemiológica. Caderno 8, Brasília, 2010.

SUSUKI, A. et al. Identifying Rodent Hantavirus Reservoirs, Brazil. Emerging Infectious Diseases. Vol. 10, nº 12, 2004.

UJVARI, S.C. Meio ambiente \& epidemia. In: Meio abiótico. São Paulo: Ed. Senac. 2004.

WEISS,S. et al, Hantavirus in Bat, Sierra Leone. Emerg Infect Dis. 2012 January; 18(1): 159-161.

WINTERS A. M. et al. Spatial Risk Models for Human Plague in the West Nile Region of Uganda. American Journal Tropical Medicine Hygiene. 80(4), 2009, pp. 1014-1022.

YOUNG J.C et al. The incubation period of hantavírus pulmonary syndrome. American Journal Tropical Medicine Hygiene. Vol. 62, 2000. Pág. 714-7.

ZEIER, M. et. al. New Ecological Aspects of Hantavirus Infection: A Change of A Paradigm and a Challenge of Prevention- A Review. Virus Genes. Volume 30, Issue 2, 2005. pp 157180.

ZHANG W. Y. et al. Predicting the Risk of Hantavirus Infection in Beijing, People's Republic of China. American Journal Tropical Medicine Hygiene. 80(4), 2009, pp. 678683. 


\title{
CAPÍTULO 2
}

\section{ARTIGO 1: ESPAÇO E DOENÇA: MUDANÇAS ANTRÓPICAS E A HANTAVIROSE ${ }^{2}$}

\begin{abstract}
RESUMO
O contexto histórico da Geografia demonstra a existência de uma relação entre o espaço e a Epidemiologia, pois as primeiras observações nas ocorrências e também na distribuição das doenças já levavam em conta as características geográficas do local de ocorrência e a possível existência de algum tipo de correlação. Assim, faz-se importante uma breve retrospectiva da relação entre a ciência geográfica e a saúde, bem como uma análise teórica da paisagem e a sua importância para a Epidemiologia das doenças infecciosas. Através do estudo da teoria dos focos naturais e antropúrgicos do parasitologista Eugene N. Pavlovsky (1884-1965), é possível averiguar novas perspectivas para a compreensão da espacialidade da Hantavirose. A importância do entendimento da organização do espaço geográfico na gênese e distribuição das doenças contagiosas possibilita a oferta de subsídios para uma melhor gestão nos programas de vigilância epidemiológica e de saúde ambiental para o controle das zoonoses e, em especial, da Hantavirose.

Palavras-chave: Geografia da Saúde; Focos antropúrgicos; Hantavirose
\end{abstract}

\begin{abstract}
The historical context of Geography demonstrates the existence of a relationship between the space and the epidemiology, since the first observations in occurrences and also on the distribution of diseases already took into account the geographical characteristics of the place where they occurred and if they had any correlation. Thus, it is a brief synopsis of the relationship between the geographical science and health and also a theoretical analysis of the landscape and its importance for the epidemiology of infectious diseases. Through the study of the theory of natural foci and anthropurgic the parasitologist Eugene N. Pavlovsky (1884-1965) notes that new perspectives for the understanding of the spatiality of hantaviruses. The importance of understanding the organization of geographic space in genesis and in the distribution of infectious diseases makes it possible to offer subsidies for better management in epidemiological surveillance programs and environmental health for the control of zoonoses and, in particular, the hantavirus.
\end{abstract}

Keywords: Geography of Health; Anthropurgic foci; Hantavirus

\footnotetext{
${ }^{2}$ Artigo no prelo -Revista Pan-Amazônica de Saúde
} 


\section{INTRODUÇÃO}

Nos últimos anos, a Geografia da Saúde tem apresentado grande evolução acerca do seu referencial teórico, metodológico e até mesmo do seu próprio conceito, pois o espaço geográfico onde ocorre a interação entre o homem e a natureza tem seu limiar de pesquisa na Epidemiologia, acarretando no desenvolvimento de trabalhos científicos na área.

Um dos elementos geográficos mais importantes para a epidemiologia é a paisagem, pois ali vários elementos podem agir como barreiras ou como trampolins para a dispersão de patógenos, hospedeiros ou vetores, dependendo do agente etiológico em questão. Têm-se ainda as paisagens antropizadas, ou seja, aquelas que apresentam um forte dinamismo na sua estrutura, o que permite o surgimento de condições favoráveis para a propagação de doenças contagiosas com ênfase nas zoonoses - doenças que podem ser transmitidas entre os animais vertebrados e o homem.

Uma vez que a intervenção humana no espaço natural tem se dado rapidamente, certos conceitos, como, por exemplo, a teoria dos focos naturais, tornaram-se obsoletos, sendo que o espaço natural praticamente não existe mais (SILVA, 1997). No entanto, permitiu-se a abertura de uma nova perspectiva com a teoria dos focos antropúrgicos - que vislumbra uma análise epidemiológica centrada sobre o espaço organizado pelas necessidades econômicas.

Neste sentido, as zoonoses possuem alguma relação com as mudanças de origem antropogênica e, neste grupo de doenças, tem-se a Hantavirose. As pressões exercidas pelas atividades socioeconômicas vêm interferindo em processos relacionados à saúde da população e promovendo a ocorrência ou emergência de doenças emergentes e reemergentes. A introdução de novos patógenos em ecossistemas nativos e a diminuição da resiliência de tais ambientes diante das pressões de origem antropogênica são propulsores no referido processo (OSTEFELD et al., 2005).

Percebe-se, então, um crescimento nos casos de Hantavirose nos estados do Sul, Sudeste e Centro-Oeste (OLIVEIRA et al., 2014). Aquelas Unidades da Federação (UFs) apresentam padrões semelhantes em termos de expansão da agricultura e do crescimento de pequenas e médias cidades, que pressionam e afetam os ecossistemas, permitindo, assim, as ocorrências de surtos de Hantavirose. Donalísio et al. (2008) e Oliveira (2013) alegam que as atividades agrícolas funcionam como um impulso para a dispersão do hantavírus, reforçando, 
assim, a afirmação de que as mudanças ambientais ocasionadas pelo tipo de ocupação do solo têm um papel fundamental na Epidemiologia da Hantavirose no Brasil.

Neste contexto, a presente revisão tem como objetivo explicitar a relação entre as paisagens e a ocorrência de doenças infecciosas, em particular, a Hantavirose. A compreensão deste processo é muito importante para o entendimento do papel da organização do espaço geográfico na gênese e na distribuição das doenças, a fim de concretizar o estabelecimento de programas de vigilância epidemiológica e em saúde ambiental.

\subsection{A DIMENSÃO DO ESPAÇO NA GEOGRAFIA DA SAÚdE: CONTEXTO HISTÓRICO}

A união entre a Medicina e a Geografia é antiga. Conforme Santos (2009), remonta à Antiguidade, iniciando-se talvez com a própria história da Medicina. Aquele autor destaca a obra Ares, Águas e Lugares, de Hipócrates de Cós (460-370 a.C.), como o marco inicial da Geografia Médica. O médico romano Claúdio Galeno (129-199), com base nas concepções de saúde de Hipócrates, fez observações relacionadas aos efeitos das 04 (quatro) propriedades físicas (calor, frio, úmido e seco) sobre a fisiologia humana. Além disso, desenvolveu a teoria dos miasmas, atribuindo a origem das epidemias à influência do ar pútrido dos pântanos, dos corpos em decomposição e do calor abafado. As ideias de Galeno tiveram como forte influência a ciência médica ocidental.

Valencius (2000) menciona as investigações de Thomas Sydenham nas epidemias de Peste em Londres no período 1661-1675. As investigações tiveram como foco principal o desenvolvimento de uma abordagem quantitativa para o estudo dos fatores ambientais da doença; e ainda, permitiram informar aos médicos e cientistas da época os avanços obtidos a partir dos estudos empíricos das relações entre o clima, a topografia e as doenças.

Para Riley (1987), alguns médicos sob a influência hipocrática argumentavam a necessidade da utilização de recursos matemáticos e de observações meteorológicas para analisar os efeitos ambientais sobre as condições sanitárias das populações. Conforme aquele autor, o interesse da geografia médica era oferecer alguns subsídios que permitissem a compreensão dos ambientes e sua conexão com a saúde coletiva.

No século XIX, o geógrafo, naturalista e explorador alemão Alexander von Humboldt trouxe uma enorme contribuição à Geografia Médica através do mapeamento da distribuição de certas patologias e povos nos lugares por onde andou. A cartografia foi um elemento de grande importância nas suas obras: a Medicina e a Geografia influenciavam os geógrafos na 
criação de mapas referentes à topografia, à vegetação e ao clima, correlacionando-os com as doenças das áreas estudadas, estabelecendo, assim, suas causas e seus efeitos (VALENCIUS, 2000).

No entanto, as obras e as investigações desenvolvidas pelos geógrafos e médicos residiam na relação determinista entre o homem e o meio. A concepção de espaço prevalente nas Ciências Sociais e na saúde pública era expressa somente nas dimensões físicas e cartográficas, tendo seu status científico diminuído. Inclusive para a Epidemiologia Descritiva - a conceituação clássica compreendia o espaço como um conjunto de determinantes, em geral, de natureza biológica ou natural, tais como: clima, vegetação, latitude e topografia. Neste sentido, não se tem aí nenhuma conexão com os problemas socioeconômicos e ambientais de origem antropogênica. Nota-se, portanto, uma Geografia da Saúde determinística.

As interações entre o espaço geográfico e a ocorrência de doenças como objeto de estudo apresentam uma história de altos e baixos, alternando interesse e desinteresse por parte da comunidade científica. Embora o interesse pela participação dos fatores ligados ao espaço sempre tenha sido grande, os conceitos utilizados eram implícitos, nunca discutidos em si mesmos, e a interpretação do papel que desempenhavam apresentou suas variações. Os motivos destas oscilações, de acordo com Silva (2000), residem nas próprias variações dos paradigmas vigentes tanto na ciência geográfica como na Epidemiologia (das doenças transmissíveis).

Portanto, a partir do final do século XIX, com o desenvolvimento da Microbiologia, a concepção de doença, tendo como única etiologia um agente infeccioso, pôs à margem outras abordagens sobre a determinação das doenças (ANDRADE, 2000). O ambiente deixou de apresentar a importância que vinha assumindo desde os escritos hipocráticos, relegando-se pouco a pouco a um segundo plano, e a velha tradição que atribuía ao meio físico a influência sobre a vida do homem, especificamente nos aspectos da saúde-doença.

Na França, Maximillien Sorre, geógrafo acadêmico de sólida formação clássica, publica em 1943 o primeiro volume de sua obra máxima, Les fondements de la géographie humaine, de cunho fundamentalista biológico. Aquela obra buscou estabelecer os pontos de contatos entre a Geografia e as Ciências Sociais e Biológicas.

Nos limites teóricos impostos pela abordagem ecológica das relações entre o homem e o meio (marcantes na obra de Sorre), o conceito de complexo patogênico amplia o poder 
analítico e explicativo de uma Geografia antes restrita quase exclusivamente à descrição do meio físico, conforme se segue:

\begin{abstract}
Aparentemente os fatores determinantes da área de extensão das grandes endemias eram infinitamente mais complexos do que se supunha. Separou-se da noção de clima, quase imutável desde época de Hipócrates, elementos de cuja existência nem mesmo se suspeitava (SORRE, 2006, p. 02).
\end{abstract}

Sua obra é marcada por uma preocupação teórica: fornecer uma base conceitual à geografia médica que permitisse investigações de natureza interdisciplinar. A semelhança entre ambos os esquemas conceituais é evidente, especialmente porque ambos partem de uma interpretação ecológica das relações entre o homem e o meio. Neste sentido, Sorre, (2006, p. 2) atenta: "Percebeu-se que o homem poderia ter uma ação preponderante sobre a propagação e extinção de endemias".

Tem-se aí uma aproximação de causa-efeito sobre as doenças, em especial, as doenças endêmicas das regiões tropicais, tais como: malária, doença do Sono, doença de Chagas, febre amarela e outras. Tais enfermidades, segundo Sorre (2006), são frutos das inter-relações e da dinâmica de organismos que, para sobreviverem, não lutam isoladas umas das outras, mas sim, formam complexos biológicos que permitem o parasitismo entre as espécies e o possível impacto epidemiológico sobre o homem, uma vez que ingressa neste contexto tanto como paciente quanto como agente. Além disso, o homem pode agir diretamente sobre o complexo através da modificação do habitat de espécies vetores e reservatórios de organismos patógenos, favorecendo a dispersão ou esterilizando os complexos através de medidas profiláticas e curativas. Como exemplo deste tipo de ação, tem-se a utilização de quinino no combate à malária, acarretando em uma redução drástica dos casos em diversos países.

Para Ferreira (1991), mesmo sendo elaborado dentro dos limites teóricos imposto pela abordagem ecológica das relações entre o homem e o meio que marca a obra de Sorre, o conceito do complexo patogênico ampliava o poder analítico e explicativo de uma Geografia antes restrita quase exclusivamente à descrição do meio físico e, assim, procurava contraatacar a escola alemã, cujas bases se assentavam no determinismo da natureza sobre a ação do homem.

A noção de complexo patogênico provocou a necessidade de analisar profundamente os efeitos da ação humana na organização do espaço e de compreender a dinâmica de tais processos sobre as condições sanitárias das populações envolvidas sob a ótica da Epidemiologia. 


\subsection{A TEORIA DOS FOCOS NATURAIS E A EPIDEMIOLOGIA PAISAGÍSTICA}

Com o avanço da fronteira agrícola soviética no início da era Stálin, várias áreas da então União das Repúblicas Socialistas Soviéticas (URSS) e, em particular, da Sibéria e da Ásia Central, estavam sendo desbravadas e exploradas, tanto para a agricultura, quanto por seus recursos naturais (madeira, minerais, peles e tantos outros). Consequentemente, deu-se o surgimento das mais variadas zoonoses, quais sejam: leishmaniose, tularemia, riquettsiose, entre outras.

Na década de 1930, o geógrafo e parasitologista russo Eugene Nikanorovich Pavlovsky (1884-1965) - presidente das sociedades de Geografia e Entomologia da então URSS formulou a teoria dos focos naturais das doenças humanas, também conhecida como "teoria da nidalidade natural das doenças transmissíveis". Sua obra era fortemente marcada pela necessidade de obtenção de respostas que permitissem resolver rapidamente alguns problemas de saúde importantes com os quais os russos se confrontavam, quais sejam: as encefalites por arbovírus na Sibéria, a febre amarela e a dengue (PAVLOVSKY, 1966).

A Epidemiologia Paisagística, que é a delimitação geográfica de áreas propícias ao desenvolvimento de zoonoses, foi o principal efeito da teoria dos focos naturais, sendo de suma importância para o planejamento de empreendimentos que ocorriam na época de Pavlovsky, pois Stalin tinha dado início a projetos de exploração econômica - agricultura, mineração e assentamentos urbanos - em regiões que hoje são as ex-repúblicas soviéticas na Ásia Central e na Sibéria (MEADE; EARICKSON, 2005). Ademais, a teoria foi empregada na elaboração de projetos de moradias, equipamentos de proteção individual e tantos outros que ajudariam na prevenção de doenças zoonóticas.

Conforme a teoria de Pavlovsky (1966), o foco natural de uma doença transmissível (zoonoses) exigiria a presença de 05 (cinco) elementos, a saber: (1) de animais reservatórios onde vivem e se multiplicam um agente infeccioso, do que depende sua sobrevivência, e como se reproduz para que possa ser transmissor de um hospedeiro suscetível; (2) de animais vetores que transportam, em seu corpo, um parasita, que ali se multiplica ou passa por mais de um estágio de desenvolvimento ontogenético (origem e desenvolvimento do organismo); (3) de animais hospedeiros suscetíveis que, em circunstâncias naturais, permitem a subsistência ou o alojamento de um agente infeccioso; (4) de agentes patógenos, que são os microorganismos (vírus, bactérias, protozoários, helmintos e fungos) capazes de infectar um hospedeiro; e, (5) de condições ambientais que sejam favoráveis à cadeia de transmissão. A 
formação dos referidos focos naturais dependem de variáveis ambientais, tais como: altitude, microclimas, solo, salinidade, $\mathrm{pH}$, vegetação e outros aspectos favoráveis nos lugares onde se dá a circulação de agentes patógenos, vetores e hospedeiros.

Através destes elementos é possível perceber que as doenças transmissíveis, em especial, àquelas que são transmitidas por vetores, têm o seu próprio habitat natural da mesma forma que uma espécie animal, vegetal ou fúngica. Assim, o nicho (foco natural) de uma doença existe sob condições específicas de clima, vegetação, solo e microclima favoráveis, onde os agentes patogênicos, vetores e reservatórios estão associados como uma biocenose, ou seja, com uma paisagem geográfica específica, como, por exemplo, a taiga, as estepes, as florestas tropicais e outros tipos de paisagens. A infecção humana, então, se dá quando o homem (hospedeiro suscetível) interfere no referido nicho.

O nicho, segundo Alho (2012), é o local onde ocorrem as interações e combinações nos processos biológicos e ecológicos entre as comunidades de organismos, e onde constantemente sofre perturbações de origem biótica (como, por exemplo, a competição de espécies, a extinção ou a redução das populações de certos componentes da microbiota) e abiótica (como as mudanças nos ciclos biogeoquímicos). Assim, tais interações são interconectadas e devem ser observadas sistematicamente, pois os reflexos das mudanças que ocorrem sobre o nicho são sentidos em todas as partes do sistema, inclusive, na saúde humana.

Neste sentido, Ávila-Pires (2000) faz uso do conceito de patocenose, que é justamente uma instabilidade no balanço ecológico entre os hospedeiros e os micro-organismos impactados pelas alterações no ecossistema, que promove a ocorrência de um incremento na patogenicidade dos micro-organismos presentes naquela área, permitindo, assim, a eclosão de epidemias. O conceito de patocenose é bastante utilizado na Ecologia Médica para analisar os ciclos de transmissão de doenças zoonóticas através da compreensão da influência dos fatores abióticos e bióticos ali existentes.

Entretanto, tal conceito refere-se apenas à transformação inicial dos focos naturais, não apresentando elementos suficientes para o estudo das doenças transmissíveis em situações onde a dinâmica de modificação do espaço pelo homem se dá de forma ampliada e acelerada, ou seja, as alterações nas paisagens provocadas por fatores antropogênicos, tais como: desmatamento, irrigação, atividades agropastoris, mineração e outros, promovem modificações bruscas na composição qualitativa e quantitativa da fauna e flora e também nos ciclos biogeoquímicos que, por sua vez, refletem nas condições sanitárias das populações ali 
residentes. Mas, posteriormente, Pavlovsky discute a referida problemática na teoria dos focos antropúrgicos.

Vale ressaltar que a definição de foco natural limita-se às doenças transmitidas por animais vetores, não se referindo ao estudo de doenças que, mesmo apresentando agente etiológico definido, propagam-se através do contato direto ou mesmo pela inalação de ar contaminado, tais como: difteria, varíola, escarlatina etc. Neste sentido, Balashov (2010) observa que a teoria dos focos naturais não é obrigatoriamente aplicável somente às zoonoses com transmissão por animais vetores, mas também às enfermidades que têm como mecanismos de transmissão a água ou solo, pois servem como vetores para vírus, bactérias e helmintos que infestam os animais e o homem e, assim, desenvolvem os mais variados agravos à saúde pública.

A intromissão humana em novos espaços naturais, impelida por atividades econômicas, criou oportunidades para a infecção de novas espécies hospedeiras e para a dispersão de patógenos antes restritos àqueles espaços naturais. Os surtos de doenças (como, por exemplo, a febre hemorrágica causada pelo vírus Ebola e outras doenças emergentes ou reemergentes) fizeram renascer o interesse pelos espaços naturais, inalterados ou muito pouco modificados.

\subsection{A TEORIA DOS FOCOS ANTROPÚRGICOS}

Tanto na Geografia da Saúde como na Epidemiologia, a utilização da categoria espaço não pode limitar-se à mera localização de eventos de saúde. Tal categoria tem sua importância na análise de eventos de saúde através do inter-relacionamento dos elementos que compõem o próprio espaço geográfico, sendo a paisagem um dos elementos de grande importância na compreensão do processo saúde-doença e, em especial, no trato das doenças infecciosas humanas.

A paisagem é, assim, um fator epidemiológico, pois suas características são as mesmas do ecossistema local. Neste sentido, Rodriguez et al. (2007), define o conceito de paisagem como um sistema inter-relacionado de formações naturais e antroponaturais, ou seja, um sistema que contém e reproduz recursos, um meio de vida e da atividade humana e uma fonte de percepções estéticas. Trazendo o conceito da paisagem para a Epidemiologia, Lambin et al. (2010) recordam que a análise integrada da paisagem permite uma melhor compreensão das interações existentes com as mudanças nos ecossistemas, pressionadas pelos padrões de uso da terra e suas consequências sobre a circulação de vetores e de animais hospedeiros de agentes patogênicos. 
Como consequência do desbravamento do ambiente na procura por recursos naturais, como, por exemplo, madeira e minerais, a população ficou susceptível à leishmaniose nas estepes da Ásia Central, e às encefalites por arbovírus na taiga da Sibéria. Neste sentido, Pavlovsky (1966) introduziu a ideia da transformação do espaço de circulação de agentes de doença pela ação humana, ou seja, a formação de focos antropúrgicos (antropos - homem e urgico - ação). Tal vertente seria a primeira aproximação entre as mudanças ambientais de origem antropogênica e as doenças emergentes (Ebola, febre de Lassa, Hantavirose e tantas outras) e reemergentes (leishmanioses, febre amarela, dengue), pois a crescente atividade humana tem impactado os ecossistemas naturais, perturbando a estrutura e a função do sistema natural.

Porém, a teoria dos focos antropúrgicos respondia apenas pela transformação inicial dos focos naturais e ainda sem elementos suficientes que permitissem o seu aprimoramento, tendo em vista que naquela época não existiam ainda outros estudos que associassem as doenças contagiosas com as mudanças de origem antropogênica. Deste modo, a teoria não avançou.

Em razão do crescimento da população humana e das mudanças ambientais causadas pelo aumento da demanda por alimentos e commodities, bem como da expansão da urbanização que fragmentam os ecossistemas e reduzem a biodiversidade de espécies, acarretando no aparecimento das doenças que impactam a saúde pública em todo mundo, a teoria foi retomada para possíveis análises na dinâmica de certas zoonoses (PATZ et al., 2004; WHO, 2005; FOLEY et al., 2005; JONES et al., 2008; MYERS et al., 2013; MURRAY; DASZAK, 2013).

O fato é que apesar da teoria dos focos antropúrgicos não ter sido aperfeiçoada, os princípios deste conceito apontavam que no interior da paisagem existem estruturas biofísicas e antrópicas que criam condições ideais para o desenvolvimento de doenças transmitidas por contato com animais vetores ou reservatórios. A exemplo disso, Patz et al. (2004) demonstraram o aumento dos casos de encefalites causadas pelos vírus Nipah na Malásia. Ali, o desmatamento de áreas florestais para a criação de porcos permitiu a interação entre o hospedeiro e o patógeno, pois, instalados sob as árvores, os chiqueiros ficavam cheios de frutas mordidas, fezes e urina infectadas de morcegos frugívoros da família Pteropodidae particularmente as espécies pertencentes ao gênero Pteropus. Os porcos adoeciam e as pessoas eram contaminadas pela carne ou pelos excrementos dos animais. 


\subsection{A HANTAVIROSE SEGUNDO A TEORIA DOS FOCOS ANTROPÚRGICOS}

Com base no referido exemplo, a Hantavirose possui também nuances com a teoria dos focos antropúrgicos, embora em seu ciclo de transmissão não há a participação de um animal vetor (mosquitos, pulgas e carrapatos). Contudo, sua circulação está acoplada a um ambiente com mudanças de origem antropogênicas, pois se observa que as alterações nas estruturas dos ecossistemas têm contribuído na composição da população de roedores reservatórios do hantavírus.

Retornando ao conceito de paisagem como uma expressão complexa de elementos naturais e artificiais (SANTOS, 2008), é possível observar que tal expressão tem um profundo significado para a Hantavirose, pois, por ser uma doença emergente e que possui uma casualidade com os fatores antropogênicos, faz parte daquilo que Confalonieri (2005) denomina por "paisagens de doenças", ou seja, estruturas favoráveis para a propagação de uma doença infecciosa.

A Figura 1, a seguir, expressa a esquematização destas “paisagens de doenças”, além de auxiliar na compreensão da dinâmica espacial da Hantavirose.

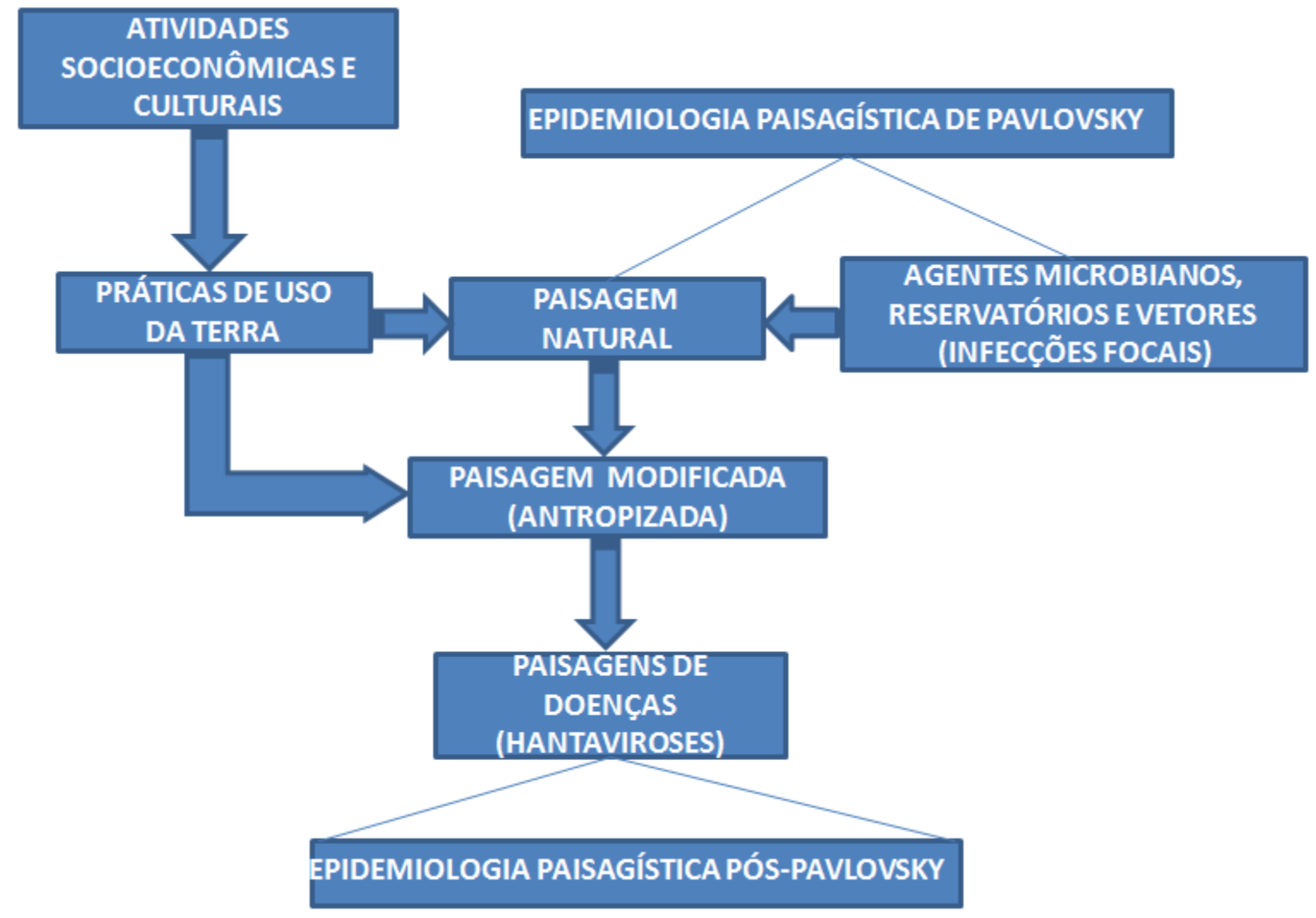

Figura 1 - Esquematização da formação de "paisagens de doenças" - Exemplo: Hantavirose. 
A esquematização apresentada anteriormente demonstra que as atividades socioeconômicas e culturais indicam de que maneira se dá o uso dos recursos existentes naquela paisagem pouco explorada ou ainda a ser explorada. De certa maneira, na referida paisagem natural tem-se a ocorrência de circulação de patógenos, reservatórios e vetores.

Com a pressão exercida sobre a paisagem natural, é possível identificar uma mudança em toda sua estrutura ambiental, o que permite a formação de uma paisagem antropizada. Contudo, a paisagem antropizada permite a formação de um cenário onde as populações humanas entram em contato com os patógenos de doenças infecciosas (aquelas de origem zoonóticas), participando como hospedeiro intermediário e acidental no ciclo de transmissão. Desta forma, observa-se a formação de "paisagens da Hantavirose", isto é, uma junção entre uma paisagem antropizada que possui na sua estrutura condições que permitam o desenvolvimento de uma zoonose. Por fim, é preciso destacar a Epidemiologia Paisagística "pós-Pavlovskiana", ao incluir características do elemento humano e suas interações com o ambiente como partes constituintes das paisagens - determinantes das dinâmicas epidemiológicas.

Justificando os fundamentos até aqui apresentados para a existência da Hantavirose, é possível perceber que em certas épocas do ano, em algumas áreas dos biomas Cerrado e Caatinga, o cultivo de cereais (como, por exemplo, o milho, o feijão, etc.) e o cultivo da canade-açúcar aumentam a oferta de alimentos para os roedores sinantrópicos e silvestres. Os grãos são armazenados em paióis rudimentares ou dentro das casas de moradias, onde as condições de higiene e de armazenamento são precárias, propiciando o contato com as excretas contaminadas dos roedores. Neste sentido, Santos (2011) observou que no Distrito Federal onde os surtos de Hantavirose ocorreram em áreas destinadas para a agricultura familiar, e Verdade et al. (2012) relataram que a Hantavirose pode se tornar um grande problema de saúde pública em certas áreas do interior do Estado de São Paulo, em consequência da expansão da lavoura canavieira ali existente - as plantações de cana-deaçúcar costumam abrigar roedores silvestres das espécies Necromys lasiurus e Calomys tener e estão próximas das áreas suburbanas dos municípios, elevando, assim, o risco de se contrair Hantavirose. Também Myers et al. (2013) demonstraram por meio de experimentos no Panamá que a exposição ao hantavírus aumenta quando da diminuição da biodiversidade em áreas florestais em razão da expansão de áreas agrícolas que destroem essas áreas e com isso, expulsando os roedores para as habitações humanas mais próximas. 
Em suma, as situações então apresentadas permitem compreender como os fatores antrópicos impactam na saúde pública, uma vez que as paisagens modificadas trazem consigo intencionalmente ou acidentalmente elementos que provocam agravos às populações.

\subsection{CONSIDERAÇÕES FINAIS}

O espaço geográfico não é meramente uma categoria estática para a Epidemiologia, mas sim, uma categoria que apresenta na sua essência a natureza e a sociedade e que, por sua vez, introduz novas perspectivas de análise para a saúde pública. E a paisagem como um conceito-chave da geografia tem um papel importante na relação saúde-ambiente.

É possível observar que na composição da estrutura das paisagens existem elementos discutidos nas abordagens de Pavlovsky que possuem um forte potencial para influenciar a dinâmica de certas doenças contagiosas, uma vez que os impactos sobre tais estruturas provocam a formação de patocenoses ou paisagens de doenças. As intervenções antrópicas causam alterações tanto macroambientais quanto microambientais, modificando a distribuição espacial dos agentes patogênicos.

Ainda que a teoria dos focos antropúrgicos necessite de avanços na sua Epistemologia, a mesma oferece subsídios para a constituição de uma visão sistêmica dos problemas relacionados às doenças de origem zoonóticas. Neste sentido, a Hantavirose serve como exemplo para a constatação da referida teoria, pois é uma patologia que se apresenta como uma espécie de indicador de ambientes alterados, uma vez que de sua ocorrência em ambientes rurais e nas bordas de áreas que apresentam expansão urbana.

O emprego da análise da paisagem da Hantavirose e também em outras zoonoses (como, por exemplo, raiva, febre maculosa, leishmanioses e tantas outras) poderia oferecer subsídios com o intuito de orientar as estratégias de monitoramento e de vigilância epidemiológica na saúde pública, tendo em vista que a exploração dos recursos naturais sem planejamento e com ausência de investigação de presença agentes patogênicos sujeita indivíduos habitantes da natureza a se adaptarem a novos hospedeiros e novas condições ambientais, bem como expõem os seres humanos e seus animais domésticos ao convívio com animais silvestres e seus agentes causadores de doenças.

O próprio Pavlovsky dedicou-se na elaboração de programas de saúde pública para o controle de doenças zoonóticas em áreas de exploração de recursos naturais, reduzindo, assim, a endemicidade das referidas doenças - exemplo que poderia ser levado em conta nos estudos de empreendimentos de grande impacto ambiental. 


\subsection{REFERÊNCIAS BIBLIOGRÁFICAS}

ALHO, C.J.R. Importância da biodiversidade para a saúde humana: uma perspectiva ecológica. Estudos Avançados, v. 26, n. 74, p. 151-166, 2012.

ANDRADE, M.E.B. Geografia médica: origem e evolução. In: BARATA, R.B.; BRICEÑOLEÓN, R.E., orgs. Doenças endêmicas: abordagens sociais, culturais e comportamentais. Rio de Janeiro: Editora FIOCRUZ, 2000. p. 151-166.

ÁVILA-PIRES, F.D. Princípios de Ecologia Médica. Florianópolis: Editora UFSC, 2000. $328 \mathrm{p}$.

BALASHOV, Y.S. The $70^{\text {th }}$ aniversary of E.N. Pavlovsky's concept of natural nidality of human diseases. Entomological Review, vol 90, nº 4, 2010, pp. 533-536.

CONFALONIERI, U. E. C. Saúde na Amazônia: um modelo conceitual para a análise de paisagens e doenças. Estudos Avançados, v. 19, n. 53, p. 221-236, 2005.

DONALÍSIO, M.R et al. Aspectos climáticos em áreas de transmissão de hantavirose no estado de São Paulo, Brasil. Cadernos de Saúde Pública, v. 24, n. 5 , p. 1141-1150, 2008.

FERREIRA, M.U. Epidemiologia e geografia: o complexo patogênico de Max. Sorre. Cadernos de Saúde Pública, v. 7, n. 3, p. 301-309, 1991.

FOLEY, J.A. et al. Global consequences of land use. Science, vol. 309, p. 570-573, 2005.

JONES, $\mathrm{K}$ E. et al. Zoonosis emergence linked to agricultural intensification and environmental change. Procceding National Academic Sciences, v. 451, n. 7181, p. 990993, 2008.

LAMBIN, E.F. et al. Pathogenic landscapes: Interactions between land, people, disease vectors, and their animal hosts. International Journal of Health Geographics, v. 9, n. 54, p. $2-13,2010$.

MEADE, M. S.; EARICKSON, R.J. Medical Geography. $2^{a}$ ed. New York: Guilford Press, 2005. $500 \mathrm{p}$.

MURRAY, K.A.; DASZAK, P. Human ecology in pathogenic landscapes: two hypotheses on how land use change drives viral emergence. Current Opinion in Virology, v. 3, n. 1, p. 7983, 2013.

MYERS, S.S. Human health impacts of ecosystem alteration. Proccedings of the National Academic Sciences, v. 110, n.47, p. 18753-18760, 2013.

OLIVEIRA, S.V. Análise preditiva da distribuição geográfica de hantavírus no Brasil. Dissertação (mestrado) - Universidade de Brasília, Faculdade de medicina, Pós-Graduação em Medicina Tropical, 2013. 129 pp.

OLIVEIRA, S.V.; ESCOBAR L.E.; PETERSON A.T.; GURGEL-GONÇALVES, R.; Potential Geographic Distribution of Hantavirus Reservoirs in Brazil. PLoS ONE, v. 8, n.12, 2014.

OSTEFELD, R. S.; GLASS, G. E.; KESSING, F. Spatial epidemiology: an emerging (or reemerging) discipline, Trends in Ecology \& Evolution, v. 20, n. 6, p. 328-326, 2005. 
PATZ, J.A. et al. Disease emergence from global climate and land use change. Medical Clinics of North America, v. 92, n. 6, p. 1473-1491, 2008.

PAVLOVSKY, E.N. Natural nidality of transmissible diseases in relation to landscape. Epidemiology of zooanthroponoses. Moscow: Ed. Peace Publishers, 1966. 249p.

RILEY, J.C. The Eighteenth-Century Campaign to Avoid Disease. New York: St Martin's Press, 1987.

RODRIGUEZ J.M.M.; SILVA, E.V.; CAVALCANTI, A.P.B. Geoecologia das Paisagens: uma visão geossitêmica da análise ambiental. Fortaleza: Ed. UFC, 2007.

SANTOS, J. P. Aspectos geoambientais e epidemiológicos em áreas de transmissão da Hantavirose no Distrito Federal, 2009. p.89. Dissertação de Mestrado. Universidade de Brasília, Brasília.

SANTOS, J.P.; STEINKE, E.T.; GARCIA-ZAPATA, M.T.A. Uso e ocupação do solo e a disseminação da hantavirose na região de São Sebastião, Distrito Federal: 2004 - 2008. Revista da Sociedade Brasileira de Medicina Tropical, v. 44, n. 1, p. 53-57, 2011.

SANTOS, M. Metamorfoses do Espaço Habitado: Fundamentos Teóricos e Metodológicos da Geografia. São Paulo: EDUSP, 2008. 136 p.

SILVA, L. J. Ocupação do espaço e doenças endêmicas. In: BARATA, R.B.; BRICEÑOLEÓN, R.E., orgs. Doenças endêmicas: abordagens sociais, culturais e comportamentais. Rio de Janeiro: Editora FIOCRUZ, 2000.

SILVA, L.J. O conceito de espaço na epidemiologia das doenças infecciosas. Caderno Saúde Pública, v. 13, n. 4, p. 585-593. 1997.

SORRE, M. Complexes pathogènes et géographie médicale. Hygeia, Revista Brasileira de Geografia Médica e da Saúde, v. 2, n. 2, p. 2-14, 2006.

VALENCIUS, C.B. Histories of Medical Geography. Journal Medical History, v. 20. 2000.

VERDADE, L.M; GHELER-COSTA, C; PENTEADO, M; DOTTA, G. The impacts of sugarcane expansion on wildlife in the state of São Paulo, Brazil. Journal of Sustainable Bioenergy Systems, v. 2, n. 4, p. 134-138, 2012.

WORLD HEALTH ORGANIZATION. Ecosystems and Human Well-beig: Current State and Trends. New York: Island Press, 2005. 


\title{
CAPÍTULO 3
}

\section{ARTIGO 2: MODELAGEM DE NICHO ECOLÓGICO DO Necromys lasiurus (LUND, 1841): CONTRIBUIÇÕES À ECOEPIDEMIOLOGIA DA HANTAVIROSE.}

\begin{abstract}
RESUMO
A Modelagem de Nicho Ecológico (MNE) representa uma excelente ferramenta para caracterização da ecologia e distribuição geográfica de espécies em um cenário real. A ferramenta é uma das alternativas que podem ser utilizadas com o intuito de analisar possíveis rotas de disseminação de doenças infecciosas. Com base em tais aspectos foram construídos modelos de adequabilidade ambiental para o roedor Necromys lasiurus - o principal reservatório do hantavírus Araraquara (ARAV) no Brasil. Com o auxílio do algoritmo MAXENT (Maximum Entropy) (MAXENT versão 3.3.3) foram produzidos mapas temáticos indicando as áreas mais favoráveis ao estabelecimento desta espécie. Os resultados apontaram as diferenças de distribuição potencial da espécie em razão da inclusão e da exclusão da variável 'uso da terra'.
\end{abstract}

Palavras-chave: Modelagem de Nicho Ecológico; Ecoepidemiologia; Hantavirose

\begin{abstract}
Modeling of Ecological Niche (MFA) is an excellent tool for characterization of ecology and geographical distribution of species in a real scenario. The tool is an alternative which can be used in order to analyze possible routes of dissemination of infectious diseases. Based on these aspects were built environmental suitability models for the rodent Necromys lasiurus, which at the moment is the main reservoir of Araraquara hantavirus (ARAV) in Brazil. With the help of MAXENT algorithm (Maximum Entropy) (MAXENT version 3.3.3) were produced thematic maps indicating the most favorable to the establishment of this species areas. The results showed the potential distribution of the species differences due to the inclusion and exclusion of the variable "land use".

Keywords: Ecological Niche Modeling; Ecoepidemiology; Hantavirus
\end{abstract}




\subsection{INTRODUÇÃO}

A palavra "modelo" possui muitas nuanças em seu significado. Para Cristofoletti (1999, p. 08), o modelo pode ser compreendido como sendo "qualquer representação simplificada da realidade" ou de um aspecto do mundo real que seja do interesse do pesquisador, que possibilite reconstruir a realidade ou prever um comportamento, transformação ou algum tipo de evolução.

Os processos que envolvem a modelagem são complexos e abrangentes, incorporando os resultados da modelagem climática geral e conhecimentos relacionados à ecologia e às condições sociais e econômicas. Além disso, a modelagem (ambiental) pode ser considerada como um tipo de instrumento entre os procedimentos metodológicos da pesquisa científica (PETERSON et al., 2011) .

A justificativa para as linhas que se seguem reside no fato de que a construção de modelos a respeito dos sistemas ambientais representa a expressão de uma hipótese ou de uma premissa científica, que necessita ser avaliada como sendo enunciado teórico sobre o sistema ambiental focalizado.

Gianinni et al. (2012) relatam que a perda e a fragmentação de habitats e as mudanças climáticas são apenas 02 (dois) exemplos de alterações ambientais causadas por fatores antropogênicos, com consequências diretas sobre a distribuição das espécies. Tais ameaças (crescentes) demandam novas tecnologias e ferramentas de análise, para que se possa adquirir ou aprofundar o conhecimento existente sobre as espécies e auxiliar em sua proteção e conservação.

A Modelagem de Nicho Ecológico (MNE) tem muito a oferecer para o campo da saúde pública e, particularmente, para o campo da Epidemiologia. Neste sentido, segundo Peterson et al. (2011), não se tem conhecimento suficiente sobre muitas doenças infecciosas em relação aos fatores ambientais que possam influenciá-las, bem como na extensão geográfica de suas ocorrências. Logo, a modelagem poderia trazer contribuições para a compreensão dos processos ecológicos e geográficos das doenças transmissíveis. Para ilustração, aqueles autores apontam como exemplo as ocorrências de infecções provocadas pelo vírus Marburg, onde a modelagem permitiu esclarecer as condições ecológicas do surgimento do vírus e o provável ponto geográfico de sua origem. 
O desenvolvimento de uma análise espacial para a distribuição do roedor Necromys lasiurus fazendo uso de um algoritmo e que tem como finalidade a inclusão de variáveis ambientais (como, por exemplo, clima, vegetação e topografia) e antrópicas (o uso da terra, por exemplo) faz com que a compreensão da dispersão do roedor reservatório do hantavírus seja bem compreendida e digna de predizer os lugares que possivelmente desenvolverão surtos de Hantavirose, conforme a adequabilidade ambiental para permanência do mesmo.

Neste sentido, Pearson et al. (2004) descrevem que as mudanças nos padrões de uso da terra que levam à perda de habitat são fatores essenciais na modelagem preditiva de espécies, uma vez que a fragmentação dos ecossistemas altera substancialmente a distribuição das espécies e, assim, a introdução desta variável na modelagem terá um peso significativo na simulação. Aqueles autores ainda apontam que existem poucos estudos que abordam explicitamente a modelagem com ênfase nas mudanças de uso da terra e os seus impactos sobre os habitat das espécies.

Nesta mesma abordagem verifica-se ainda a necessidade de analisar os efeitos dos padrões de uso da terra na modelagem de nicho de espécies partícipes da cadeia de transmissão de doenças infecciosas ao homem. Assim, Santos et al. (2011) e Brito (2012) atentam para os efeitos dos padrões do uso da terra na distribuição espacial da Hantavirose no Distrito Federal e no Estado de Minas Gerais, explicitando a necessidade do uso de técnicas que permitam analisar as condições que sustentam os nichos dos roedores reservatórios do hantavírus.

O uso de modelos espaciais para a geração de mapas de risco, seguido de avaliação da sensibilidade e especificidade destes modelos, podem levar à formulação de planos específicos de gestão ou de controle da doença. Técnicas de Epidemiologia Espacial podem gerar novas recomendações sobre o alvo de intervenções para prevenir a propagação da doença, mas a utilidade das intervenções sugeridas exigirá esforços colaborativos entre ecologistas, epidemiologistas e profissionais de saúde, a fim de avaliar a viabilidade e eficácia destas técnicas. Tais colaborações, se bem-sucedidas, poderiam estimular o desenvolvimento da modelagem ambiental para doenças emergentes e reemergentes. 
Diante do exposto, as linhas que se seguem tem por objetivo realizar a MNE do roedor silvestre Necromys lasiurus - reservatório do hantavírus Araraquara (ARAV) -, visando estimar a distribuição potencial da espécie, bem como analisar o papel do uso da terra na modelagem e distribuição da espécie.

\subsubsection{Pressupostos da Modelagem de Nicho Ecológico e sua aplicabilidade à Hantavirose}

A primazia da aplicação do conceito de nicho é atribuída frequentemente a Joseph Grinnell (1877-1939), que discutiu em seus artigos o nicho de algumas espécies de pássaros e mamíferos (GRINNELL, 1917, 1924). Tal fato se deu por meio das observações sobre a ocorrência de indivíduos e as características ambientais do habitat (temperatura, altitude, pluviosidade e cobertura vegetal) em diversos pontos de cobertura da distribuição da espécie e de elementos comuns destes pontos que revelariam quais as condições ambientais apropriadas para sua ocorrência.

Assim, Grinnell indicou uma forte relação entre o nicho e a distribuição das espécies, enfatizando o papel dos fatores ambientais (em especial, a temperatura e a cobertura vegetal) sobre a distribuição geográfica de Toxostoma redivivum. Conforme as descrições daquele autor, o nicho consistiria não exatamente em um atributo da espécie, mas sim, do espaço, sendo definido como a soma das exigências de habitat e comportamentos que permitiriam uma espécie de persistir e produzir descendência. Neste sentido, o nicho possuiria uma característica essencialmente ambiental.

Posteriormente, Elton (1927) apresentou o nicho de uma espécie com o seu papel dentro da cadeia alimentar, analisando tanto o impacto sofrido pela espécie, quanto o que ela causava em seu ambiente. Segundo aquele autor, a importância de se estudar o nicho se dá em razão da dinâmica de uma espécie de animal que permite observar como diferentes comunidades de animais podem assemelhar-se com outras em função de suas interações com o meio. $\mathrm{O}$ foco do conceito eltoniano se dá em função da espécie dentro da cadeia trófica e suas relações com os predadores e as presas.

A conceituação de nicho ecológico deu um grande salto a partir dos trabalhos de George Evelyn Hutchinson, que definiu o termo "nicho" como a soma de todos os fatores ambientais que atuam sobre o organismo: "uma região de um hiper-espaço $n$-dimensional”, sendo que o 
termo "hiper-espaço" foi substituído posteriormente por "hiper-volume" (HUTCHINSON, 1957, p. 416). Segundo aquele autor, definido um número qualquer ( $n$ ) de fatores limitantes (como, por exemplo, luminosidade, temperatura e recursos alimentares) à sobrevivência do organismo, a amplitude de tolerância a estes fatores, ou seja, os valores mínimos e máximos dos limites de tolerância para cada fator, constituiria, então, um hiper-volume com $n$ dimensões. Portanto, o espaço abrangido por este hiper-volume representaria a faixa de variação dos fatores ambientais onde a espécie é capaz de sobreviver e reproduzir.

Soberón (2007) detalha que Hutchinson mencionou que os conceitos de Grinnell e Elton apresentam elementos que os distinguem, pois, para ele, o conceito de nicho de Grinnell discute o fato de que a distribuição das espécies estaria relacionada à influência de elementos abióticos e menos interativos, tais como: a geologia, o clima, os solos, etc. O conceito grinnelliano expõe que os elementos que não são consumidos e aqueles que não ocorrem nenhuma competição são chamados de scenopoetic. Em relação ao conceito eltoniano onde o nicho é definido pela presença de elementos dinâmicos que se interagem em razão da cadeia trófica e que, neste caso, podem ser consumidos e serem objetos de competição, estes são denominados de bionômicos.

Pulliam (2000) atenta que todas as espécies não somente respondem às variações no ambiente, mas também as influenciam. Segundo aquele autor, a maioria dos casos de competição interespecífica são interações indiretas entre as espécies mediadas pela influência de uma espécie com os recursos limitativos de outra espécie. Assim, é possível encontrar indivíduos em locais onde as condições não são inteiramente adequadas à sobrevivência e à reprodução da espécie. Por outro lado, as espécies podem apresentar limites de dispersão e, consequentemente, não chegar aos locais adequados. Portanto, a dinâmica denominada por Pulliam de "fonte-dreno" (os habitats-fontes são aqueles nos quais a reprodução local excede a mortalidade, e nos drenos se dá o contrário) prevê que uma espécie possa ser encontrada fora dos limites de seu nicho fundamental, enquanto que, ao contrário, o limite na capacidade de dispersão prevê que certos locais, potencialmente adequados, possam não ser ocupados por determinadas espécies. 
Diante do fato, Soberón e Peterson (2005) publicaram, então, um modelo (Figura 1) que trazia a representação no formato do diagrama de Venn, a influência simultânea das condições abióticas, bióticas e a dispersão na distribuição geográfica das espécies. Assim, na Figura 1, o círculo vermelho representa os fatores abióticos, o verde apresenta os fatores bióticos e o círculo rosa representa o acesso (movimentação) para a espécie.

\section{CONCEITOS DE NICHO}

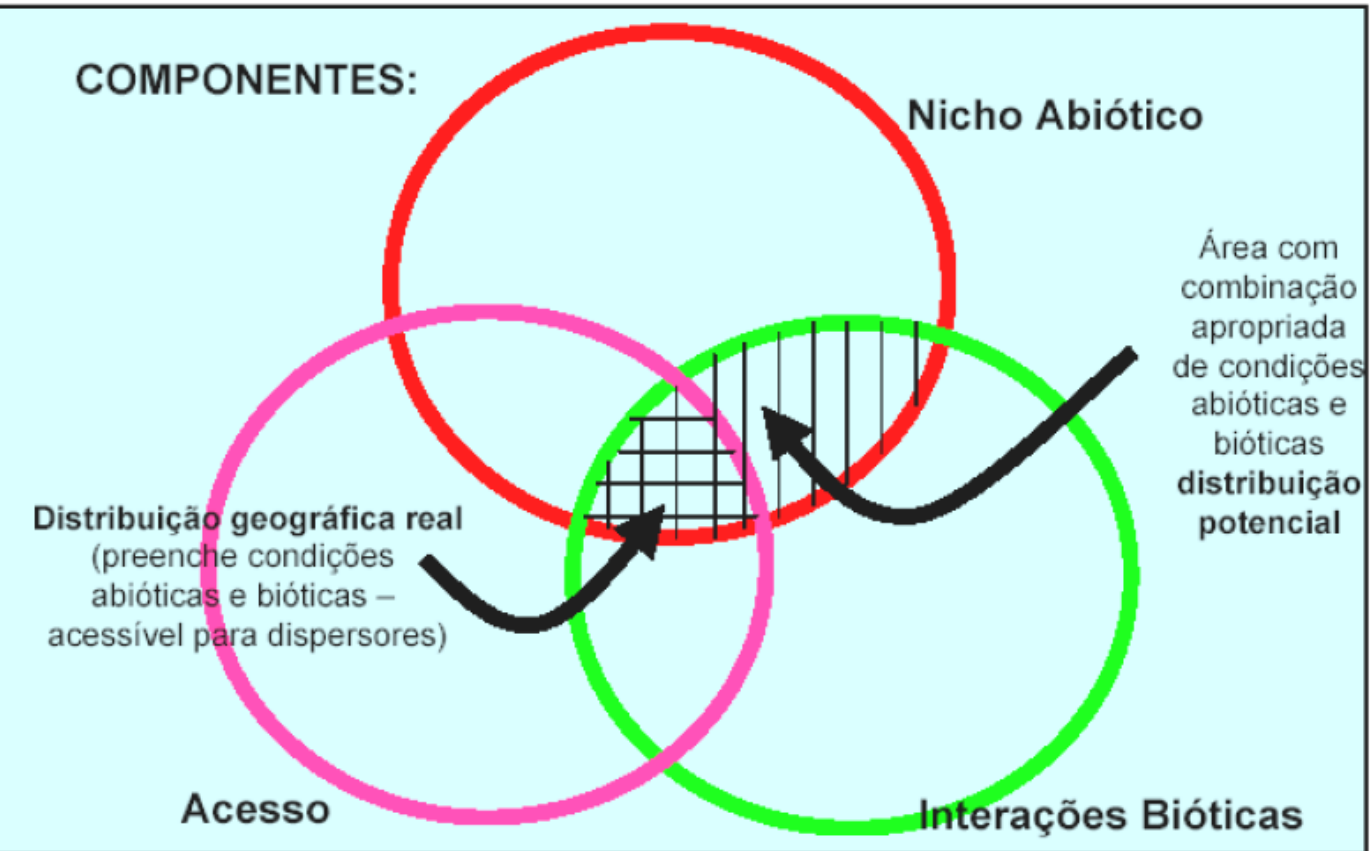

Figura 1 - Diagrama BAM (Biótico, Abiótico e Movimento) representando os fatores que afetam a distribuição das espécies. Fonte: Soberón e Peterson (2005)

Conforme o diagrama heurístico apresentado anteriormente, a distribuição potencial de uma determinada espécie se dá em uma área que possui condições abióticas e bióticas adequadas para o desenvolvimento desta. Já a distribuição geográfica real apresenta, além das condições bióticas e abióticas ideais, as regiões geográficas que foram acessíveis para as espécies dentro de um determinado intervalo de tempo. As intersecções entre tais variáveis apresentam diferenças importantes para a interpretação dos modelos espaciais de nicho.

Contudo, a aplicação da MNE para uma determinada espécie requer conhecimentos da ecofisiologia desta espécie, a fim de realizar uma distribuição mais próxima do nicho da espécie estudada. Neste sentido, Donalísio e Peterson (2011) enfatizam que a distribuição dos 
hantavírus está relacionada diretamente com a distribuição geográfica de seus hospedeiros reservatórios; contudo, pode ser limitada pelas alterações climáticas e pelo uso da terra. Assim, os fatores ambientais e antropogênicos podem ser utilizados para desenvolver uma compreensão do potencial preditivo das espécies. Tal afirmativa expõe a necessidade da compreensão das características ecofisiológicas do Necromis lasiurus no sentido de oferecer subsídios necessários para a realização de MNEs com mais exatidão.

Mills et al. (2010) justificam a importância do uso de modelos preditivos para a Hantavirose em razão dos fatores intrínsecos e extrínsecos que afetam a dinâmica da população de roedores, reforçando o fato de que a questão do estudo sobre as causas da dispersão de animais que são vetores e reservatórios de patógenos exige um domínio multidisciplinar em assuntos ligados à Ecologia, Geoestatística, Epidemiologia e outras áreas específicas, pois cada variável tem que ser analisada sistematicamente e não separada em razão da complexidade que envolve a dispersão do roedor e do hantavírus.

A mesma opinião é compartilhada por Susuki et al. (2004) ao relatarem que os habitats e o comportamento dos roedores representam um aspecto importante na compreensão da Epidemiologia da Hantavirose. Além disso, detalham que até o presente momento, o hantavírus identificado no Necromys lasiurus é o Araraquara (ARAV).

É conveniente informar que o bioma Cerrado apresenta um ótimo suporte para a fauna de pequenos mamíferos (MARES; ERNEST; GETTINGER, 1986) e, de acordo com Alho (1982) e Rocha et al. (2011), aquele bioma e, em especial, suas áreas de campo oferecem refúgio e alimentação a esses roedores. Isto porque a densidade do capim permite que o Necromys lasiurus faça túneis que são utilizados como abrigos.

O Necromys lasiurus apresenta uma dieta onívora. Segundo Talomini et al. (2008), aquele roedor, na época da estação chuvosa, alimenta-se de insetos, e na estação da seca, de sementes, raízes e folhas, ou seja, mostra-se, assim, como uma espécie generalista. Já Alho (2005) e Santos (2011), ao analisarem os casos de hantavirose em São Sebastião, Distrito Federal, constataram que a combinação que algumas atividades agrícolas como as culturas de milho e da cana-de-açúcar; o plantio de soja, do arroz e para reflorestamento; e os capins braquiária e colonião atraem os roedores.

Além dos fatores ambientais - como, por exemplo, a topografia, as variáveis climáticas e a vegetação, que são utilizados para desenvolver modelos preditivos com a finalidade de compreender a distribuição potencial do Necromys lasiurus -, os fatores antropogênicos (o 
uso da terra, por exemplo) merecem uma atenção especial na MNE em razão do distúrbio que gera no ambiente. Neste sentido, Peterson et al. (2011) afirmam que algumas variáveis ambientais são mais estáticas do que outras, no sentido de que estas podem se modificar lentamente (como, por exemplo, a topografia e o clima), enquanto outras são mais dinâmicas (como, por exemplo, a cobertura do solo) devido à ampla influência dos seres humanos sobre o meio ambiente.

Colacicco-Mayhugh, Masuoka e Grieco (2010) detalham em seu artigo a importância da inclusão da variável 'uso da terra' na modelagem. Na modelagem elaborada para avaliar a distribuição dos Phlebotomus alexandri e Phlebotomus papatasi - duas espécies de mosquitos transmissores da leishmaniose cutânea na região do Oriente Médio - notou-se que a camada uso e cobertura da terra apresentaram uma maior porcentagem de contribuição na modelagem. E ainda, aqueles autores concluíram que tal variável possuía informações importantes que indicavam uma forte influência sobre a distribuição das espécies de flebótomos.

De fato, a MNE busca estimar a ocorrência de uma espécie, como é o caso do Necromys lasiurus, através de dados ambientais, bem como fazendo uso de dados de origem antropogênica. É a distribuição das condições ambientais referente aos pontos de ocorrência da espécie, com base nos dados ambientais utilizados. Contudo, é importante perceber que os fatores bióticos, como, por exemplo, a interação entre espécies e as barreiras geográficas, não são consideradas no processo da modelagem, acarretando na existência de uma preocupação maior com os processos de validação.

Enfim, o propósito das linhas que se seguem é de realizar a MNE visando predizer a ocorrência do Necromys lasiurus, bem como realizar análises comparativas entre a modelagem com a inclusão/exclusão da variável preditora do uso terra.

\subsection{MATERIAIS E MÉTODOS}

A MNE, para sua execução, requer basicamente 03 (três) elementos, quais sejam: (1) pontos de presença e ausência (quando disponíveis) da espécie em estudo; (2) camadas ambientais e antrópicas no formato raster, que sintetizam as características bióticas e abióticas do ambiente; e, (3) algoritmo para modelar a distribuição da espécie (WALTARI; PERKINS, 2010, p. 146). A partir da aglutinação das referidas informações (da ocorrência da espécie e das camadas ambientais/antrópicas) e da escolha do algoritmo (MAXENT Maximum Entropy),) foi possível a realização da modelagem seguindo os passos apresentados no fluxograma esquemático da Figura 2, a seguir. 


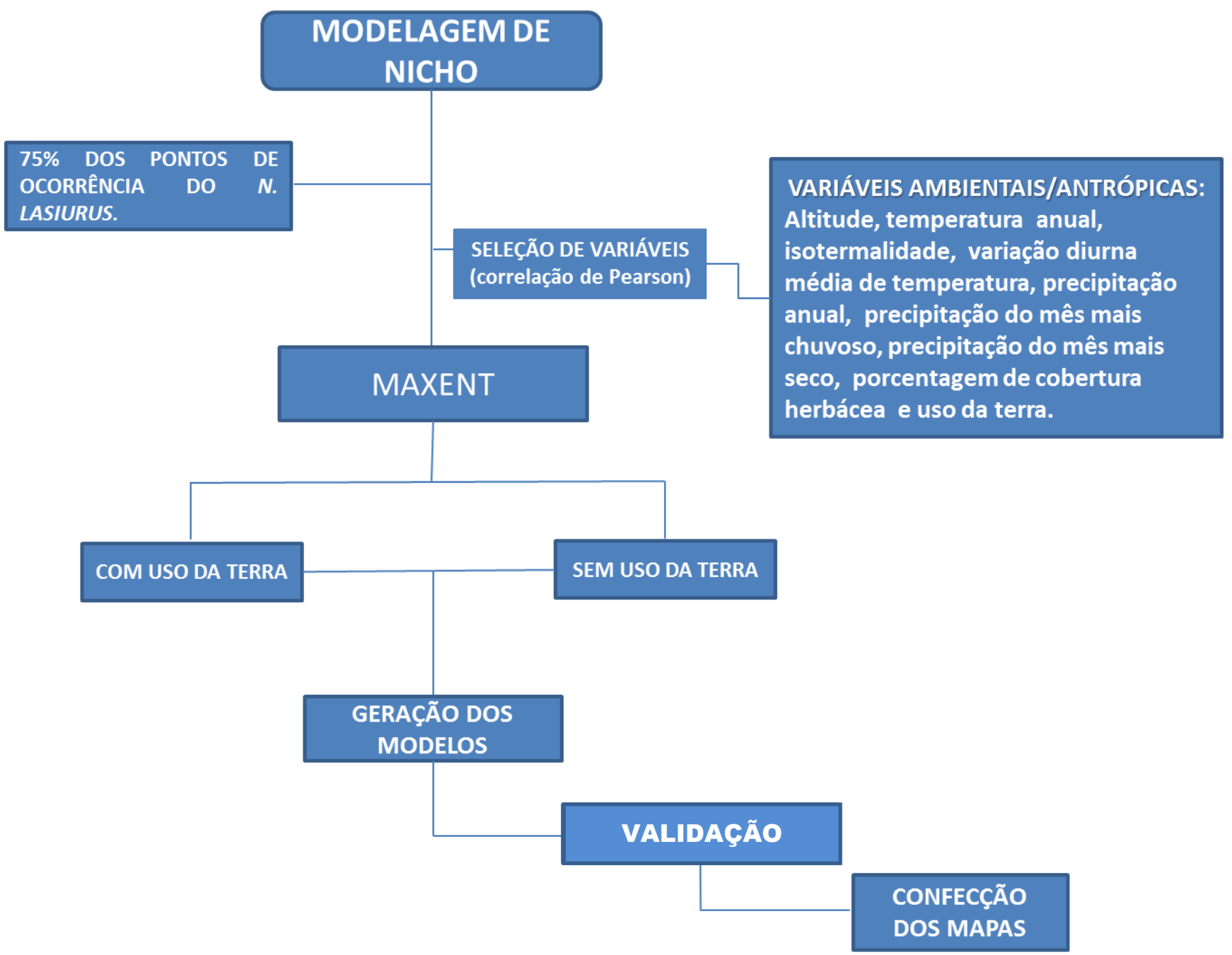

Figura 2 - Diagrama dos procedimentos metodológicos.

Elaboração: Janduhy Santos

\subsubsection{Dados de ocorrência do Necromys lasiurus}

Os pontos de presença da espécie aqui analisada foram compilados a partir dos dados sobre a ocorrência do N. lasiurus, obtidos a partir do sistema SpeciesLink, que integra as informações de coleções biológicas provenientes dos seguintes museus e centros de pesquisas: Coleção de Mamíferos da Universidade do Estado de Mato Grosso (UNEMAT) - Campus Nova Xavantina (CM), Coleção de Mamíferos da Universidade Federal de Mato Grosso (CMUFMT), Coleção Mastozoológica DZUP (DZUP-Mammalia), Coleção Zoológica de Referência da Seção de Vírus Transmitidos por Artrópodos (IAL-Roedores), Banco de Dados 
de Mamíferos do Espírito Santo (Mamiferos-ES), Coleção de Mamíferos do Museu de História Natural Capão da Imbuia (MHNCI) (MHNCI-Mamiferos), Coleção de Mamíferos do Museu de Zoologia (MZUEL-Mamiferos), Sistema de Informação do Programa Biota/Fundação de Amparo à Pesquisa do Estado de São Paulo (FAPESP) (SinBiota) e Coleção de Mamíferos do Museu de Zoologia da Universidade Estadual de Campinas (UNICAMP) (ZUEC-MAM). Estas bases de dados agregam informações biológicas de coleções científicas de acesso gratuito.

E ainda, fez-se uma busca na literatura acadêmica especializada no estudo do Necromys lasiurus (QUADROS, J, MONTEIRO-FILHO, E. L. A., 2006; LUSTOSA et al., 2007; OLIVEIRA, J. A., 2010; CARMIGNOTTO, A. P.; AIRES, C. C., 2011).

Os dados de ocorrência foram coletados e disponibilizados em coordenadas geográficas (latitude/longitude) no formato em graus decimais (DD) com o Datum WGS-84. Foram obtidos 64 pontos de ocorrência, onde, de acordo com Giannini et al. (2012), os modelos que apresentam uma maior acurácia são aqueles que possuem pelo menos 30 pontos de ocorrência. Os pontos de ocorrência de Necromys lasiurus foram separados em 02 (dois) conjuntos, a saber: 1) treino ( $75 \%$ dos pontos para experimentar o modelo); e, 2) teste (25\% dos pontos para avaliar o modelo).

Waltari e Perkins (2010) advertem que os dados provenientes de bancos de dados online podem conter registros falsos devido a erros de escrita, revisão taxonômica e registro impreciso ou duplicado, o que exige dos pesquisadores maior cuidado na seleção dos dados em questão. E novamente Gianinni et al. (2012) relatam que as coleções biológicas e museus podem apresentar limitações devido à imprecisão da informação ou viés na escolha de áreas de coletas que privilegia locais onde o acesso é mais fácil e menos custoso.

No entanto, para Gianinni et al. (2012), o uso das informações é frequentemente justificado em razão da falta de levantamentos sistemáticos, bem como da demanda crescente por mapas de distribuição de espécies e estimativas sobre mudanças potenciais nesta distribuição devido às alterações ambientais.

Os dados foram agrupados, sendo removidos os registros duplicados ou duvidosos, considerando-se as informações que continham as coordenadas geográficas do ponto de coleta do respectivo espécime. 


\subsubsection{Dados ambientais e antropogênicos}

As múltiplas variáveis ambientais têm sido empregadas na modelagem da distribuição das espécies. As mais comuns são as variáveis relacionadas ao clima (temperatura e precipitação), à topografia (elevação e aspecto), à vegetação (cobertura herbácea) e ao uso da terra. Estas tendem a descrever principalmente o ambiente abiótico, embora exista potencial para interações que incluam os fatores bióticos e antropogênicos (o uso da terra, por exemplo) dentro da modelagem.

Peterson et al. (2011) explicam que as questões que envolvem a dimensionalidade e a transformação de dados na modelagem e que podem afetar a qualidade dos resultados do modelo de nicho são pouco explorados. Assim, faz-se importante a realização de outras pesquisas a fim de melhorar as práticas atuais nesta área, em especial, no que diz respeito à incorporação de conhecimento prévio sobre os organismos, sua história natural e sua fisiologia. Como consequência, com o intuito de evitar estes problemas, vários esquemas têm sido propostos para explorar as inter-relações variáveis e reduzir a dimensionalidade para o modelo de desenvolvimento. Todas as informações ambientais se dão em forma de grades, no formato ASCII-raster, projetadas no sistema de coordenadas geodésicas de projeção "LatLong", Datum WGS-84, com resolução espacial de 30 arc-segundos, ou aproximadamente $1 \mathrm{~km}$.

Alguns pesquisadores têm utilizado a análise de correlação para identificar conjuntos de menor variável correlacionada, e outros têm gerado variáveis originais para produzir um novo eixo, não correlacionadas através da análise de componentes principais ou através da correlação de Pearson como entrada para a modelagem (GUISAN; THUILLER, 2005).

Buscando observar as referidas recomendações foram selecionadas as camadas de acordo com a análise de correlação de Pearson, conforme exposto na Tabela 1, a seguir, que contém os dados utilizados na modelagem potencial do Necromys lasiurus, obtidos junto à Food and Agriculture Organization of the United Nations (2010), ao Oak Ridge National Laboratory (ORNL) (2012) e ao Instituto de Nacional de Pesquisas Espaciais (INPE) (2013). 
Tabela 1 Dados utilizados na modelagem de distribuição potencial do Necromys lasiurus.

\begin{tabular}{|c|c|c|c|c|}
\hline Dados & Tipo & Resolução Espacial & Resolução Temporal & Fonte \\
\hline Topografia & Elevação & $90 \mathrm{~m}$ & 2000 & *INPE \\
\hline Bio 1 & Temperatura média anual & $1 \mathrm{~km}$ & $1950-2000$ & INPE \\
\hline Bio 2 & Variação diurna média de temperatura & $1 \mathrm{~km}$ & $1950-2000$ & INPE \\
\hline Bio 3 & Isotermalidade & $1 \mathrm{~km}$ & $1950-2000$ & INPE \\
\hline Bio 12 & Precipitação anual & $1 \mathrm{~km}$ & $1950-2000$ & INPE \\
\hline Bio 14 & Precipitação do mês mais seco & $1 \mathrm{~km}$ & $1950-2000$ & INPE \\
\hline Porcentagem de cobertura herbácea & Vegetação & $500 \mathrm{~m}$ & 2001 & $* * \mathrm{ORNL}$ \\
\hline Uso da terra & Uso e cobertura da terra. & 1: 5.000 .000 & 2008 & $* * * \mathrm{FAO}$ \\
\hline
\end{tabular}


As variáveis bioclimáticas selecionadas na Tabela 1 (BIO 1, BIO 2, BIO 3, BIO 12 e BIO 14) apresentada anteriormente são parâmetros que correspondem à dados de observação, representativos de 1950 a 2000 e que foram interpolados para a resolução de 30 arc-segundos $(1 \mathrm{~km})$. Os valores de temperatura são fornecidos em ${ }^{\circ} \mathrm{C}$ (graus celsius) e os valores de precipitação em mm (milímetros). A informação referente à topografia (elevação) provém dos dados do Shuttle Radar Topographic Mission (SRTM), de resolução horizontal (resolução espacial) de $1 \mathrm{~km}$, e resolução vertical (altura) de $1 \mathrm{~m}$. A camada referente à porcentagem de cobertura herbácea é proveniente do sensor MODIS, que contém a estimativa de cobertura de vegetação herbácea. O raster possui resolução espacial de 500 metros com resolução temporal de 2000 a 2010, e o raster do uso e cobertura da terra foi elaborado em 2010 com escala de 1: 5.000.000 com Datum WGS-84. Os dados foram 'reamostrados' (vizinho mais próximo) para permitir a compatibilização da base para os recortes apresentados e, assim, permitir sua utilização do algoritmo MAXENT.

\subsubsection{Algoritmo MAXENT}

O algoritmo utilizado na Modelagem de Nicho Ecológico é o MAXENT (Máxima Entropia), que tem como objetivo modelar a distribuição geográfica potencial de espécies. Para que o modelo possa desenvolver os algoritmos e encontrar as relações não aleatórias é necessário inserir os dados de ocorrência do Necromys lasiurus e os dados ambientais e antrópicos mencionados anteriormente.

Com base em Kamino (2009), o MAXENT foi considerado o algoritmo mais apropriado, tendo em vista o objetivo da pesquisa e o conjunto de dados a ser utilizado, que é composto apenas por dados de presença. Aquele autor também afirma que o referido algoritmo, implantado no software de mesmo nome, tem por base o princípio da máxima entropia, que significa a melhor aproximação para uma distribuição de probabilidades desconhecidas, satisfazendo qualquer restrição à distribuição.

Júnior e Siqueira (2009) também destacam a vantagem do MAXENT em trabalhar somente com os pontos de presença, bem como o fato da variável gerada no modelo ser algo contínuo dentro do intervalo 0 a 100, indicando adequabilidade relativa. Além da técnica do Maxent apresentar uma definição matemática concisa, esta última é facilmente interpretável dentro dos conceitos clássicos de análise de probabilidades. 
De acordo com Phillips et al. (2006), a ideia da aplicação do MAXENT para modelos de distribuição de espécies é estimar a probabilidade de ocorrência da espécie encontrando a distribuição de probabilidade da máxima entropia, sujeita a um conjunto de restrições que representam a informação incompleta sobre a distribuição do alvo - fato conhecido por princípio da máxima entropia.

O princípio da entropia é expresso sobre um conjunto finito $X$ (que mais tarde interpretará o conjunto de pixels na área de estudo). Neste sentido, refiro-me aos elementos individuais do $X$ como pontos. A distribuição $\pi$ atribui uma probabilidade não negativa de $\pi(x)$ para cada ponto $x$, sendo que tais probabilidades somam 1. Aproximação de $\pi$ é também uma distribuição de probabilidade, sendo possível denotar que é $\pi$. Assim, a entropia de $\pi$ é definida como:

$$
H(\hat{\pi})=\underset{\mathrm{x} \in \hat{X}}{-\sum \hat{\pi}(x)} \ln \hat{\pi}(x)
$$

Onde: ln é o logaritmo natural.

O algoritmo MAXENT computa, então, a distribuição probabilística sobre as variáveis ambientais da área de estudo (background). Para cada pixel, o algoritmo indica um valor numérico que varia de 0-1, melhor definido como adequabilidade ambiental e não como probabilidade de ocorrência (PEARSON et al., 2007).

Neste sentido, é preciso salientar que o presente estudo fez uso da versão 3.3.3 do software Maxent, mantendo os valores padrões do programa.

\subsubsection{Avaliação dos modelos gerados}

A avaliação da qualidade dos modelos gerados é uma das etapas mais importantes do processo de modelagem. A ausência deste tipo de avaliação faz com que a interpretação de um modelo perca o seu sentido, tendo em vista que tudo o que está representado pode estar incorreto ou com graus inaceitáveis de imprecisão (GIANINNI et al., 2012). 
Para Phillips (2006), não existe nenhum método de avaliação de desempenho de modelos que seja único. Assim, a escolha de uma estratégia de validação será influenciada pelo objetivo da modelagem, os tipos de dados disponíveis e o tipo de algoritmo a ser utilizado.

Na geração dos modelos aqui apresentados foram utilizados somente dados da presença do Necromys lasiurus, pois não se tem qualquer tipo de literatura científica ou bancos de dados de coleções biológicas sobre as áreas com ausência do referido roedor no Brasil. Contudo, Pearce e Boyce (2006) detalham o crescente interesse em MNE no uso de (somente) dados de presença, isto é, na observação ou na coleta da espécie, mas sem dados confiáveis sobre a área em que a espécie não foi encontrada.

A utilização de métodos estatísticos, como, por exemplo, as curvas características de operação (ROC) para a avaliação de modelos de distribuição de espécies, têm sido constantemente acionadas, conforme relato de Phillips et al. (2006), uma vez que o cálculo da área sob a curva (AUC) oferta uma medida única do desempenho do modelo, independente da escolha prévia de um limite de corte específico, pois a curva é construída a partir de vários limiares (cada limite de corte é responsável por um ponto da curva) e o cálculo da área sob a curva elimina, então, a escolha de um limite específico.

Uma área igual a 1 representaria o "modelo perfeito"; uma área de 0,5 indica que o modelo seleciona ao acaso. De modo prático, um teste de validação pode adotar os valores de AUC, a seguir, como indicadores da qualidade do modelo (METZ, 1986): excelente (0,90 $1,0)$; bom $(0,80$ - 0,90); médio $(0,70-0,80)$; ruim $(0,60-0,70)$; muito ruim $(0,50-0,60)$.

Para identificação das variáveis que mais influenciaram a distribuição das espécies de roedores fez-se uso do teste Jackknife, implementado no software Maxent (PHILLIPS et al., 2006), que mede os efeitos preditivos de cada variável no modelo, ao verificar a qualidade dos modelos produzidos somente com a variável em teste e de modelos com a variável em teste omitida. 


\subsection{RESULTADOS}

Conforme Reis et al. (2006), a área delimitada em que o roedor Necromys lasiurus pode ser encontrado (Figura 3), compreende as formações abertas e florestais do bioma Cerrado e ao longo do ecótono Mata Atlântica-Cerrado, além de áreas de vegetação aberta no Estado do Pará .

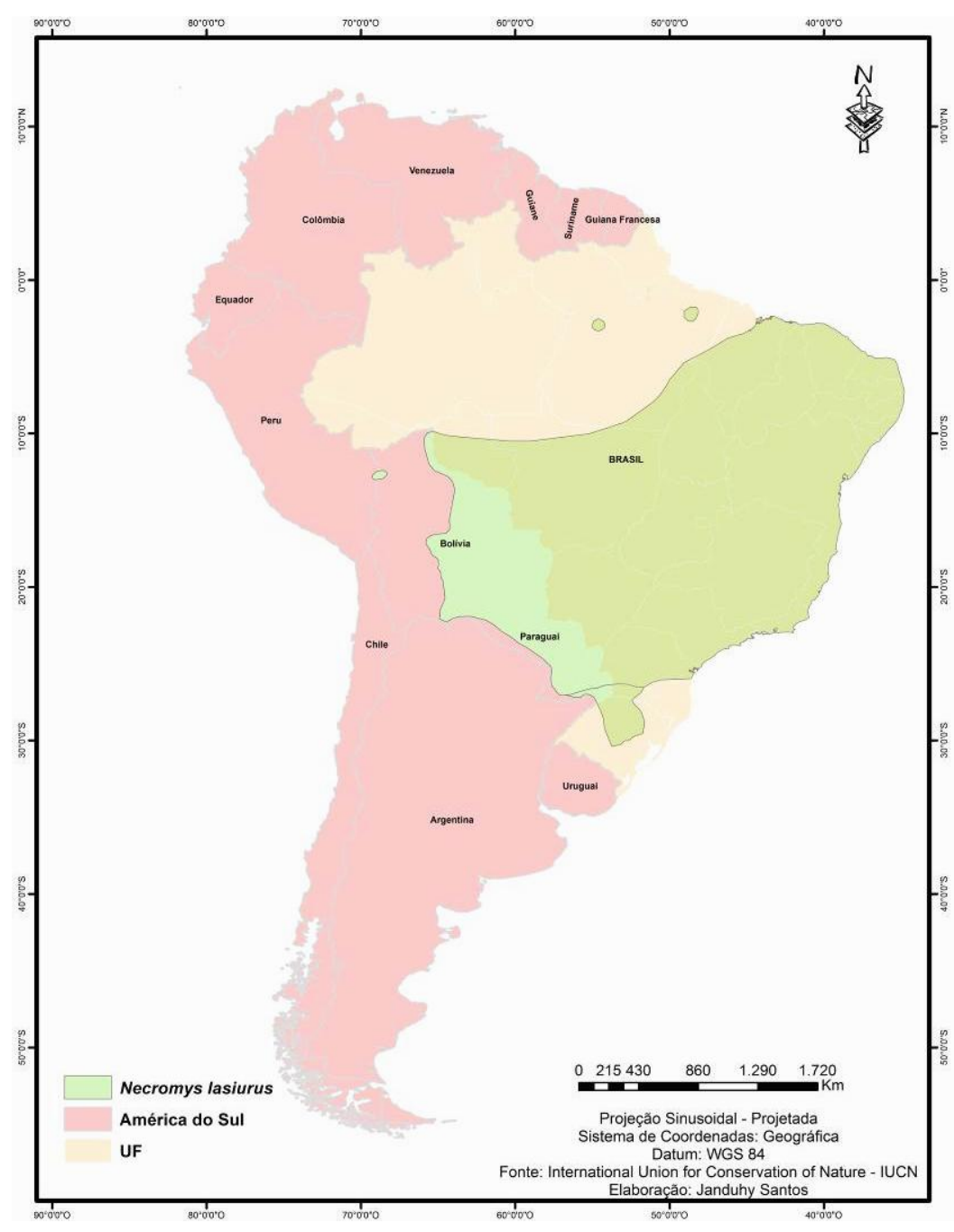

Figura 3 - Distribuição geográfica do Necromys lasiurus. Elaboração: Janduhy Santos

Com a exclusão de ocorrências duvidosas, duplicidades e de pontos em áreas superamostradas foram considerados 64 registros espacialmente únicos, utilizados na modelagem do $N$. lasiurus. 
A partir daí, os resultados obtidos pelo algoritmo MAXENT apontaram as áreas que possuem adequabilidade ambiental (condições ambientais que favorecem a sobrevivência da espécie) para o $N$. lasiurus, com a inclusão e exclusão da variável 'uso da terra' (Figuras 4 e 5). Neste sentido, na Figura 4 é possível observar se a modelagem para o N. lasiurus, com a inserção da variável uso da terra e os resultados obtidos, demonstram uma distribuição potencial em áreas que, de acordo com Ab’Saber (2003) e Ross (2006), pertencem ao domínio da floresta de encosta e semi-decidual do planalto atlântico e também ao domínio da transição Mata Atlântica-Caatinga-Cerrado, e ainda, de algumas áreas da Amazônia, reforçando, assim, o cartograma da Figura 3, apresentada anteriormente.

Na Figura 4 observam-se também as áreas com forte adequabilidade no sentido nortesul - seu início se dá no nordeste de Roraima (que possui vegetação tipo savânica - cerrado); o mapa ainda apresenta uma adequabilidade na região de Novo Airão, Amazonas, e na foz do rio Tapajós nas proximidades de Santarém, Pará, e na região norte do município de Óbidos, Pará, que apresenta feições fitogeográficas do cerrado (o cerradão e o campo sujo). Também é possível observar um forte potencial de presença do roedor no sudoeste do Estado de Rondônia e na região central do Estado do Mato Grosso, especificamente no Planalto dos Parecis e nos arredores da capital desta Unidade da Federação (UF).

Na região Nordeste verifica-se um forte potencial em áreas mais elevadas, como, por exemplo, as serras da Ibiapaba e Baturité e na chapada do Cariri - divisa entre os Estados do Ceará, Pernambuco e Paraíba. E ainda, em algumas áreas do Rio Grande do Norte, em especial, nas regiões do Seridó e do Borborema. Além disso, também nas áreas próximas ao rio São Francisco e nas regiões de planaltos cobertos por cerrados nos Estados de Goiás, Minas Gerais e São Paulo.

Infere-se também uma forte representatividade nas regiões das serras da Mantiqueira e do Mar nas regiões Sudeste e Sul do Brasil, e em áreas ocupadas originalmente pela Mata Atlântica nos litorais dos Estados do Paraná, Santa Catarina e do Rio Grande do Sul. 


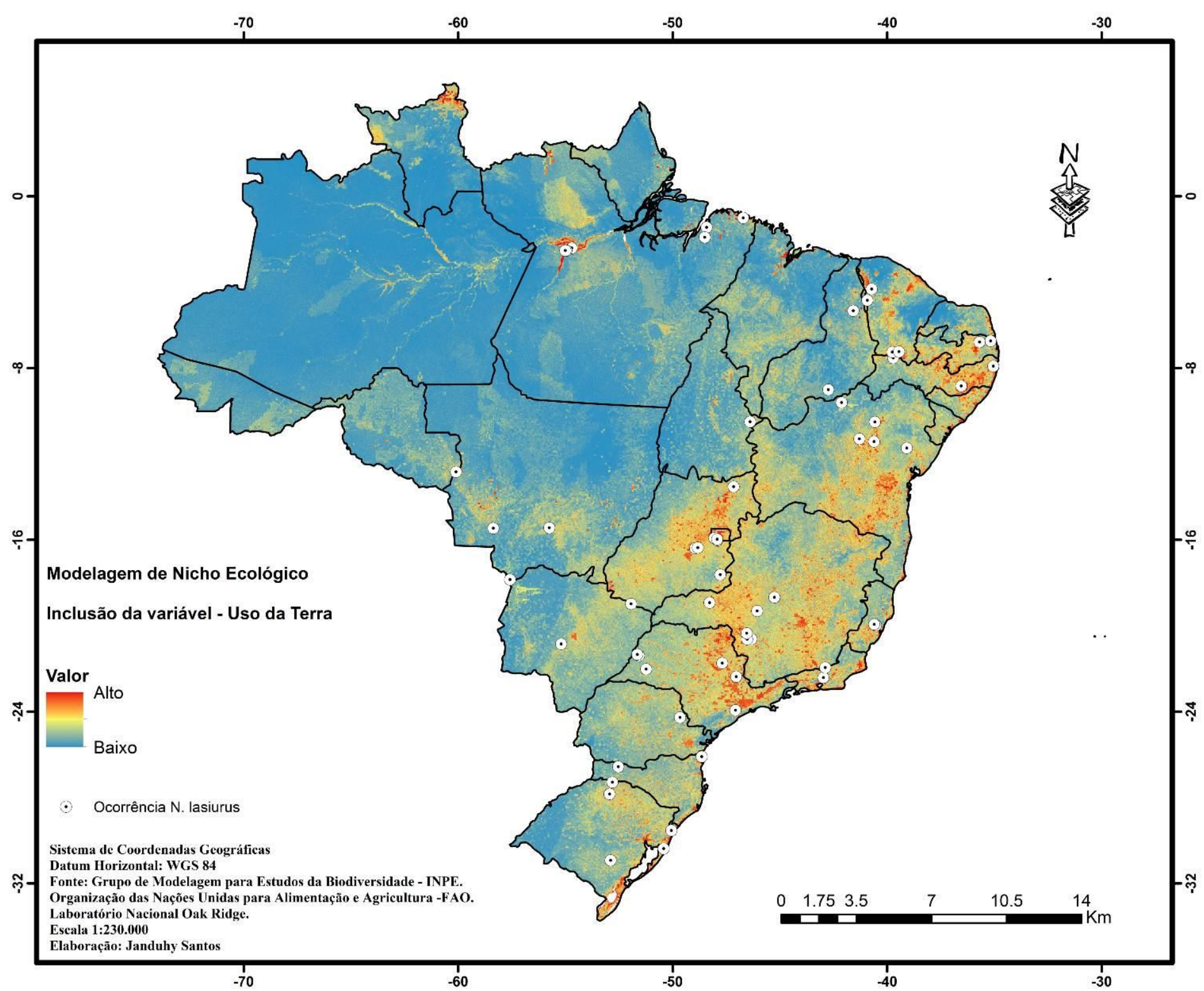

Figura 4 - Mapa de adequabilidade ambiental do Necromys lasiurus com a influência do uso da terra. 
Em uma visão geral, o cartograma da Figura 5 (a seguir) apresenta a modelagem sem a inserção da camada de uso e cobertura da terra no MAXENT. Ali se destacam as áreas com forte adequabilidade ambiental no Baixo Amazonas, nas proximidades do Município de Santarém, Pará. Na região Nordeste têm-se as áreas localizadas nas serras da Ibiapaba, Baturité e Araripe, no Estado do Ceará, na região do cariri paraibano, no agreste pernambucano, no litoral sergipano e também na região centro-norte do Estado da Bahia. No centro-sul do Brasil são observadas áreas com boa adequabilidade para o Necromys lasiurus na região do Entorno do Distrito Federal e da capital do Estado de Goiás, além do Triângulo Mineiro e no Alto do Paranaíba, e ainda, na Serra do Espinhaço até o vale médio do rio São Francisco no Estado de Minas Gerais, e nas áreas de Mata Atlântica dos litorais dos Estados do Espírito Santo e Rio de Janeiro, e nas serras do Mar e da Mantiqueira. É possível notar também um expressivo potencial no noroeste de São Paulo, onde se tem a presença do bioma Cerrado com forte antropismo por ocasião das lavouras canavieiras, e nos litorais dos Estados do Espírito Santo, Rio de Janeiro, Santa Catarina e Rio Grande do Sul, com complexo vegetacional bastante diversificado com áreas florestais (Mata Atlântica), manguezais e vegetação de restinga.

Outra área evidenciada e que apresentou uma predição considerável por meio da MNE para o Necromys lasiurus, conforme as Figuras 4 e 5 apresentadas anteriormente, foi a região noroeste do Estado de Roraima, mais conhecida por "Lavrado" ou também de Campos Gerais do Rio Branco, caracterizada por áreas muito arenosas da chamada Formação Boa Vista (AB'SABER, 2010), com colinas recobertas por gramíneas extensivas e recortadas por estreitas florestas-galeria, e vegetação rupestre composta por cactáceas. Portanto, têm-se aí características biológicas (florísticos) e ecossistêmicas únicos (edáficos e pedológicos), com maior similaridade com as savanas do bioma Cerrado e que, segundo Bonvicino et al. (2008), é o habitat do roedor da família Cricetidae - o Necromys urichi.

Além de Roraima, o Necromys urichi pode ser encontrado nas terras altas do norte e do sul da Venezuela, além de Colômbia e Trinidad e Tobago e, até o momento, não apresenta evidências como reservatório de qualquer tipo de hantavírus. 


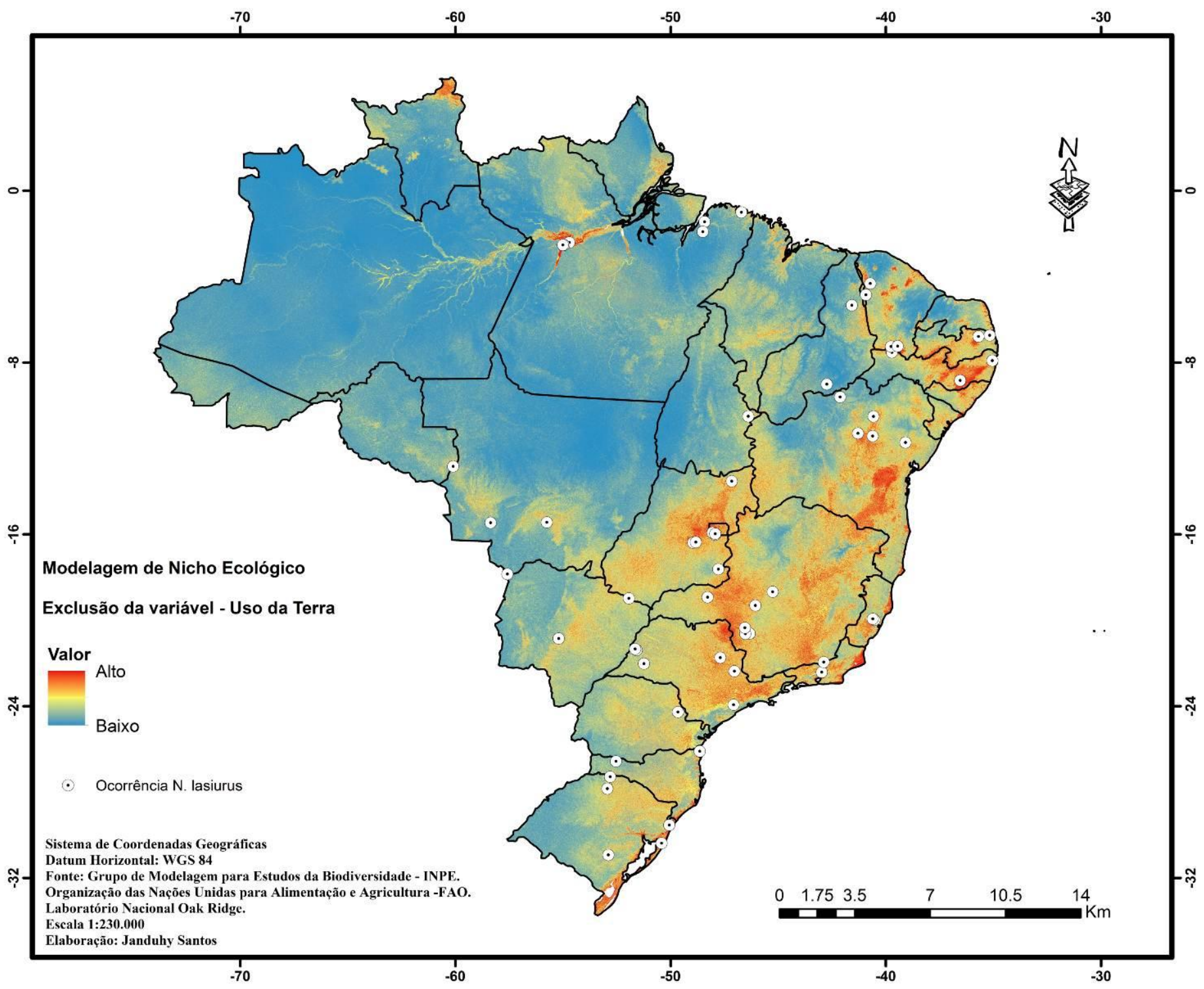

Figura 5 - Mapa de adequabilidade ambiental do Necromys lasiurus sem a influência do uso da terra. 
A Tabela 2, a seguir, apresenta os resultados estatísticos do algoritmo MAXENT, que demonstram os valores de corte (threshold) do Minimum Presence Training (MPT) que é o limite de corte escolhido para analisar as áreas com boa adequabilidade ambiental para o roedor com a inclusão/exclusão da variável uso da terra na modelagem do Necromys lasiurus.

Tabela 2 Desempenho dos modelos de distribuição potencial do Necromys lasiurus.

\begin{tabular}{lcccc}
\hline $\begin{array}{c}\text { Variável } \\
\text { (Uso da terra) }\end{array}$ & $\begin{array}{c}\text { Valor do } \\
\text { limite de corte }\end{array}$ & $\begin{array}{c}\text { Area fracional } \\
\text { predita }\end{array}$ & $\begin{array}{c}\text { Taxa de } \\
\text { omissão }\end{array}$ & AUC \\
\hline Presença & 0.075 & 0.504 & 0.100 & 0.93 \\
Ausência & 0.049 & 0.678 & 0.033 & 0.92 \\
\hline
\end{tabular}

Elaboração: Janduhy Santos

Os resultados apontados na tabela apresentada anteriormente demonstram que todos os modelos associados aos valores de limite de corte estabelecidos apresentaram bom desempenho, altamente significativos e melhores do que o acaso $(P<0,001)$. A área fracional predita, que é a proporção de área prevista para sobrevivência de uma espécie, mostrou que quando se tem a exclusão da camada do uso da terra, registra-se o aumento do valor do limite de corte em relação ao valor da área predita com a inserção da camada do uso da terra. A taxa de omissão apresentada, que é proporção das ocorrências da espécie que estejam fora da previsão, mostrou também que a modelagem, com ausência da camada do uso da terra, foi muito melhor do que com a dada variável.

$\mathrm{Na}$ avaliação de desempenho, fazendo uso da área sob a curva (AUC) para os pontos de ocorrência utilizados para o treino, os dados expostos na tabela apresentada anteriormente denotam que os valores derivados das curvas Receiver Operating Characteristic (ROC) indicam que as modelagens com e sem a variável 'uso da terra' tiveram um bom desempenho, não apresentando grandes diferenças em seus valores.

A Tabela 3 apresenta as estimativas das contribuições das variáveis utilizadas em cada modelo. Estas são calculadas por meio do jackknife sobre os pontos utilizados no treino para a análise preditiva do Necromys lasiurus. 
Tabela 3 Contribuição (\%) das variáveis ecogeográficas com e sem a camada de uso da terra.

Contribuição da

Variável modelagem com Uso da

Terra $(\%)$
Contribuição da modelagem sem Uso da Terra (\%)
Elevação

Isotermalidade

Porcentagem de Cobertura Herbácea

Precipitação Anual

Precipitação do mês mais seco

Temperatura média anual

Uso da terra.

Variação diurna média de temperatura
8.9

0.3

40.5

05

2.2

38.6

4
15.4

1.3

63.6

6.8

10.9

3.8

* Variável foi excluída do modelo final.

Elaboração: Janduhy Santos

Para o modelo com o uso da terra, o teste de jackknife indicou na tabela 3 apresentada anteriormente que a variável 'Porcentagem de Cobertura Herbácea' respondeu por $40 \%$ da modelagem, e a camada do uso da terra respondeu por 39\%; ou seja, nos referidos aspectos, têm-se o mesmo peso na modelagem com a inclusão da camada do uso da terra. Em relação à modelagem sem o uso da terra, também a camada 'Porcentagem de Cobertura Herbácea' apresentou ganho de mais de $60 \%$ no teste jackknife. E ainda, de acordo com o teste realizado, quando a variável 'Porcentagem de Cobertura Herbácea' é omitida, tem-se uma perda de ganho nas duas modelagens. 


\subsection{DISCUSSÃO}

De acordo com as informações descritivas e quantitativas da modelagem preditiva para o Necromys lasiurus, é possível observar que a camada do uso da terra inserida na modelagem tem ali um papel significativo. Apesar da camada de Porcentagem de Cobertura Herbácea apresentar uma maior contribuição para os modelos, conforme o método estatístico jackknife, a camada antrópica (o uso da terra) exerce influência na predição da espécie, apresentando diferenças visuais bastante significativas (conforme exposto anteriormente nas Figuras 4 e 5) quando da inclusão e exclusão desta camada.

Na inclusão da variável 'uso da terra' observa-se uma diminuição dos pixels preditivos, diferentemente quando da ocorrência da exclusão desta camada, em que se pode observar um aumento dos pixels preditivos. Infere-se que a modelagem preditiva apresentada com a inclusão da camada de uso da terra demonstra uma diminuição do habitat do roedor e, por sua vez, uma fraca representação no cartograma (conforme exposto anteriormente na Figura 4).

Os resultados apresentados são próximos às análises realizadas por Yan et al. (2007), Fang et al. (2009) e Wei et al. (2011), na China, indicando que a variável antrópica (uso da terra) é significativa na distribuição das espécies, uma vez que as mudanças ambientais de origem antrópica como o uso da terra acarretam na diminuição da biodiversidade. E ainda, vale destacar que o roedor aqui analisado é uma espécie generalista quanto ao uso do habitat, mas parece preferir áreas abertas, estando ausente ou pouco frequente em ambientes florestais úmidos, o que sugere que as áreas desmatadas nos últimos anos poderiam explicar uma maior ocorrência da espécie no bioma Mata Atlântica, reforçando a importância da análise dos espaços antropizados para o roedor.

Observando a distribuição do Necromys lasiurus no território nacional para ambos os modelos, os resultados apresentados mostraram a compatibilidade com os modelos descritos por Oliveira et al. (2014), que, além de apresentar um potencial de distribuição no centro-sul do país também demonstrou que as áreas mais ao norte e nordeste do Brasil também são favoráveis para os roedores Necromys lasiurus e Oligoryzomys nigripes, o que sugere um potencial para a transmissão de hantavírus em outras áreas do território nacional. 
Lima et al. (2011) também mencionam a presença de anticorpos de hantavírus em indivíduos assintomáticos provenientes do Estado do Ceará - UF que até o momento não apresentou nenhum caso de Hantavirose - e a captura de Necromys lasiurus com os mesmos anticorpos na serra da Ibiapaba - local destacado nos dois cartogramas apresentados anteriormente como área preditiva para o roedor.

Em relação à distribuição potencial do Necromys lasiurus no litoral, a possibilidade de ocorrência do roedor se deve pela presença do capim Brachiaria spp. e de outras gramíneas exóticas cultivadas para a constituição de pastagens ali existentes e, assim, fornecendo abrigo e alimento para os roedores desta espécie.

\subsection{CONSIDERAÇÕES FINAIS}

A variável 'uso da terra' demonstrou que as camadas antrópicas utilizadas na distribuição potencial tem peso significativo nos modelos, e a utilização da variável se faz necessária para o estado atual da espécie, uma vez que as alterações ambientais proporcionadas por modelos de uso da terra vêm ultimamente alterando a biodiversidade de espécies da fauna e da flora. Ao analisar os resultados qualitativos e quantitativos da modelagem realizada com o uso desta variável é possível notar a diminuição da ocorrência do Necromys lasiurus.

No caso de estudos de animais silvestres envolvidos no ciclo de transmissão de doenças infecciosas, que tratam dos efeitos "diluição" e "transbordamento" - que são modelos ecológicos de transmissão de doenças - tem-se aí importantes complementos em estudos que envolvam a distribuição potencial destes animais, uma vez que o cruzamento dos resultados geram informações sobre as "áreas quentes" para o surgimento de epidemias.

É importante relatar o desafio na obtenção de dados ambientais e antrópicos em escalas espaciais adequadas para a realização de estudos preditivos. A obtenção destas informações requer escalas compatíveis com o estudo da distribuição da espécie e, assim, se faz necessário o acompanhamento das curvas ROC a fim de evitar superestimativas da distribuição potencial das espécies, causando uma cascata de incertezas.

Ressalta-se a importância do conhecimento da verdadeira participação destes roedores em ciclos epidemiológicos da doença, tendo em vista que a modelagem realizada apontou forte potencialidade em áreas das regiões Norte e Nordeste do Brasil - áreas silenciosas na transmissão da Hantavirose. Assim, tem-se o aumento da preocupação com as populações destas áreas em razão do conhecimento epidemiológico e o acesso ao diagnóstico do agravo. 
Portanto, um dos objetivos da modelagem espacial de nicho ecológico é justamente traçar rotas de agentes infecciosos e de animais reservatórios destes agentes.

É importante frisar que é necessária cautela em relação à interpretação dos resultados, pois se tem uma exigência dos conhecimentos ecofisiológicos do roedor em estudo para que seja realizada uma compreensão correta das áreas potenciais para o desenvolvimento do roedor. Além disso, é preciso uma análise melhor sobre a movimentação da espécie, ou seja, da capacidade de dispersão que reflete quais os locais são acessíveis para aqueles indivíduos.

Em suma, como foi relatado anteriormente, é necessário o aperfeiçoamento do conhecimento dos ciclos enzoóticos das cepas de hantavírus existentes no território brasileiro, e, para tanto, o emprego de ferramentas de análise ecoepidemiológica e espacial tem sido de grande serventia no entendimento da complexidade da Hantavirose e no desenvolvimento das vigilâncias epidemiológicas no Brasil.

\subsection{REFERÊNCIAS BIBLIOGRÁFICAS}

pp. 225-229. 1924.

Geography and Evolution. Ecological Society of America. Vol. 5, $\mathrm{N}^{\mathrm{o}} 3$,

AB'SABER, A.N. Os Domínios de Natureza no Brasil: Potencialidades Paisagísticas. Ed. Ateliê Editorial. 2003.

AB'SABER, A.N.; JÚNIOR, M. Costa. Contribuição ao estudo do Sudoeste Goiano. In: MODENESI-GAUTTIERI et al. (ORG.). A Obra de Aziz Nacib Ab'Saber. São Paulo: Ed. BECA, 2010.

ALHO, J.R.C, Brazilian rodents: their habitats and habits. Pymatuning Laboratory of Ecology Special Publications. Nº6, 1982.

ALHO, J.R.C, Intergradation of habitats of non-volant small mammals in the patchy cerrado landscape. Arquivos do Museu Nacional, Vol. 63, $\mathrm{n}^{\circ}$ 1. 2005.

BONVICINO C.R; OLIVEIRA J.A; D'ANDREA P.S. Guia dos roedores do Brasil, com chaves para gêneros baseadas em caracteres externos. Organização Pan-Americana da Saúde. Rio de Janeiro, 2008.

BRITO, M.G. O uso da terra e a distribuição espacial de casos humanos da síndrome cardiopulmonar por hantavírus em Minas Gerais, 1996 a 2007. 2012. 81 p., enc. Tese (doutorado) - Universidade Federal de Minas Gerais.

CARMIGNOTTO, A.P; AIRES, C.C. Mamífeors não voadores (Mammalia) da Estação Ecológica Serra Geral do Tocantins. Biota Neotropica., 11(1): 313-328. 2011.

CENTRO DE REFERÊNCIA EM INFORMAÇÃO AMBIENTAL. Rede SpeciesLink. Disponível em: <http://www.cria.org.br>. Acesso em: 26 set. 2013. 
COLACICCO-MAYHUGH, M.G.; MASUOKA, P.M.; GRIECO, J. P. Ecological niche model of Phlebotomus alexandri and P. papatasi (Diptera: Psychodidae) in the Middle East. Int J Health Geogr, v. 9, n. 2, 2010.

CRISTOFELlETI, A. Modelagem de Sistemas Ambientais. Editora Edgard Blücher, São Paulo, 1999.

DONALÍSIO M.R; PETERSON, A.T. Environmental factors affecting transmission risk for hantaviruses in forested portions of southern Brazil. Acta Tropica. Vol. 119. 2011.

ELTON, C. S. The Animal Community. In__Animal ecology. University of Chicago Press, 1927.

FANG, L.Q. et al. Spatiotemporal Dynamics of Hemorragic Fever with Renal Syndrome, Beijing, People's Republic of China. Emerging Infectious Disease. Vol. 15, no 12, 2009.

FOOD AND AGRICULTURAL ORGANIZATION OF THE UNITED NATIONS. Mapping Land Use Systems at global and regional scales for Land Degradation Assessment Analysis. Technical report $\mathrm{n}^{\circ}$ 08, version 1.1. 2010.

GIANNINI, T. C. et al. Desafios atuais da modelagem preditiva de distribuição de espécies. Rodriguésia, Rio de Janeiro, v. 63, n. 3, 2012. Disponível em <http://www.scielo.br/scielo〉. Acesso em: 01 abr. 2014.

GRINNELL, J. The Niche-Relationships of the California Thrasher. American Ornithologists' Union. Vol. 34, No. 4, pp. 427-433. 1917.

GUISAN, A; THUILLER, W. Predicting species distribution: offering more than simple habitat models. Ecology letters, v. 8, n. 9, p. 993-1009, 2005.

HUTCHINSON, G.E. Concluding remarks. Cold Spring Harbor Symposia on Quantitative Biology. 22 (2): 415-427. 1957.

INSTITUTO NACIONAL DE PESQUISAS ESPACIAIS. Variáveis Ambientais para Modelagem de Distribuição de Espécies. Grupo de Modelagem para Estudos da Biodiversidade. 2013.

KAMINO, L.H.Y. Modelos de distribuição geográfica potencial: aplicação com plantas ameaçadas de extinção da Floresta Atlântica. Tese (doutorado) - Universidade Federal de Minas Gerais. 2009. 133f.

LIMA, D. M. et al . Hantavirus infection in suspected dengue cases from State of Ceará, Brazil. Rev. Soc. Bras. Med. Trop., Uberaba, v. 44, n. 6, 2011. Disponível em <http://www.scielo.br >. Acesso em: 26 set. 2014.

LUSTOSA,G.S LEITE, F.H.R, MARQUES-OLIVEIRA, F.N. SANTOS, M.P.D. Análise da composição e riqueza de pequenos mamíferos em três fitofisionomias na Fazenda Bonito, município de Castelo do Piauí. Anais do VIII Congresso de Ecologia do Brasil. Caxambu, 2007.

MARCO JÚNIOR, P.; SIQUEIRA, M. F. Como determinar a distribuição potencial de espécies sob uma abordagem conservacionista. Megadiversidade, v. 5, p. 65-76, 2009.

MARES, M.A; ERNEST, K.A; GETTINGER, D.D. Small mammal community structure and composition in the Cerrado Province of central Brazil. Laboratory of Parasitilogy. Vol. 2. 1986. 
METZ, C. E. ROC methodology in radiologic imaging. Investigative Radiology, v. 21, n. 9, p. $720-733,1986$.

MILLS, J.N.; AMMAN, B. R.; GLASS, G. E.; Ecology of hantaviruses and their hosts in North America. Vector-Borne and Zoonotic Diseases, v. 10, n. 6, p. 563-574, 2010.

OAK RIDGE NATIONAL LABORATORY. Vegetation Cover Types from MODIS, 500m, South America: 2000-2001. 2012.

OLIVEIRA S.V.; ESCOBAR L.E.; PETERSON A.T.; GURGEL-GONÇALVES, R.; Potential Geographic Distribution of Hantavirus Reservoirs in Brazil. PLoS ONE, v. 8, n.12, 2013.

PEARCE, J. L.; BOYCE, M. S. Modelling distribution and abundance with presence-only data. Journal of Applied Ecology, v. 43, n. 3, p. 405-412, 2006.

PEARSON, R. G. et al. Predicting species distributions from small numbers of occurrence records: a test case using cryptic geckos in Madagascar. Journal of Biogeography, v. 34, n. 1, p. 102-117, 2007.

PEARSON, R. G; DAWSON, T. P; LIU, C. 2004. Modelling species distributions in Britain: a hierachical integration of climate and landcover data. Ecography 27: 285-298. 2004.

PETERSON, A.T et al. The Geography of Disease Transmission. In__Ecological Niches and Geographic Distributions. Princenton University Press. 2011.

PHILLIPS, S. J. et al. Maximum entropy modeling of species geographic distributions.

Ecol. Model. 190: 231-259. 2006.

PULLIAM, H. R. On the relationship between niche and distribution. Ecology Letters, v. 3, $n^{\circ} .4$, p. 349-361, 2000.

QUADROS, J; MONTEIRO-FILHO, E.L.A. Revisão conceitual, padrões e microestruturais proposal nomenclatura. Rev. Bras. Zool. vol 23, nº 1, pp. 279-292. 2006.

REIS, N.R.; PERACCHI, A.L.; PEDRO, W.A.; LIMA, I.P. Mamíferos do Brasil. Editora UEL. 2006.

ROCHA, C.C; RIBEIRO, R; TAKAHASHI, F.S.C; MARINHO-FILHO, J. Microhabitat use by rodent species in a central Brazilian cerrado. Mammalian Biology. Vol. 76. 2011

ROSS, J.L.S. Ecogeografia do Brasil. Subsídios para Planejamento Ambiental. Ed. Oficina de Textos. São Paulo, 2006.

SANTOS, J.P.; STEINKE, E.T.; GARCIA-ZAPATA, M.T.A. Uso e ocupação do solo e a disseminação da hantavirose na região de São Sebastião, Distrito Federal: 2004 - 2008. Revista da Sociedade Brasileira de Medicina Tropical, v. 44, n. 1, p. 53-57, 2011.

SOBERÓN, J. Grinnellian and Eltonian niches and geographic distributions of species. Ecology Letters. V. 10:1115-1123. 2007.

SOBERÓN, J; PETERSON, A.T. Interpretation of models of fundamental ecological niches and species distributional areas. Biodiversity informatics. 2005. 2:1-10.

SUSUKI, A. et al. Identifying Rodent Hantavirus Reservoirs, Brazil. Emerging Infectious Diseases. Vol. 10, $\mathrm{n}^{\circ}$ 12, 2004. 
TALAMONI, S.A; COUTO, D; JÚNIOR D.A.C; DINIZ, F.M. Diet of some species of Neotropical small mammals. Mammalian Biology. Vol. 73. 2008.

WALTARI, E; PERKINS, S.L. In the hosts' footsteps? Ecological niche modelling and its utility in predicting parasite distributions. In:_The biogeography of host-parasite interactions. pp. 145- 157. Oxford University Press, Oxford. 2010.

WEI, L. et al. Using Geographic Information System-based Ecologic Niche Models to Forecast the Risk of Hantavirus Infection in Shandong Province, China. American Journal Tropical Medicine Hygiene, Vol 84, 2011.

YAN, L. et al. Landscape Elements and Hantaan Virus-related Hemorrhagic Fever with Renal Syndrome, People's Republic of China. Emerging Infectious Diseases. Vol, 13, nº 9, 2007. 


\title{
CAPÍTULO 4
}

\section{ANÁLISE DE DEPENDÊNCIA ESPACIAL DE CASOS DE HANTAVIROSE NO ESTADO DE GOIÁS E NO DISTRITO FEDERAL, 2003-2010. ${ }^{3}$}

\begin{abstract}
RESUMO
A Hantavirose é uma antropozoonose emergente no Brasil e apresenta letalidade em torno de $40 \%$. Os roedores silvestres são os seus principais reservatórios e as infecções estão relacionadas ao contato com aerossóis de urina, fezes e saliva infectadas. No Estado de Goiás, a sua ocorrência é reconhecida desde 2000, e no Distrito Federal, os primeiros casos foram registrados em 2004, porém, pouco se sabe sobre a distribuição espacial e as condições geográficas, socioeconômicas e ambientais que favorecem a transmissão. Diante do exposto, o presente estudo tem por objetivo realizar a análise espacial da Hantavirose no Estado de Goiás e no Distrito Federal, no período 2003-2010. As técnicas de análise espacial utilizadas para o cumprimento do objetivo são o Índice de Moran Global e da análise de Hotspots através do algoritmo Getis-Ord $\mathrm{Gi}^{*}$. Os resultados obtidos por meio do Índice de Moran Global apontaram que em relação à análise espacial da incidência de Hantavirose no Estado de Goiás não se tem uma evidência de dependência espacial no território goiano. Contudo, à análise de Hotspots identificou 02 (dois) "bolsões" de hotspots em 02 (duas) áreas naquele Estado. No Distrito Federal, o Índice de Moran Global obtido foi de 0,208187. Em relação à análise de Hotspots, as Regiões Administrativas (RAs) de Planaltina, Paranoá e São Sebastião foram consideradas como regiões críticas para a ocorrência da Hantavirose. Assim, o uso de técnicas de estatística espacial como o Índice Global de Moran e o algoritmo Getis-ord Gi* revelaram-se de fundamental importância na análise de dependência espacial da Hantavirose no Estado de Goiás e no Distrito Federal.
\end{abstract}

Palavras-chave: Zoonoses. Hantavírus. Análise Espacial.

\section{ANALYSIS OF SPATIAL DEPENDENCE OF CASES HANTAVIRUS IN GOIÁS AND THE FEDERAL DISTRICT, 2003-2010}

\begin{abstract}
The hantavirus is an emerging anthropozoonosis in Brazil, and presents lethality around $40 \%$. Wild rodents are the major reservoirs and infections are related to contact with aerosols of urine, feces and infected saliva. In the state of Goiás, its occurrence has been recognized since 2000 and the Federal District, the first cases were recorded in 2004, but little is known about the spatial distribution and geographic, socioeconomic and environmental conditions that favor transmission. Given the above, the present study aims to conduct spatial analysis of hantavirus in the state of Goiás and the Federal District, between the years 2003 to 2010. The spatial analysis techniques used to meet the goal are the Moran index global Hotspots and analysis through the Ord-Getis $\mathrm{Gi}^{*}$ algorithm. The results obtained using the global Moran index showed that the spatial analysis of the incidence of hantavirus infection in Goiás state that there is no evidence of spatial dependence in Goiás, however the Hotspots analysis identified two "pockets" of hotspots in two areas in the state. While the Federal District, the global Moran index obtained was 0.208187. On the analysis of Hotspots demonstrated that administrative regions Planaltina, Paranoá and San Sebastian are considered critical areas for the occurrence of hantavirus. Thus, the use of spatial statistical techniques such as the Global Moran Index and Getis-Ord $\mathrm{Gi} *$ algorithm proved to be of fundamental importance in the analysis of spatial dependence of hantavirus in the state of Goiás and the Federal District.
\end{abstract}

Keywords: Zoonosis. Hantavirus. Spatial Analysis.

\footnotetext{
${ }^{3}$ Artigo publicado na Hygeia 10 (18): 98 - 109, Jun/2014.
} 


\subsection{INTRODUÇÃO}

Para Moore e Carpenter (1999), os 03 (três) elementos básicos à análise de surtos de doenças contagiosas são: as pessoas, os lugares e o tempo. Historicamente, o foco na investigação epidemiológica tem sido na pessoa e no tempo, com pouca atenção para as implicações na categoria 'espaço'. Os primeiros mapeamentos de surtos foram realizados há mais de 100 anos, porém, somente nas últimas décadas do século XX é que as análises dos padrões e processos espaciais na saúde pública passaram a ter melhor capacidade e rapidez através de ferramentas disponíveis nos Sistemas de Informações Geográficas (SIG).

A utilização destas ferramentas promoveu discussões voltadas para as políticas públicas de saúde, uma vez que estas permitiam a ampliação de investigações epidemiológicas na vigilância em saúde, não somente na elaboração de mapas coropléticos contendo a localização de eventos, mas também em análises que permitam a elaboração de subsídios para o controle de doenças ou na localização de áreas propícias para a instalação de equipamentos públicos de saúde para a população.

Segundo Druck et al. (2004), a compreensão da distribuição espacial de dados oriundos de fenômenos ocorridos no espaço constitui atualmente um grande desafio, pois, os padrões espaciais destes dados são frequentemente intricados e complexos para a definição de questões centrais em diversas áreas do conhecimento, em especial, na saúde pública. A utilização de técnicas de análise espacial, como, por exemplo, a integração da estatística espacial com os sistemas de informações geográficas, permitiu não somente a visualização do fenômeno, mas também a análise do padrão deste fenômeno.

São poucos os epidemiologistas que reconhecem que em cada epidemia existe uma geografia (espaço). A razão desta ação é que os epidemiologistas não estão cientes de que as avaliações da distribuição espacial das doenças podem colaborar em uma visão mais ampla do problema. E ainda, o emprego dos métodos de análise espacial ajuda a controlar possíveis fatores de confusão e evita inferências enviesadas que desconsideram os efeitos de grupo, isto é, onde as condições socioeconômicas da população desempenham papel preponderante na explicação das condições de saúde destes grupos (MINISTÉRIO DA SAÚDE, 2007).

A análise espacial é composta por um conjunto de procedimentos conexos cuja finalidade é a escolha de um modelo inferencial que considere explicitamente o relacionamento espacial existente no fenômeno (DRUCK et al., 2004). As técnicas de análise 
espacial permitem descrever a distribuição das variáveis de estudo, bem como identificar observações atípicas não somente em relação ao tipo de distribuição, mas também em relação aos vizinhos, além de buscar a existência de padrões na distribuição espacial; também permitem proporcionar formas inovadoras de visualização e análise de dados pontuais de saúde, o que faz com que os gestores de saúde pública identifiquem locais de elevadas taxas de morbidade e mortalidade de diversos agravos e, posteriormente, priorizem as áreas para investigação e intervenção.

Moore e Carpenter (1999) reforçam que para a utilização de métodos espaciais de análise é necessário entender a natureza dos dados espaciais com a finalidade de verificar a qualidade destes dados, a fim de evitar problemas de subestimação nos resultados das análises. Outro aspecto apontado por aqueles autores é o problema da dependência espacial, análoga à dependência temporal. As localidades próximas são susceptíveis de possuir atributos semelhantes, ou seja, faz-se importante a existência e manutenção de uma matriz de vizinhança que possa garantir resultados confiáveis.

Portanto, 03 (três) tipos de dados são os mais utilizados para a realização das análises espaciais, quais sejam: 1) os dados pontuais; 2) as superfícies contínuas; e, 3) as taxas agregadas (áreas). Os dados atributos de área são os mais utilizados no estudo da saúde pública (MINISTÉRIO DA SAÚDE, 2007).

Os dados de área (agregados) são provenientes de áreas geográficas com limites definidos - em geral, divisões político-administrativas. Tais dados são compostos por indicadores de doenças transmissíveis e não transmissíveis ou de número de óbitos por Município, acidentes de trânsito, taxas de criminalidade, bem como coletas do censo sobre contagem populacional, renda média familiar, percentual de adultos analfabetos, entre outros aspectos que são exemplos do processo (LAI et al., 2009).

Os fenômenos citados são agregados por Municípios, bairros ou setores censitários, onde não se tem, conforme relatado por Câmara et al. (2004), a localização exata dos eventos, mas sim, um valor de área. E a forma como os dados estão distribuídos no espaço é um importante indicador da interação espacial, revelada nas medidas de associação ou autocorrelação espacial. Segundo Marques et al. (2010), a análise espacial exploratória permite apontar como os valores das áreas estão arranjados no espaço, além de estimar a magnitude da dependência espacial, ou seja, têm-se uma caracterização da dependência espacial. 
Assim, a dependência espacial se dá justamente quando um fenômeno apresenta padrões específicos de associação com o espaço, isto é, ação não aleatória. No caso de uma associação espacial, faz-se importante saber o que está causando a observação de um determinado fenômeno em um local e se a constatação deste fenômeno é semelhante ou diferente em relação aos seus vizinhos. Tal associação pode ser expressa de forma positiva ou negativa. A dependência espacial é diferente da estacionariedade, pois, a primeira (dependência espacial) tem por base o fato de que as distâncias observadas entre as ocorrências de objetos (ou fenômenos) interferem diretamente na relação entre eles, e também não é uma constante em toda região. Já em relação à estacionariedade, é possível notar que os objetos são constantes em toda a região estudada (MINISTÉRIO DA SAÚDE, 2007).

As aplicações de técnicas de análise espacial na investigação de doenças zoonóticas, como, por exemplo, a Hantavirose, estão sendo bastante utilizadas como norte de pesquisa. Os trabalhos de Yan et al. (2007), Fang et al. (2009) e Wei et al. (2011) fizeram uso de sistemas de informações geográficas e estatística espacial para análises da disseminação do agravo na China. E ainda, o estudo de Castro e Singer (2007) buscou avaliar se a transmissão da malária apresentava correlação espacial, e se áreas afetadas com alta ou baixa concentração de casos poderiam ser identificadas através do uso de indicadores locais de associação espacial, no caso, com uso da técnica de análise espacial conhecida como o teste $G i^{*}$, recomendado para identificação de conglomerados significativos de valores altos ou baixos próximos a uma localidade.

Cromley e Mclafferty (2002) relatam 02 (duas) técnicas de estatística espacial que são importantes para a análise da dispersão de doenças zoonóticas, a saber: 1) os indicadores locais de autocorrelação espacial, como, por exemplo, o Índice Global de Moran; e, 2) a técnica de análise espacial Getis $\operatorname{Ord} G i^{*}$, que afere a associação entre um valor em um determinado lugar e os valores para as áreas próximas ou adjacentes. As referidas técnicas são úteis para encontrar grupos de doenças com base em dados de área.

Diante do exposto, o presente estudo teve por objetivo realizar a análise espacial dos casos de Hantavirose no Estado de Goiás e no Distrito Federal, no período 2003-2010, fazendo o uso de medidas de associação voltadas à dependência espacial, de áreas de agrupamentos (clusters) da Hantavirose, além de investigar a existência de relacionamento espacial significativo que possa identificar as áreas de risco, buscando subsidiar ações de controle deste agravo nas referidas Unidades da Federação (UFs). 


\subsection{MATERIAIS E MÉTODOS}

\subsection{1 - Área de estudo}

O Estado de Goiás, cuja área de $340.103,467$ km², se localiza na região Centro-Oeste do Brasil (vide Figura 1, a seguir) e se estende entre os paralelos $13^{\circ} 00^{\prime}$ e $19^{\circ} 00^{\prime} \mathrm{S}$ e os meridianos $46^{\circ} 00^{\prime}$ e $53^{\circ} 00^{\prime} \mathrm{W}$ (IBGE, 2012). Limita-se ao norte, com o Estado do Tocantins; ao sul, com os Estados de Minas Gerais e Mato Grosso do Sul; a leste, com os Estados da Bahia e Minas Gerais; e a oeste, com o Estado do Mato Grosso. Possui 246 Municípios e tem como capital a cidade de Goiânia, localizada na porção central do Estado (CEPED, 2011).

Em relação aos seus aspectos naturais, o Estado de Goiás apresenta relevo suavemente ondulado em regiões de cerrado, com uma topografia simples e estrutura geológica complexa, de terrenos cristalinos sedimentares antigos e áreas de planaltos bastante trabalhadas pela erosão. O clima é classificado como tropical, com 02 (duas) estações bem definidas (úmida e seca, respectivamente), sendo mais expressivo o período chuvoso - que se dá entre os meses de setembro a abril - e seco - que se dá entre os meses de maio a agosto, com índice pluviométrico médio anual entre 1.200 a $2.500 \mathrm{~mm}$.

No que tange à vegetação, o bioma Cerrado cobria 97\% do seu território, sendo que nos últimos 40 anos, mais de 50\% das áreas de cerrados foram convertidas em campos agrícolas para o cultivo de grãos e fibras, com pastagens plantadas com o capim braquiária (ROSS, 2006).

A referida UF apresenta uma população de 6.004 .045 habitantes, densidade demográfica de $17,47 \mathrm{hab} / \mathrm{km}^{2}$ e taxa de crescimento de $20 \%$ correspondente ao mesmo período, segundo dados do Instituto Brasileiro de Geografia e Estatística (IBGE) (2012). A dinâmica econômica regional em Goiás tem sido profundamente caracterizada pela rápida penetração da moderna agropecuária, altamente mecanizada, articulada a partir de grandes e médias propriedades de terra, concentrada na produção de grãos e da pecuária de corte, com elevados níveis de produtividade que permitem ocupar um espaço crescente no agronegócio e nas exportações brasileiras. Além das atividades agropecuárias destacam-se também as atividades industriais, em especial, a indústria química (polo farmacêutico), a metalúrgica 
básica, a fabricação de produtos minerais não metálicos, a confecção de artigos de vestuário e acessórios e a agroindústria (IMB, 2013).

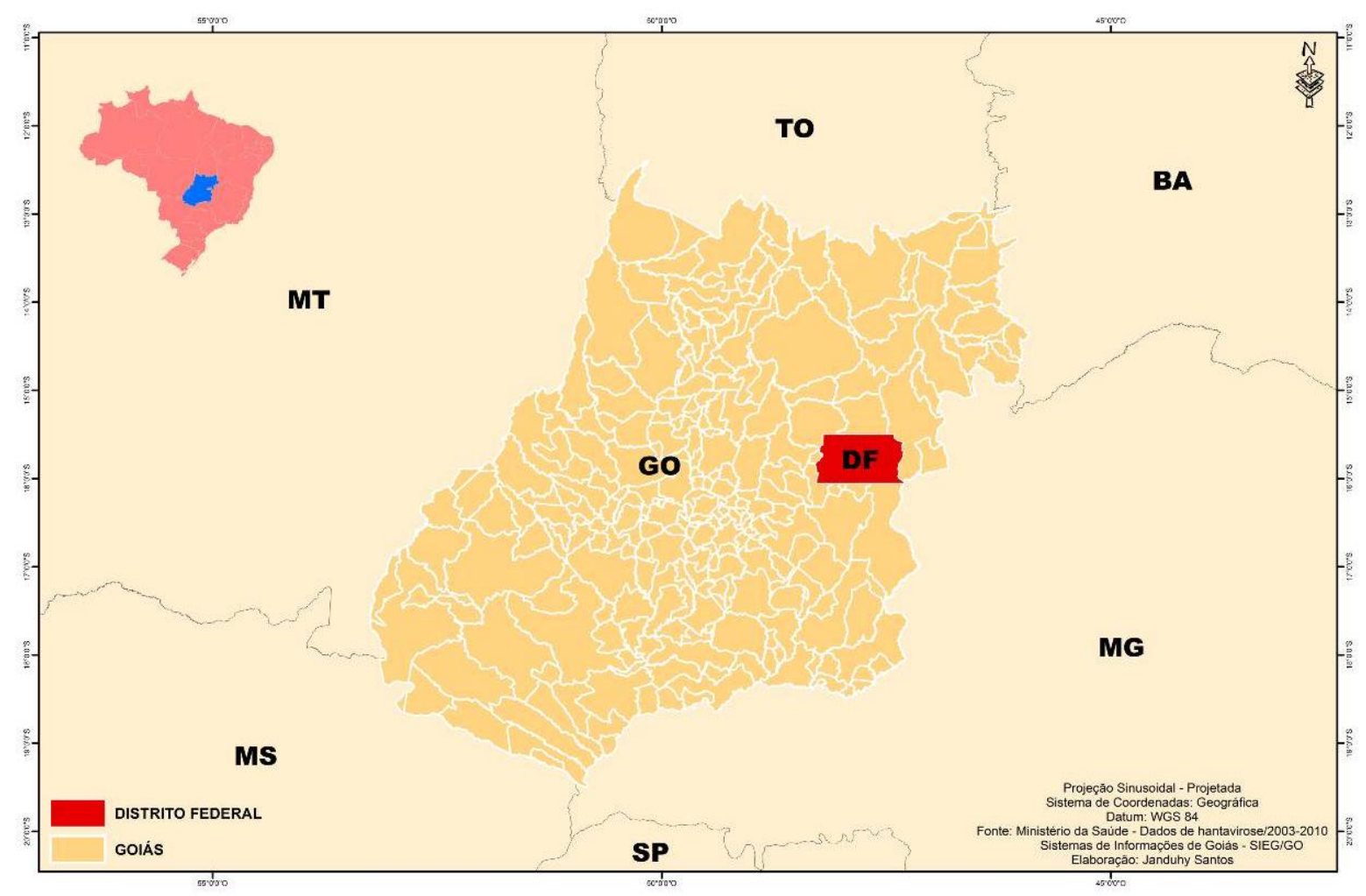

Figura 1 - Mapa de localização do Estado de Goiás e do Distrito Federal.

O Distrito Federal é um enclave de Goiás, pois é circundado por praticamente todo o território daquele Estado, conforme exposto na figura apresentada anteriormente. Entretanto, em uma pequena ponta a sudeste, faz divisa com o município de Cabeceira Grande (CEPED, 2011). Assim, possui uma área de $5.814 \mathrm{Km}^{2}$ e limita-se ao norte pelo paralelo de $15^{\circ} 30^{\prime} \mathrm{S}$, ao sul pelo paralelo $16^{\circ} 03^{\prime} \mathrm{S}$, a leste pelo rio Preto $\left(47^{\circ} 25^{\prime} \mathrm{W}\right)$ e a oeste pelo rio Descoberto $\left(48^{\circ} 12^{\prime} \mathrm{W}\right)$.

Atualmente aquela UF encontra-se dividida em 31 Regiões Administrativas (RAs), das quais apenas 19 são reconhecidas oficialmente pelo IBGE (2012) pelo fato de que as poligonais das RAs restantes ainda não foram aprovadas pela Câmara Legislativa do Distrito Federal (CLDF) (SANTOS, 2014). 
Conforme Santos (2009), a referida UF é drenada por rios que pertencem a 03 (três) das mais importantes bacias hidrográficas da América do Sul, quais sejam: 1) Paraná (rios Descoberto e São Bartolomeu); 2) São Francisco (rio Preto); e, 3) Tocantins/Araguaia (rio Maranhão). O relevo do Distrito Federal caracteriza-se por uma topografia plana a plana ondulada com cotas entre 830 e 1.000 metros, constituindo-se nos divisores de água das bacias hidrográficas da região. O bioma Cerrado ocupa todo o território daquela UF; contudo, apresenta um alto nível de antropização (SANTOS, 2014).

Com uma população estimada em 2.570.160 habitantes (IBGE, 2012) e com a densidade demográfica mais alta do Brasil, de 444,07 habitantes por $\mathrm{km}^{2}$, o crescimento demográfico anual do Distrito Federal na última década foi de 25\% (CEPED, 2011). O processo de urbanização e o crescimento da ocupação agrícola no bioma Cerrado implicaram significativamente na redução da vegetação nativa e, consequentemente, na perda da biodiversidade. No período 1954-2001, as áreas de ocupação urbana evoluíram de 0,02\% para 7,39\% no território do Distrito Federal, e as áreas de ocupação agrícola passaram de 0,02\% para 47,56\%, alcançando aproximadamente metade de seu território (DISTRITO FEDERAL, 2009).

\subsection{2 - Procedimentos metodológicos}

Para tanto, os procedimentos metodológicos apresentados no fluxograma esquemático da Figura 2, apontam uma visão da realização de todo processo de análise espacial da Hantavirose no Estado de Goiás e no Distrito Federal. Assim, tais procedimentos permitiram descrever a distribuição das variáveis de estudo e identificar as observações atípicas não somente em relação ao tipo de distribuição, mas também em relação aos vizinhos, além de buscar a existência de padrões na distribuição espacial. 


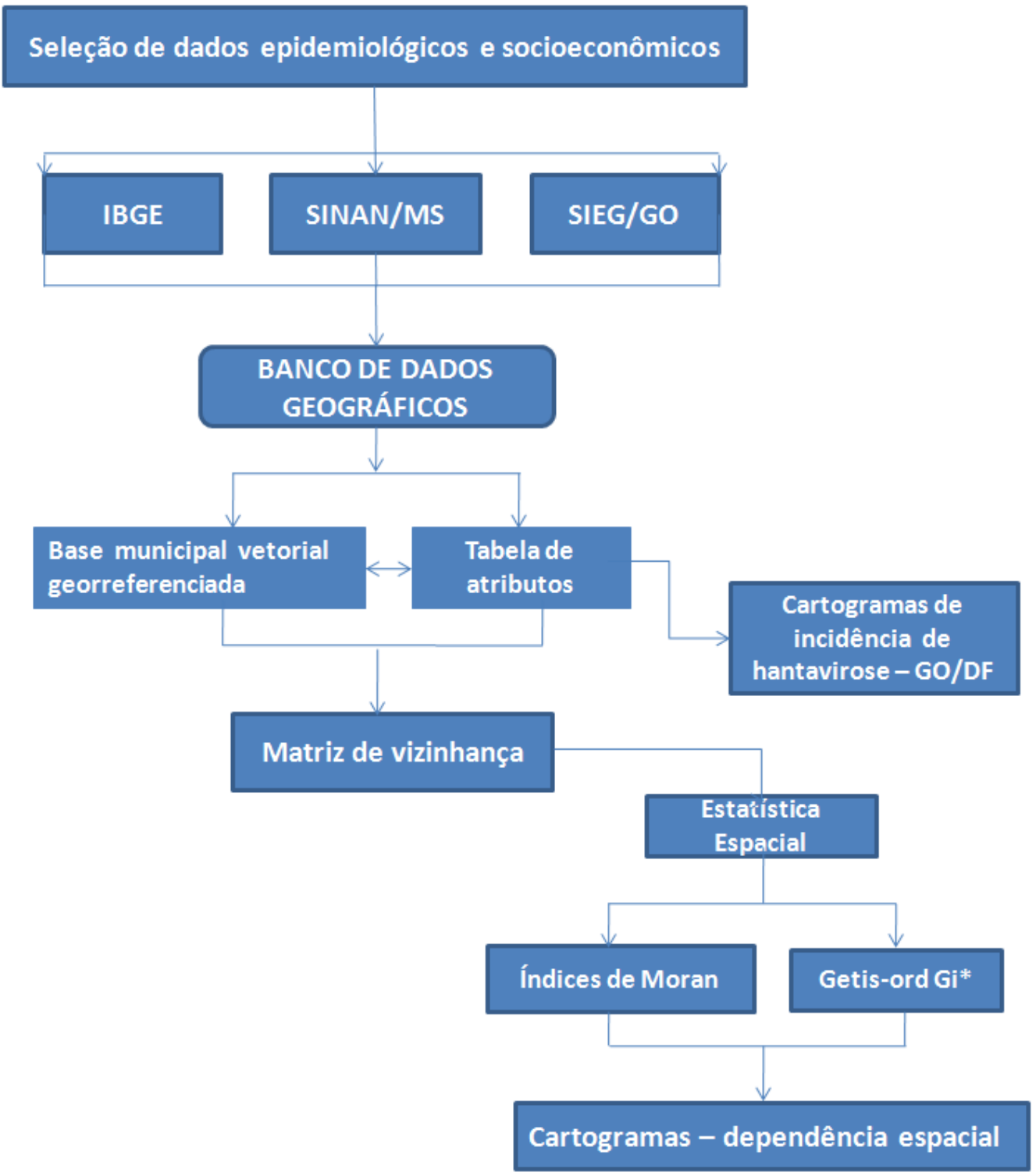

Figura 2 - Fluxograma dos procedimentos metodológicos da análise espacial da Hantavirose no Estado de Goiás e no Distrito Federal. Elaboração: Janduhy Santos

Para a realização da análise espacial da Hantavirose no Estado de Goiás e no Distrito Federal foram realizados procedimentos para criação de um banco de dados com os dados socioeconômicos e epidemiológicos das referidas UFs, provenientes do IBGE, do Ministério da Saúde (MS) e Instituto Mauro Borges de Estatísticas e Estudos Socioeconômicos (IMB). Os dados oriundos destes órgãos foram reunidos e sistematizados em um único banco de dados geográfico, permitindo, assim, a realização da montagem dos cartogramas de incidência e a montagem da matriz vizinhança. Com a criação da matriz de vizinhança foram realizadas 02 (duas) operações de estatística espacial, a saber: 1) o Índice de Moran; e, 2) a análise espacial com Getis-ord-Gi*. Com os resultados estatísticos obtidos após a realização destas operações foram elaborados cartogramas com a visualização das informações ali geradas. 


\subsubsection{Dados epidemiológicos e demográficos}

Os dados epidemiológicos da Hantavirose são provenientes do Sistema Nacional de Agravos de Notificação (SINAN), na versão SINAN-NET, correspondente ao período 20032010. Os dados foram obtidos a partir das fichas de notificação e investigação (FIE). Foram verificadas possíveis inconsistências de registros, sendo excluídas informações duplicadas (MINISTÉRIO DA SAÚDE, 2014).

Foram apresentados os casos notificados e confirmados, bem como os coeficientes de incidência, calculado por 100 mil habitantes. Os cálculos foram realizados para o Distrito Federal e o Estado de Goiás. Para análise da incidência foram utilizados dados das estimativas populacionais obtidos dos censos demográficos do período 2003-2010. Para os cálculos dos coeficientes médios de incidência, fez-se uso da média aritmética dos respectivos coeficientes anuais (ROUQUAYROL, 2013).

Em relação aos dados demográficos, estes foram obtidos no banco de dados do IBGE, referentes ao censo de 2010, e a variável selecionada foi a população (total), com o intuito de realizar o cálculo de incidência da Hantavirose no período descrito nas 02 (duas) regiões em estudo. Tais informações foram reunidas junto aos dados vetoriais permitindo a formação de uma tabela de atributos.

Os dados vetoriais do Estado de Goiás são provenientes do IMB que, através do Sistema Estadual de Geoinformação (SIEG/GO), disponibilizou a malha municipal do Estado de Goiás com escala de 1:250.000, com sistemas de coordenadas no formato LAT/LONG, e o Datum no formato WGS 1984.

Os dados vetoriais do Distrito Federal, com a divisão por RAs (19 RAs), são oriundos do banco de dados geográficos do Departamento de Estradas de Rodagem do Distrito Federal (DER-DF) com escala de 1:250.000 e sistemas de coordenadas geográficas e o datum no formato WGS 1984.

Os dados descritos foram reunidos em um banco de dados geográficos para a realização de análises estatísticas, visualização e elaboração de cartogramas contendo os resultados das referidas operações. 


\subsubsection{Matriz de Vizinhança ou de Proximidade}

A fim de estimar a variabilidade espacial de dados de área, tem-se como ferramenta básica a Matriz de Proximidade Espacial, também chamada Matriz de Vizinhança. Dado um conjunto de $n$ áreas $\left\{A_{1}, . ., A_{n}\right\}$, construiu-se a matriz $\mathrm{W}^{(1)}$ ( $\mathrm{n} \times \mathrm{n}$ ), onde cada um dos elementos $w_{i j}$ representa uma medida de proximidade entre $A_{\mathrm{i}}$ e $A_{\mathrm{j}}$. Neste sentido, para Câmara et al. (2004), a medida de proximidade pode ser calculada a partir dos seguintes critérios:

* $w_{i j}=1$, se o centróide de $A_{\mathrm{i}}$ está a uma determinada distância de $A_{\mathrm{j}}$; caso contrário, $w_{\mathrm{ij}}=$ 0 .

$* w_{\mathrm{ij}}=1$, se A $i$ compartilha um lado comum $\operatorname{com} A_{\mathrm{j}}$; caso contrário, $w_{\mathrm{ij}}=0$.

* $w_{i j}=1_{\mathrm{ij}} / 1_{\mathrm{i}}$, onde $1_{\mathrm{ij}}$ é o comprimento da fronteira entre $A_{\mathrm{i}}$ e $A_{\mathrm{j}}$ e $1_{\mathrm{i}}$ é o perímetro de $A_{\mathrm{i}}$

Como a matriz de proximidade é utilizada em cálculos de indicadores na fase de análise exploratória, mostra-se útil normalizar suas linhas, a fim de que a soma dos pesos de cada linha seja igual a 1 . Tal fato simplifica e facilita a realização de vários cálculos de índices de autocorrelação espacial. A matriz de vizinhança foi operacionalizada no software livre TerraView, versão 4.2.2, do Instituto Nacional de Pesquisas Espaciais (INPE, 2008).

\subsubsection{Indicadores Globais de Autocorrelação Espacial: Índices de Moran Global e Local}

A autocorrelação espacial (o Índice Global de Moran) é uma medida geral de associação espacial para um conjunto de dados, que testa, entre áreas conectadas, qual o grau de autocorrelação para os indicadores estudados. Em uma matriz de vizinhança normalizada, o Índice de Moran é dado por:

$$
I=\frac{n \sum_{i=1}^{n} \sum_{j=1}^{n} w_{i j}\left(y_{i}-\bar{y}\right)\left(y_{j}-\bar{y}\right)}{\left(\sum_{i=1}^{n}\left(y_{i}-\bar{y}\right)^{2}\right) \sum \sum w_{i \neq j}}
$$

Na equação apresentada anteriormente, $n$ é o número de áreas, $y_{\mathrm{i}}$ é o valor do atributo considerado na área $i, y$ é o valor médio do atributo na região de estudo e $w_{i j}$ são os elementos da matriz normalizada de proximidade espacial. Neste caso, a correlação será computada apenas para os vizinhos de primeira ordem no espaço, conforme estabelecido pelos pesos $w_{i j}$. 
O mesmo cálculo feito para matrizes de proximidade de maior ordem para permitir estimar a função de autocorrelação para cada ordem de vizinhança (ou “lag").

Em geral, o Índice de Moran presta-se a um teste cuja hipótese nula é de independência espacial; neste caso, seu valor seria zero. Os valores positivos (entre 0 e +1 ) indicam para correlação direta, e os valores negativos (entre 0 e -1 ) para correlação inversa.

Nunes (2013) relata que o Índice Global de Moran fornece um único valor de medida da associação espacial para todo o conjunto de dados. Contudo, a fim de examinar os padrões de dados espaciais em uma escala com maior detalhamento, é recomendado o Índice de Moran Local, que permite produzir um valor específico para cada objeto em prol da identificação de agrupamentos de objetos com valores de atributos semelhantes ou objetos anômalos.

O Diagrama de Espalhamento de Moran (Figura 3) é uma maneira adicional de visualizar a dependência espacial. Através da base nos valores normalizados (valores de atributos subtraídos de sua média e divididos pelo desvio padrão), tem-se aí a análise do comportamento da variabilidade espacial.

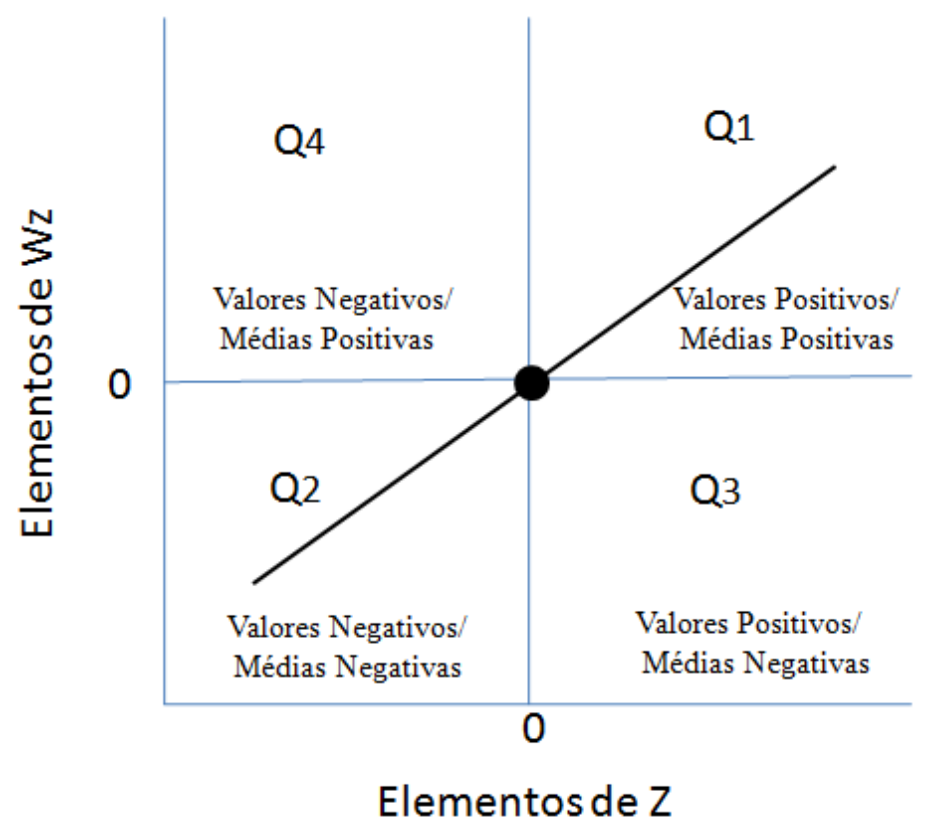

Figura 3 - Diagrama de Espalhamento de Moran (Adaptado Drucks et al, 2004).

O gráfico exposto anteriormente pode ser interpretado como Quadrante 1 (valores positivos, médias positivas) e Quadrante 2 (valores negativos, médias negativas), que indicam os pontos de associação positiva, no sentido de que uma localização possui vizinhos com valores semelhantes. E ainda, o Quadrante 3 (valores positivos, médias negativas) e o Quadrante 4 (valores negativos, médias positivas) indicam pontos de associação espacial negativa, no sentido de que uma localização possui vizinhos com valores distintos. 
As técnicas mencionadas foram realizadas em ambiente de sistemas de informações geográficas nos seguintes softwares: para elaboração dos layouts dos cartogramas, fez-se uso do ArcGIS, versão 10.2.2 ${ }^{\circledR}$, desenvolvido pela Environmental System Research Institute (ESRI); para os cálculos de associação espacial, o programa empregado foi o TerraView, versão $4.2 .2^{\circledR}$, desenvolvido pelo INPE; e, finalmente, para a realização do Diagrama de Espalhamento de Moran, o software adotado foi o GEODA, versão 1.6.6 ${ }^{\circledR}$, desenvolvido pelo Center for Geospatial Analysis and Computation.

\subsubsection{Análises de Hot Spot/Cold Spot}

O algoritmo de Getis-Ord Gi* (Getis e Ord, 1992) é um indicador espacial que permite que a análise de agrupamentos considere a estatística esperada de um polígono e seus vizinhos, em comparação à média de todas as observações. Getis-Ord Gi* é ainda um indicador de informação local para o qual é possível calcular o grau de significância para valores que estejam abaixo ou acima da média esperada para dada variável.

Neste sentido, aquele algoritmo é descrito conforme se segue:

$$
\mathbf{G} *_{\mathbf{i}}=\frac{\sum_{j=1}^{n} x_{j}}{\sum_{j=1}^{n} w_{i j}(d) x_{i}}, \mathrm{j} \neq \mathrm{i}
$$

Onde:

$\mathrm{W}_{i j}=$ valor na matriz de proximidade para região $i$ com a região $j$ em função da distância $(d)$;

$\mathrm{x}_{i}$ e $\mathrm{x}_{j}=$ valores dos atributos considerados nas áreas $i$ e $j$;

$d$ = distância entre pontos;

$n$ = número de áreas (polígonos).

Conforme o exposto, a referida ferramenta parte do principio dos testes estatísticos que iniciam com a hipótese nula. A hipótese nula da análise de Hot Spot é a completa aleatoriedade espacial. O resultado esperado é que não existe nenhum padrão na distribuição espacial do fenômeno. Os valores de $\mathrm{P}$ ( $p$-valor) e Z (escore) apontam se a hipótese da aleatoriedade pode ser descartada, indicando a existência de certo padrão na distribuição espacial do fenômeno (agrupamentos). 
Portanto, se o valor de $p$ ( $p$-valor) for muito pequeno, significa que se tem aí baixa probabilidade da ocorrência do padrão espacial do fenômeno devido ao acaso. $\mathrm{O}$ valor de $z$ (escore) indica apenas o desvio padrão. Os valores de $z$ muitos altos ou muitos baixos (negativos), combinados com valores de $p$ muito baixos indicam agrupamentos espaciais estatisticamente significativos (Hot Spots ou Cold Spots).

Para a realização da técnica de análise espacial Hot Spot/Cold Spot foi utilizado o software ArcGIS, versão $10.2 \cdot 2^{\circledR}$.

\subsection{RESULTADOS}

\subsubsection{Análise da distribuição espacial da hantavirose em Goiás}

A cepa viral presente atualmente no Estado de Goiás e no Distrito Federal é o hantavírus Araraquara (ARAV). O roedor reservatório do referido hantavírus é o Necromys lasiurus. Assim, com base nestes dados, foram realizadas análises espaciais para observar a dependência espacial da Hantavirose nas UFs analisadas.

Conforme os dados do MS (2010), período 2003-2010, foram registrados no Estado de Goiás 75 casos autóctones, com uma taxa média de incidência de 2,7/ 100.000 habitantes. Os Municípios de Buriti de Goiás e Campo Alegre de Goiás apresentaram a maior quantidade de casos, com 07 (sete) ocorrências ali registradas.

Seguindo a mesma tendência em relação às outras UFs, as exposições associadas com adoecimento foram observadas, em grande parte, na zona rural ou com características rurais, onde os moradores estavam ligados às atividades ocupacionais no ramo da agricultura ou da pecuária.

A Figura 4, a seguir, apresenta a distribuição espacial da incidência da Hantavirose no Estado de Goiás, bem como, em menor escala, no Distrito Federal, período 2003-2010, com a finalidade de observar o padrão da distribuição mencionada. 


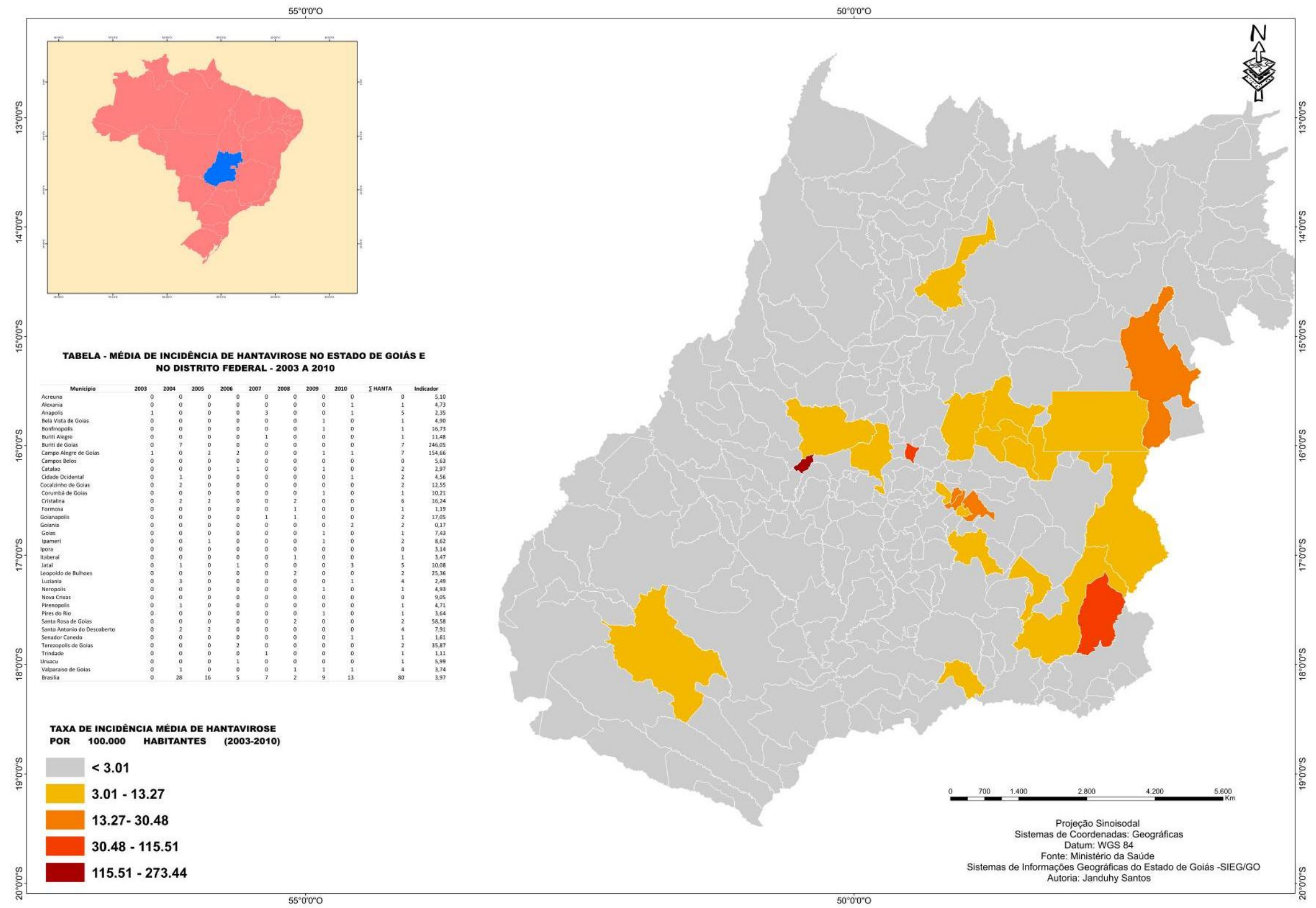

Figura 4 - Mapa da distribuição espacial da incidência de Hantavirose no Estado de Goiás e no Distrito Federal - período 2003-2010. 
No cartograma exposto na figura 4, é possível observar que dos 248 Municípios goianos, somente 31 localidades (12\% do território goiano) apresentaram casos de Hantavirose, com a taxa de incidência de 2,75/100.000 habitantes para um período de 08 (oito) anos. A distribuição espacial da incidência da Hantavirose está concentrada em áreas na região do entorno do Distrito Federal, bem como na região metropolitana da capital goiana, delimitadas geograficamente como as regionais de saúde do Entorno Norte, Entorno Sul, Pireneus e Central. (SES/GO, 2014).

Também foram observadas incidências no norte do Estado de Goiás, na cidade de Uruaçu, e no sul, nos Municípios de Buriti Alegre e Jataí. O Município de Buriti de Goiás foi o que apresentou a maior taxa de incidência: 73,4/100.000 hab. Também apresentaram incidência expressiva as localidades de Campo Alegre de Goiás e Santa Rosa de Goiás, com 115/100.000 hab. e 68,7/100.000 hab., respectivamente.

O Índice Global de Moran medido para a taxa de incidência de Hantavirose ficou em $I=$ 0.0058 , com a significância estatística de $p$-valor $=0.31$. O valor inferido destaca que não houve autocorrelação, pois o resultado apresentado indica a ausência de associação espacial na incidência de Hantavirose nos municípios do Estado de Goiás. Neste sentido, foi possível observar a ausência de correlação no Diagrama de Espalhamento do Índice de Moran, conforme evidenciado na Figura 5, a seguir.

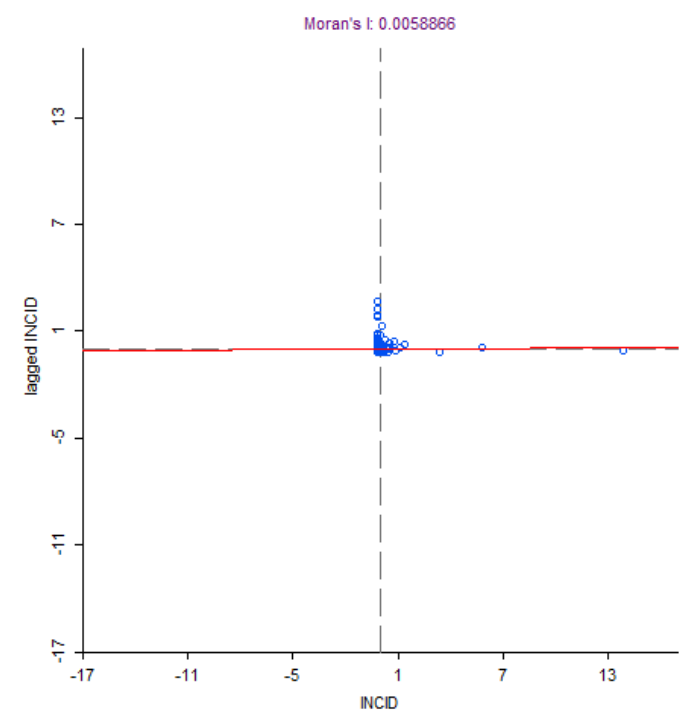

Figura 5 - Diagrama de Espalhamento de Moran da incidência de Hantavirose no Estado de Goiás.

Como o Índice Global de Moran é uma medida de associação espacial para todo o conjunto de dados, e o resultado exposto mostrou uma ausência de dependência espacial, não foi necessária a realização do mapeamento de clusters com o Indicador Local de Associação Espacial (LISA). 


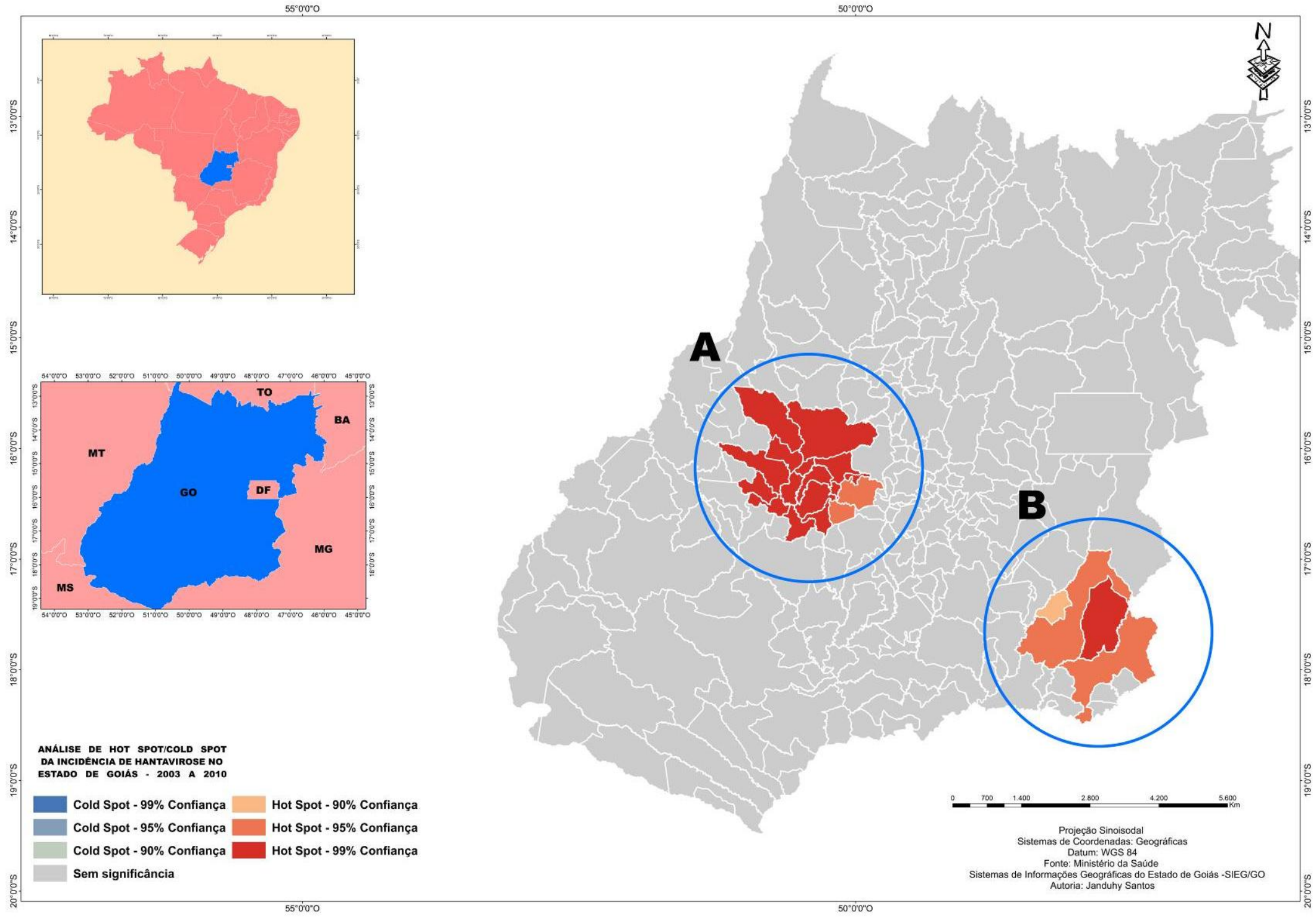

Figura 6 - Mapa de análise espacial com o indicador Getis-ord $G i^{*}$ da incidência de Hantavirose no Estado de Goiás. 
O mapa da figura 6 apresentada na figura 6 destaca a distribuição da análise espacial com o indicador Getis-ord Gi* ${ }^{*}$, que evidencia os agrupamentos de Hot Spots da incidência de Hantavirose no Estado de Goiás. Das 248 localidades goianas, 17 Municípios apresentaram evidência de que algum processo esteja determinando a formação de agrupamentos.

Neste sentido, 02 (dois) agrupamentos ("bolsões") estatisticamente significativos foram identificados pela referida técnica - estes divididos em agrupamento "A" e agrupamento "B", correspondente à Figura 6. O agrupamento "A" apresentou 13 Municípios (agrupamentos) com o grau de confiança de $99 \%$ e significância estatística de $p$-valor $<0.01$. Os Municípios que apresentaram tais resultados foram: Adelândia, Americano do Brasil, Aurilândia, Buriti de Goiás, Córrego do Ouro, Israelândia, Fazenda Nova, Firminópolis Moipora, Mossâmedes, Novo Brasil, Sancrelândia e São Luiz de Montes Belos. Os Municípios de Turvânia e Anicuns apresentaram grau de confiança de $95 \%$ e significância estatística de $<0.05$.

No agrupamento "B", somente o município de Campo Alegre de Goiás apresentou índice de confiança de 99\% ( $p$-valor < 0,01). As localidades de Catalão e Ipameri apresentaram grau de confiança de 95\% com $p$-valor < 0.05. Já o Município de Urutaí teve $p$ valor de $<0.10$ e grau de confiança de $90 \%$.

É preciso ainda destacar que em ambos os agrupamentos, os resultados apresentados descartam a aleatoriedade na distribuição espacial da Hantavirose. Os resultados representados através da espacialização dos referidos agrupamentos mostraram que o grupo "A" apresentou a maior quantidade de Municípios com resultados estatisticamente mais representativos que no grupo "B".

Em relação à presença de aglomerados de Cold Spots, a técnica empregada não identificou nenhum Município que apresentasse resultados negativos que criassem "bolsões" de baixa associação espacial da incidência da Hantavirose no Estado de Goiás. 


\subsubsection{Análise da distribuição espacial da Hantavirose no Distrito Federal}

Os primeiros casos de Hantavirose foram registrados no Distrito Federal em 2004 e, a partir daí, até 2010 foram registrados 70 casos autóctones, com uma taxa média de incidência de 3,92 /100.000 habitantes. A RA de São Sebastião (RA-XIX) apresentou o maior número de ocorrências do agravo, com o total de 23 casos.

Além da RA-XIX (com taxa média de incidência de 22,8/100.000 hab.), o mapa da incidência da Hantavirose (Figura 7) aponta que outras 02 (duas) RAs apresentaram taxa de incidência expressiva de Hantavirose no período 2004-2010, a saber: Brazlândia (13,9/100.000 hab.) e Paranoá (13,5/100.000 hab.). As RAs do Lago Sul e de Planaltina apresentaram taxas medianas de Hantavirose com 6,7/100.000 hab. e 7,58/100.000 hab., respectivamente. As outras RAs não apresentaram taxas significativas de incidência.

As RAs que não tiveram incidência de Hantavirose estão localizadas, conforme expresso na Figura 7, na área central do Distrito Federal e apresentam grande densidade populacional, além de avançada urbanização, ao contrário de outras regiões que ainda possuem áreas silvestres e também diversas atividades do ramo da agropecuária e de lazer (SANTOS, 2014).

Diante do exposto, conforme as informações epidemiológicas do Ministério da Saúde (2005), no Distrito Federal, a exposição ao hantavírus está associada às atividades laborais (armazenagem, roçagem, desmatamento e outros) em regiões agrícolas e silvestres, bem como de atividades ligadas ao ecoturismo ou aos esportes em ambientes silvestres ou rurais (a caça e a pesca, por exemplo), que representa um risco na exposição ao hantavírus por serem atividades ao ar livre e oferecerem contato direto com roedores mortos ou com suas excretas, ou ainda, montar acampamento em solo com sinais recentes da presença de roedores. E também a suburbanização também estão relacionadas à transmissão do vírus no Brasil. Além das alterações dos ecossistemas provocadas pelo desenvolvimento econômico, como construções de estradas e de hidroelétricas, podem contribuir com a ocorrência de casos ou surtos. 


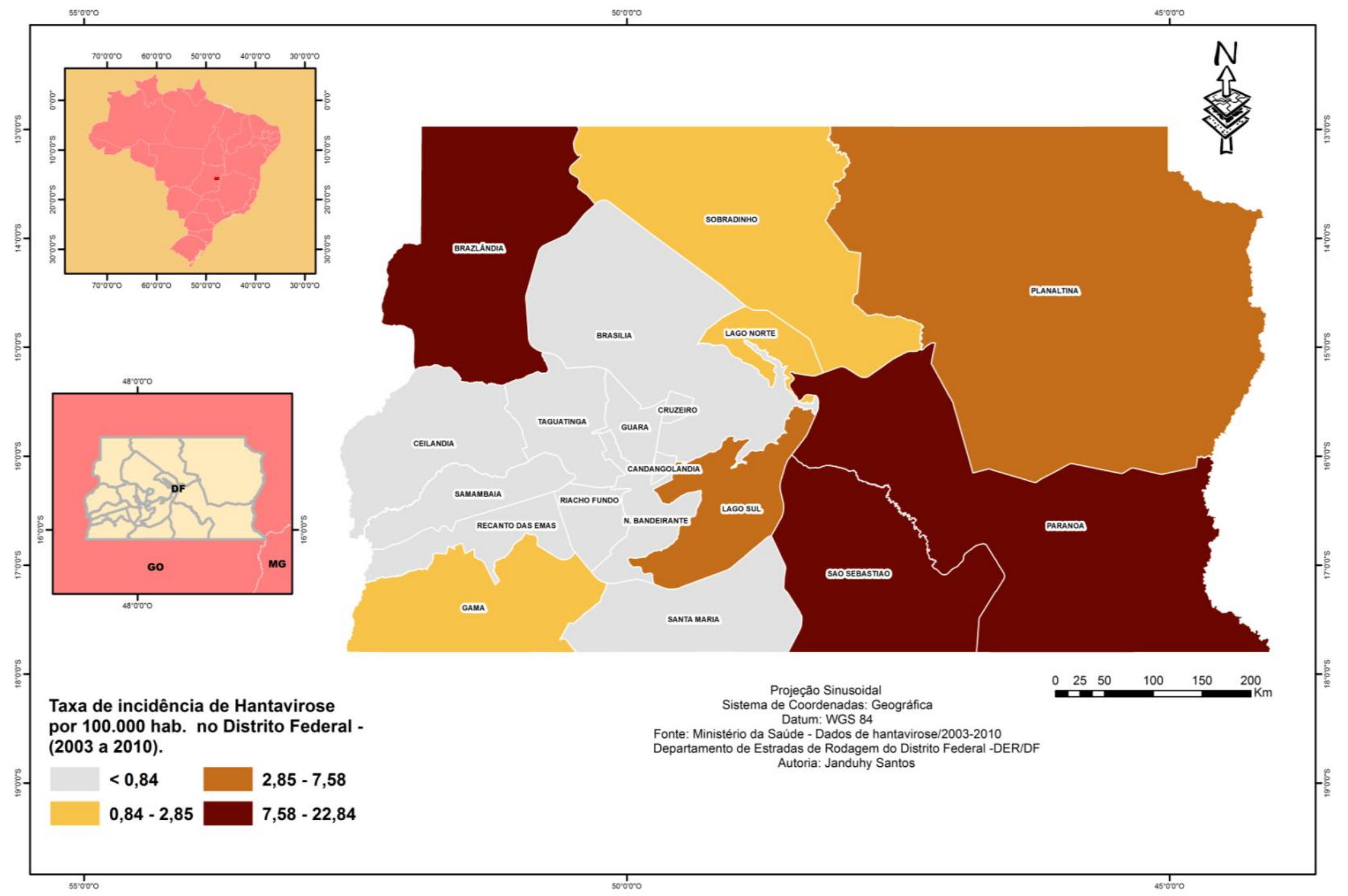

Figura 7 - Mapa da distribuição espacial da incidência de Hantavirose nas Regiões Administrativas no Distrito Federal - período 2003-2010. 
O Índice de Moran Global obtido para a incidência de Hantavirose no Distrito Federal foi igual a 0,208187 e $p$-valor $=0,06$. O valor do índice encontrado foi maior do que zero, o que sugere uma autocorrelação espacial, ou seja, apresentando áreas que possuam alguma similaridade entre si em relação à incidência da Hantavirose, conforme a sua posição em relação aos quadrantes do Diagrama de Espalhamento de Moran (vide Figura 8, a seguir).

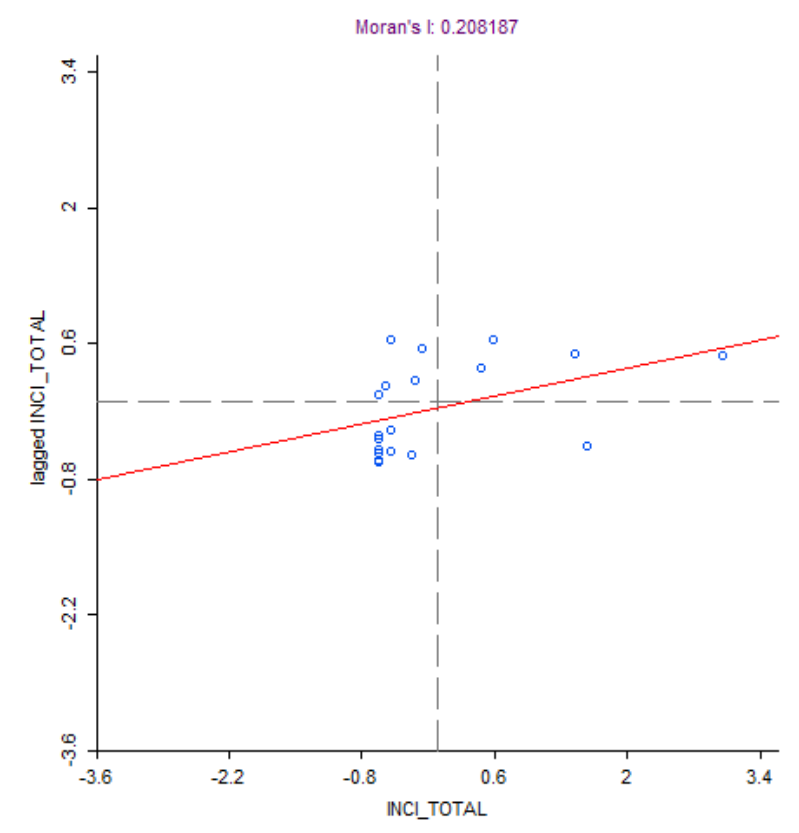

Figura 8 - Diagrama de espalhamento de Moran da incidência de Hantavirose no Distrito Federal.

O Diagrama de Espalhamento Moran da referida área de estudo, conforme a figura apresentada anteriormente, aponta que o quadrante 1 (+/+) indica 04 (quatro) RAs que possuem valores normalizados positivos e médias positivas, a saber: 1) Lago Sul; 2) Paranoá; 3) Planaltina; e, 4) São Sebastião. Alem disso, 09 (nove) RAs estão situadas no quadrante 2 (/-), ou seja, valores normalizados negativos e médias negativas, quais sejam: 1) Candagolândia; 2) Cruzeiro; 3) Guará; 4) Gama; 5) Núcleo Bandeirante; 6) Samambaia; 7) Taguatinga; 8) Recanto das Emas; e, 9) Riacho Fundo. No quadrante 3 (+l-) têm-se somente 01 (uma) RA (Brazlândia) com valores normalizados positivos e médias negativas. E no quadrante $4\left(-I_{+}\right)$apresentam-se os valores normalizados negativos com médias positivas das seguintes RAs: Brasília, Ceilândia, Lago Norte, Santa Maria e Sobradinho.

Diante do exposto, o mapa da Figura 9, a seguir, apresenta os resultados do Diagrama de Espalhamento de Moran com o uso do LISA. 


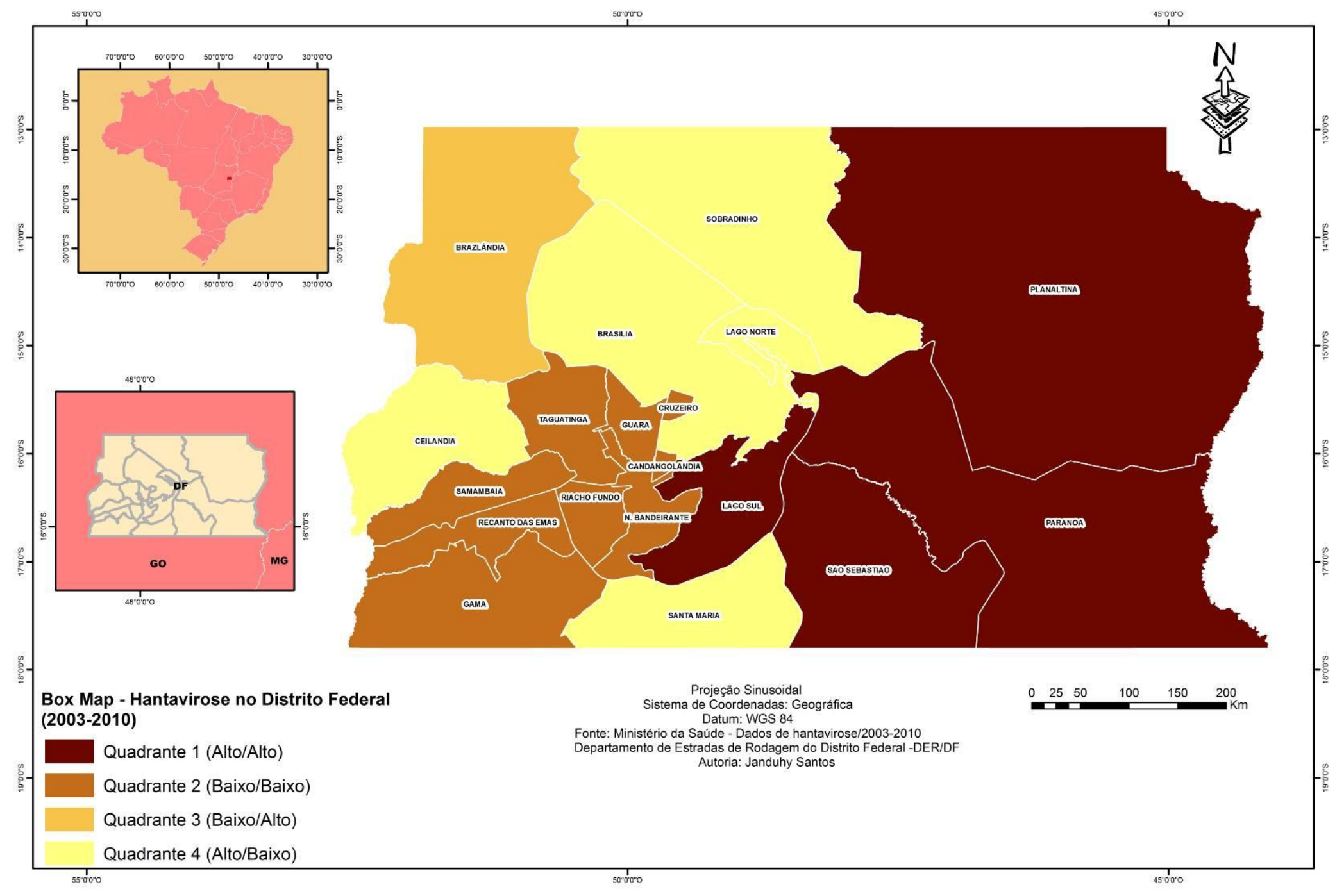

Figura 9 - Box Map do Índice Global de Moran da incidência de Hantavirose no Distrito Federal. 
De acordo com a figura apresentada anteriormente, as RAs encaixadas no quadrante 1 $(+/+)$ apresentaram uma correlação espacial positiva, formando, assim, um cluster com um eixo no sentido nordeste a sudeste do Distrito Federal. As RAs do Paranoá e de São Sebastião apresentaram as maiores taxas de incidência de Hantavirose; consequentemente, maior influência na média geral nos seus vizinhos. Também as RAs do Lago Sul e de Planaltina apresentaram homogeneidade em relação às outras regiões mencionadas e com forte dependência espacial, denotando, assim, maior prioridade para o controle da Hantavirose.

O quadrante 2 (-/-) do mapa aponta que as RAs localizadas a sudoeste do Distrito Federal (Candagolândia, Cruzeiro, Guará, Gama, Núcleo Bandeirante, Samambaia, Taguatinga, Recanto das Emas e Riacho Fundo) apresentaram associação espacial negativa; ou seja, são áreas com nenhuma significância estatística na incidência de Hantavirose.

A RA de Brazlândia, representada no quadrante 3 (+/-), apresentou resultado com tendência global na sua significância estatística, ou seja, uma transição entre as regiões com associação espacial positivas e as regiões com associação espacial negativa.

Em relação ao quadrante $4(-/+)$, as RAs que apresentaram valores normalizados negativos em relação aos seus vizinhos apesar de terem médias positivas localizam-se na área central da UF analisada (Brasília e Lago Norte), norte (Sobradinho), sul (Santa Maria) e oeste (Ceilândia) do Distrito Federal. Tanto a região do quadrante 3 (+/-) como as RAs no quadrante $4(-/+)$ apresentaram significância espacial à Hantavirose.

No mapa exposto na Figura 10, a seguir, tem-se a formação de hot spot e também de agrupamentos de Cold Spots através do uso do algoritmo Getis-Ord Gi* com objetivo da busca de clusters espaciais estatisticamente significativos nas RAs do Distrito Federal. 


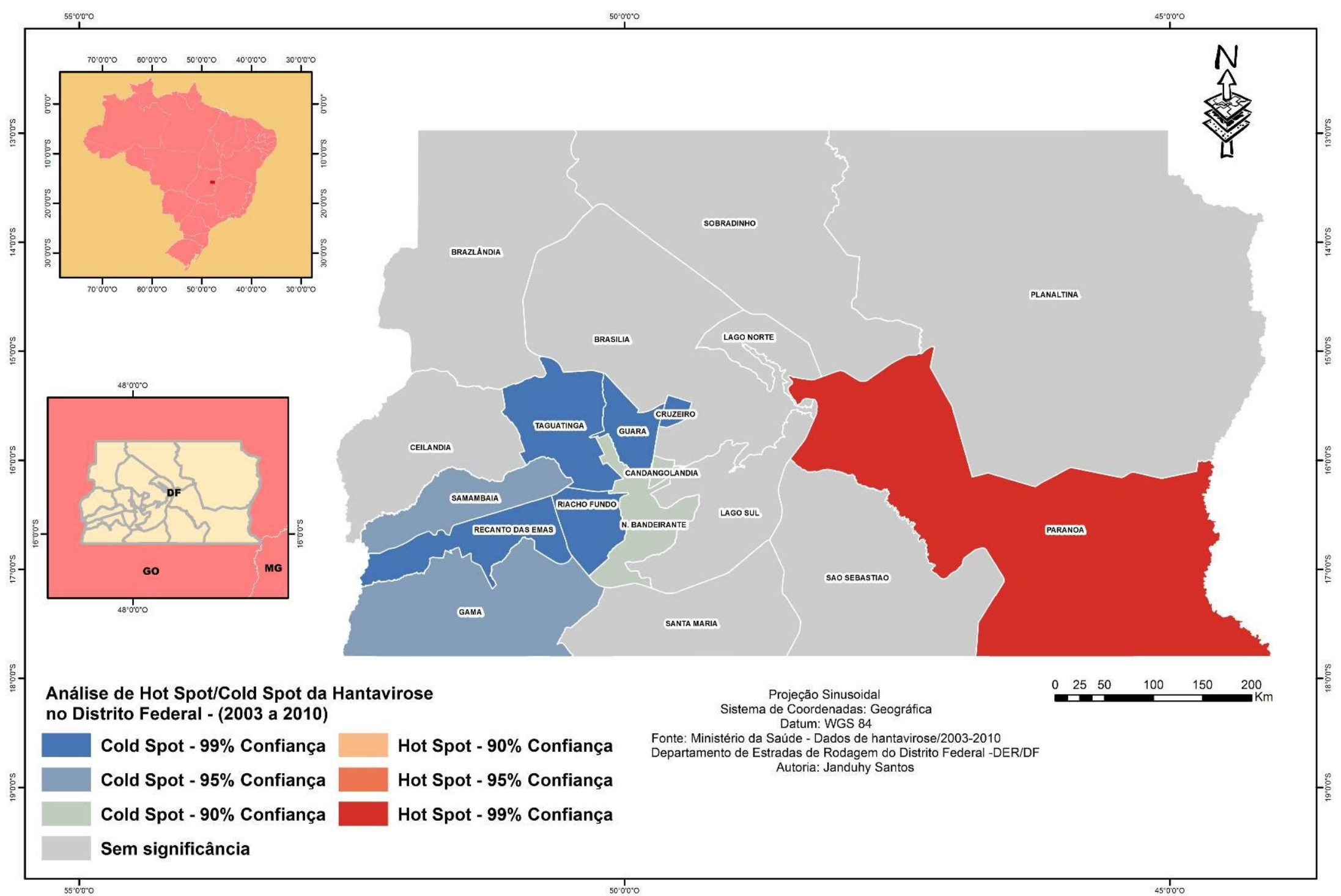

Figura 10 - Mapa de análise espacial com o indicador Getis-ord $G i^{*}$ da incidência de Hantavirose no Distrito Federal. 
Das 19 RAs oficiais existentes no Distrito Federal, observadas através da análise espacial com o Getis-ord Gi*, tem-se somente a RA do Paranoá como hot spot, que apresentou grau de confiança de $99 \%$ e significância estatística de $p$-valor $<0.01$. As RAs de São Sebastião e Planaltina, que foram identificas como áreas de prioridade no Índice de Moran, não tiveram representação na análise da técnica mencionada.

Diferentemente do que ocorre no Estado de Goiás foram identificados "bolsões" de agrupamentos cold spots no Distrito Federal, caracterizados por scores negativos e com os valores de probabilidade baixos. Assim, tais áreas são consideradas áreas que oferecem baixo risco para a Hantavirose. A sua identificação é semelhante ao que se dá no Box Map da Figura 9, onde é possível observar que as RAs que se encontram no quadrante 2 (-l-) apresentam associação espacial negativa e, portanto, assemelham-se com o padrão de distribuição espacial do mapa da Figura 10.

\subsection{DISCUSSÃO}

$\mathrm{Na}$ análise dos resultados obtidos por meio do Índice de Moran Global, com base na análise espacial da incidência de Hantavirose no Estado de Goiás, demonstrou-se a não evidência de dependência espacial no território goiano. Mostrou-se visível, através do Diagrama de Espalhamento de Moran (Figura 5), que não se tem nenhum Município localizado no quadrante $1(+\mid+)$, assim como nos quadrante $3(+/-)$ e quadrante $4(-/+)$. Neste sentido, os resultados evidenciaram a ausência de correlação espacial significativa.

Contudo, os resultados demonstrados na Figura 6 identificaram 02 (dois) bolsões de hot spots em 02 (duas) áreas do Estado de Goiás, onde uma encontra-se nas proximidades do Distrito Federal. Os dois "bolsões" identificados estão em áreas com um forte dinamismo econômico representados por atividades agropecuárias comerciais e subsistência (esta última, com base no cultivo de milho, arroz, feijão e cana-de-açúcar, além do cultivo do capim braquiária para alimentação de gado leiteiro) (ADAMI et al., 2012; AB'SABER; JUNIOR, 2010), bem como apresentam atividades significativas em ecoturismo que possibilitam maior chance de exposição ao hantavírus em razão das atividades laborais e de lazer em áreas rurais e silvestres.

Os Municípios de Buriti de Goiás e Campo Alegre de Goiás formaram o "centro de gravidade" dos "bolsões" supramencionados, uma vez que ambos apresentaram as maiores taxas de incidência (Figura 4), obtendo, assim, resultados significativos para os Municípios vizinhos, conforme a análise de Hot Spot através do indicador Getis-ord Gi*. 
A análise espacial da incidência espacial da Hantavirose no Distrito Federal permitiu a obtenção dos 02 (dois) resultados consideráveis tanto no Índice de Moran Global como na análise de Hot Spot. Apesar do índice não ter sido alto (Figura 8) para afirmar a existência de uma força de correlação espacial, é possível apontar uma evidência desta correlação que não pode ser descartada.

As RAs posicionadas no quadrante $1(+/+)$ (Paranoá, Planaltina e São Sebastião) (Figura 9) apresentaram características similares em relação aos padrões de uso da terra devido aos elevados índices de desmatamento provocados pela expansão agrícola e a contínua formação de assentamentos rurais destinados à agricultura familiar (SANTOS, 2014). Nas referidas localidades, Oliveira et al. (2012) verificaram que as condições de moradia - fator aliado à falta de cuidados básicos de limpeza e prevenção pelos moradores - sugerem alta vulnerabilidade para transmissão de hantavírus no local. Apesar do conhecimento, por parte dos moradores, da ocorrência da doença e de registros de casos e óbitos nestes ambientes, os mecanismos de prevenção da Hantavirose devem ser mais bem explorados em trabalhos educativos, a fim de estimular a comunidade a praticar as medidas preventivas.

O Índice de Moran aponta que a RA de Brazlândia, situada no quadrante 3 (+/-), apresenta também aspectos ecoepidemiológicos semelhantes às RAs do quadrante $1(+/+)$, merecendo, assim, relevante atenção na vigilância da Hantavirose.

Com certa frequência, tem se observado, em áreas hoje consideradas urbanas no Distrito Federal, a presença de roedores silvestres dos gêneros Oligoryzomys e Necromys reservatórios de hantavírus. As espécies supramencionadas, amplamente distribuídas no Brasil, conseguem manter suas populações, mesmo em pequenos fragmentos de vegetação, o que tem preocupado as autoridades de saúde diante da possibilidade de infecções em áreas urbanas e periurbanas (OLIVEIRA et al., 2013).

A estatística espacial demonstrada no algoritmo $G i^{*}$ aponta um comportamento diferente ao Índice de Moran, uma vez que somente a área que apresenta resultado estatisticamente significativo é a RA do Paranoá, indicando certo padrão na distribuição espacial do agravo. 


\subsection{CONSIDERAÇÕES FINAIS}

O estudo da dependência espacial da Hantavirose é de grande importância na compreensão da distribuição regional do hospedeiro e do patógeno, pois tal distribuição tem relação com os fatores ambientais e antropogênicos, o que reforça a necessidade de estudos contínuos sobre os impactos nos ecossistemas, no intuito do entendimento dos padrões espaciais e temporais das ocorrências da doença em estudo. Esta afirmação tem como fundamento o fato de que as atividades humanas (envolvendo as áreas sociais e culturais) em interação com o meio ambiente podem propiciar a disseminação de vírus, como, por exemplo, o hantavírus, devido ao intenso processo de degradação ambiental causado pela expansão urbana, das atividades agropastoris, da garimpagem, do ecoturismo e outros aspectos.

Ademais, um fator de grande importância no estudo da Hantavirose é a compreensão da dinâmica do uso da terra, pois as formas de uso e ocupação da terra no cerrado e, em especial, em áreas atingidas pela enfermidade em estudo merecem uma análise espacial em uma maior escala em razão da redução da biodiversidade do bioma Cerrado.

O presente estudo teve como limitação a utilização de dados secundários de um sistema de vigilância passivo do Ministério da Saúde, onde parte das informações podem estar subnotificadas. Neste sentido, faz-se necessário a realização de estudos aplicados aos Municípios do Estado de Goiás e as RAs do Distrito Federal, o que possibilitaria um olhar detalhado destes ambientes, onde foram constatados os clusters de importância para Hantavirose e, se possível, aliar a outras ferramentas estatísticas e epidemiológicas que poderiam ajudar a explicar e validar estes resultados.

O isolamento da variante Paranoá em pacientes com Hantavirose provenientes da área identificada como cluster também levanta a hipótese de que esta cepa possa ser a causa de casos com clínica diferenciada de outras áreas do cerrado no Distrito Federal, atentando para a necessidade da continuação de estudos moleculares dos hantavírus destas áreas.

Contudo, o uso de técnicas de estatística espacial, como, por exemplo, o Índice Global de Moran e o algoritmo Getis-ord $G^{*}$, revelaram-se de fundamental importância na análise do padrão espacial da Hantavirose no Estado de Goiás e no Distrito Federal. Com o uso destas ferramentas percebem-se novos agrupamentos espaciais, que não são identificados pelos estudos epidemiológicos descritivos e analíticos usuais e que, assim, merecem uma análise mais detalhada do fenômeno. 


\subsection{REFERÊNCIAS BIBLIOGRÁFICAS}

AB'SABER, Aziz Nacib; JÚNIOR, M. Costa. Contribuição ao estudo do Sudoeste Goiano. In: MODENESI-GAUTTIERI et al. (ORG.). A Obra de Aziz Nacib Ab'Saber. São Paulo: Ed. BECA, 2010.

ADAMI, M.; MELlO, M. P.; AGUIAR, D. A.; RUDORFF, B. F. T.; SOUZA, A. F. A Web platform Development to Perform Thematic Accuracy Assessment of Sugarcane Mapping in South-Central Brazil. Remote Sensing. 2012, 4, 3201-3214. doi: <10.3390/rs4103201>.

CÂMARA, G. et al. Análise espacial de áreas. In: DRUCK, S. et al. (Org.). Análise espacial de dados geográficos. Embrapa. 2004, pp. 206.

CASTRO, M. C.; SINGER, B. H. Environment and Health: a methodological approach for spatial assessment of malaria transmission in colonization projects in the Brazilian Amazon. Revista Brasileira de Estudos de População, v. 24, n. 2, p. 247-262, 2007.

CENTRO UNIVERSITÁRIO DE ESTUDOS E PESQUISAS SOBRE DESASTRES. Atlas brasileiro de desastres naturais 1991 a 2010. Volume Brasil. 2011.

CROMLEY, E.K; McLAFFERTY, S.L. GIS and Public Health. In: Analyzing Sptail Clustering of Health Events. The Guilford Press. 2002, pp. 340.

DISTRITO FEDERAL. Plano Diretor de Ordenamento Territorial do Distrito Federal PDOT. Secretaria de Estado de Desenvolvimento Urbano e Meio Ambiente do Distrito Federal. Brasília, 2009.

DRUCK, S; CARVALHO, M.S; CÂMARA, G; MONTEIRO, A.M.V. Análise espacial de dados geográficos. Embrapa. 2004, pp. 206.

ENVIRONMENTAL SYSTEMS RESEARCH INSTITUTE. Documentation Manual. Redlands, 2011.

FANG, L.Q. et al. Spatiotemporal Dynamics of Hemorragic Fever with Renal Syndrome, Beijing, People's Republic of China. Emerging Infectious Disease. Vol. 15, nº 12, 2009.

GETIS, A; ORD, J. K. The analysis of spatial association by use of distance statistics. Geographical analysis, v. 24, n. 3, p. 189-206, 1992.

INSTITUO MAURO BORGES DE ESTATÍSTICAS E ESTUDOS SOCIOECONÔMICOS. Goiás em Dados, 2012. Goiânia. Disponível em: <http://www.imb.go.gov.br/>. Acesso em 05 dez. 2013.

INSTITUTO BRASILEIRO DE GEOGRAFIA E ESTATÍSTICA. Censo demográfico 2010. Rio de Janeiro: IBGE, 2012.

INSTITUTO NACIONAL DE PESQUISAS ESPACIAIS. O projeto Terraview. São José dos Campos, 2008.

LAI, P.C.; SO, FM.; CHAN, KW. Spatial Epidemiological Approaches in Disease Mapping and Analysis. In: Areal Methods of Disease Analysis. CRC press. 2009. 
MARQUES, A.P.S. et al. Análise exploratória de dados de área para índices de furto na mesorregião de Presidente Prudente-SP. In: III Simpósio Brasileiro de Ciências Geodésicas e Tecnologias da Geoinformação. Recife - PE, 27-30 de Julho de 2010. pp. 001 - 008.

MINISTÉRIO DA SAÚDE, Hantaviroses: Situação Epidemiológica - Dados. Disponível em: 〈http://portal.saude.gov.br/>. Acesso em: 09 jan. 2014.

MINISTÉRIO DA SAÚDE. Surto da síndrome cardiopulmonar por hantavírus no Distrito Federal e Goiás - maio a setembro de 2004. Boletim eletrônico epidemiológico, $\mathrm{n}^{\circ}$ 01, 2005. Disponível em: <http://portalsaude.saude.gov.br/images/pdf/2014/julho/15/Ano05n01-surto-scp-hantavirus-df-completo.pdf> Acesso em: 10 abr. 2014.

MINISTÉRIO DA SAÚDE. Secretaria de Vigilância em Saúde. Introdução à Estatística Espacial para a Saúde Pública. Texto Básicos de Saúde. Brasília, 2007.

MOORE, D. A; CARPENTER, T.E. Spatial analytical methods and geographic information systems: use in health research and epidemiology. Epidemiologic reviews, v. 21, n. 2, p. 143$161,1999$.

NUNES, F. G. Análise exploratória espacial de indicadores de desenvolvimento socioambiental das regiões de planejamento do norte e nordeste goiano. Ateliê Geográfico, v. 7, n. 1, 2013.

OLIVEIRA, S.V. Análise preditiva da distribuição geográfica de hantavírus no Brasil. Dissertação (mestrado) - Universidade de Brasília, Faculdade de medicina, Pós-Graduação em Medicina Tropical, 2013. 129 pp.

OLIVEIRA, S.V. et. al. Conhecimentos, atitudes e práticas sobre hantavirose em um assentamento rural de Planaltina-Distrito Federal. Sciencia Plena. Vol 8, 2012.

ROSS, J.L.S. Ecogeografia do Brasil. Subsídios para Planejamento Ambiental. Ed. Oficina de Textos. São Paulo, 2006.

ROUQUAYROL, M.Z. Medidas de Saúde Coletiva. In: Epidemiologia e Saúde. $7^{\text {a }}$ Ed. Editora Med Book. Rio de Janeiro. 736p.

SANTOS, J. P. Aspectos geoambientais e epidemiológicos em áreas de transmissão da Hantavirose no Distrito Federal, 2009. p.89. Dissertação de Mestrado. Universidade de Brasília, Brasília.

SANTOS, J. P. et al. Análise da distribuição espacial da hantavirose no Distrito Federal, Brasil, 2004-2010. Hygeia, v. 10, n. 18, p. 98-109, 2014.

SECRETARIA DE ESTADO DE SAÚDE DE GOIÁS. Mapa da saúde de Goiás. Goiânia, 2014. Disponível em: < http://www.saude.go.gov.br>. Acesso em: 09 nov. 2014

UNIVERSITY OF ILLINOIS. GeoDa 0.9 user's guide. v. 51, p. 618, 2003.

WEI, L. et al. Using Geographic Information System-based Ecologic Niche Models to Forecast the Risk of Hantavirus Infection in Shandong Province, China. American Journal Tropical Medicine Hygiene, vol. 84, 2011.

YAN, L. et al. Landscape Elements and Hantaan Virus-related Hemorrhagic Fever with Renal Syndrome, People's Republic of China. Emerging Infectious Diseases. vol, 13, nº 9, 2007. 


\title{
CAPÍTULO 5
}

\section{A DINÂMICA DO USO E DA COBERTURA DA TERRA NA REGIÃO INTEGRADA DE DESENVOLVIMENTO DO DISTRITO FEDERAL E GOIÁS (RIDE-DF) E A HANTAVIROSE. \\ RESUMO}

A Hantavirose possui uma epidemiologia de muitas nuances com mudanças ambientais de origem antrópica. Assim, é possível perceber a necessidade de compreensão, a nível regional e local, das possíveis contribuições que as mudanças antrópicas trouxeram em relação àquela enfermidade para o Distrito Federal e seu entorno. Neste sentido, o presente estudo analisou as categorias de uso e cobertura da terra existentes na Região Integrada de Desenvolvimento do Distrito Federal e Entorno (RIDE-DF), tendo em vista a avaliação estatística da influência destas categorias na dinâmica da Hantavirose. Através do uso do Sistema de Informações Geográficas (SIG) e de testes estatísticos, como, por exemplo, o odds ratio e o qui-quadrado, foi possível avaliar a distribuição espaço-temporal da Síndrome Cardiopulmonar por Hantavírus (SCPH). Dados secundários de casos de SCPH referentes ao período 2004-2010 permitiram identificar 14 locais de ocorrência do agravo no entorno e 49 locais no Distrito Federal. Observou-se ainda nas análises que no Distrito Federal, as classes de uso - as áreas urbanas $(\mathrm{OR}=2.9)$ e as lavouras temporárias $(\mathrm{OR}=2.3)$ - que apresentaram medidas de associação significativas. Os resultados do teste Qui-quadrado apontou que os efeitos antrópicos são estatisticamente mais significativos no Distrito Federal $\left(\chi^{2}=9,5\right)$ do que em sua região de entorno $\left(\chi^{2}=1,8\right)$. Assim, o antropismo tem um peso importante na dispersão da Hantavirose na RIDE-DF.

Palavras-chave: Hantavirose. Uso da terra. Análise espacial.

\begin{abstract}
The Hantavirus has an epidemiological many nuances with environmental changes of anthropogenic origin. So, you can see the need for understanding, regional and local level, the possible contributions that anthropogenic changes brought in relation to that disease for the Federal District and its surroundings. In this sense, the present study analyzed the categories of use and land cover in the Region Integrated Development of the Federal District and surrounding areas (RIDE-DF), with a view to statistical evaluation of the influence of these categories in the dynamics of Hantavirus. Through the use of Geographic Information System (GIS) and statistical tests, for example, the odds ratio and the chi-square, it was possible to evaluate the spatial and temporal distribution of Hantavirus Pulmonary Syndrome (HPS). Secondary data of cases of HPS for the period 2004-2010 have identified 14 of the grievance occurrence sites in the surrounding area and 49 locations in the Federal District. It was also noted that the analysis in the Federal District, using classes - urban areas (OR = 2.9) and temporary crops $(\mathrm{OR}=2.3)$ - that showed significant association measures. The results of the chi-square test indicated that the anthropogenic effects are statistically more significant in the Federal District $(\chi 2=9.5)$ than in its surrounding region $(\chi 2=1.8)$. So the anthropism is an important factor in the spread of Hantavirus in RIDE-DF.
\end{abstract}

Keywords: Hantavirus. Land use. Spatial analysis. 


\subsection{INTRODUÇÃO}

Wu et al. (2014) detalham que sob os impactos dos eventos de origem natural e humana, os padrões de transmissão de algumas doenças infecciosas têm se alterado. Tanto os fatores naturais (como, por exemplo, a temperatura, a umidade, a pluviosidade e a vegetação) e os fatores antropogênicos (as diversas formas de uso da terra) influenciam direta ou indiretamente os surtos e a disseminação destas doenças.

Como exemplo dos fatores de origem natural, observam-se os eventos climáticos que produziram resultados drásticos para a saúde pública, como, por exemplo, o episódio analisado por Acuna-Soto et al. (2002), que realizou estudos epidemiológicos de uma febre hemorrágica conhecida como Cocoliztli, que, em 1545, atingiu a população nativa do México. Segundo aqueles autores, esta doença foi associada a uma forte estiagem que atingiu drasticamente a região e, assim, proporcionou o aumento de roedores, que eram reservatórios de um agente patogênico, causando a morte de milhares de pessoas durante o século XVI.

Outro exemplo foi a passagem do furacão Mitch na Guatemala e em El Salvador, em 1998, que provocou a morte de 9.600 pessoas, além de um surto de malária, em virtude da formação criadouros para o vetor deste agravo (FOLEY et al., 2005). Ademais, Glass et al. (2007) e Patz et al. (2008) reforçaram também a questão da influência de eventos climáticos na disseminação de doenças, como, por exemplo, no fenômeno do El Ninõ de 1992, que desencadeou um surto de Hantavirose no sudoeste dos Estados Unidos da América (EUA) e a ocorrência de surtos epidêmicos de malária na região do Punjab, Índia, em decorrência do excesso de chuvas das monções.

Ainda Patz et al. (2008) demonstraram que os surtos de cólera em Bangladesh estavam associados também ao fenômeno climático ENSO (Oscilação do Sul), que propiciava o aquecimento das águas do mar e que, por sua vez, favorecia o aumento da floração de algas que permitem alojar a bactéria Vibrio sp., contaminando, assim, os crustáceos e os moluscos (frutos do mar) que eram consumidos pela população, desencadeando surtos de cólera e também outras doenças entéricas.

Um dos efeitos da intervenção humana na natureza é a alteração na diversidade das comunidades de plantas, animais e microrganismos. Esta alteração pode ser representada por alguns fatores, quais sejam: redução da biodiversidade, introdução de espécies exóticas, poluição ambiental, surgimento de doenças contagiosas transmitidas por vetores e reservatórios e outros aspectos. Tal intervenção se dá principalmente pela implantação de 
pastagens, agricultura e reflorestamentos monoespecíficos, mas também pela eliminação de áreas naturais para dar lugar às zonas urbanas, hidrelétricas, estradas e atividades de mineração.

Neste sentido, Brearley et al. (2013) descrevem que o uso da terra já alterou mais de $75 \%$ da superfície terrestre, acarretando no declínio da biodiversidade em todo o mundo. Estas alterações, conforme aqueles autores, provocaram impactos na saúde pública. Também Gottdenker et al. (2014) descrevem que as mudanças ambientais de origem antrópica causam impactos negativos nas estruturas dos ecossistemas por perturbar os ciclos biogeoquímicos terrestres e aquáticos e, assim, alterando as propriedades daqueles ecossistemas; e ainda, introduzindo espécies não nativas e agentes patogênicos à saúde humana e animal.

Vazquez-Prokopec et al. (2006) detalham que o desequilíbrio ambiental gerado pelo desmatamento favoreceu o contato da população de triatomíneos e, consequentemente, a disseminação da doença de Chagas na região do Chaco, Argentina. Na mesma tendência, observa-se o trabalho de Estrada-Penã et al. (2014), onde a exposição ao carrapato Ixodes scapularis - reservatório da bactéria Borrelia burgdorferi, causadora da doença de Lyme apresentou aumento dos casos da doença em razão da fragmentação das áreas florestais na América do Norte.

A Hantavirose apresenta uma epidemiologia que possui correlação com as mudanças ambientais de origem antrópica. Neste sentido, Lambin et al. (2010) abordaram a Epidemiologia Paisagística da Hantavirose na Bélgica destacando a seguinte questão: em ambientes alterados por práticas agrícolas têm-se maior abundância de roedores reservatórios contaminados do que em áreas silvestres. Já Goodin et al. (2006) realizaram a correlação entre o uso e a cobertura da terra e os casos de Hantavirose no Paraguai, onde perceberam que as áreas destinadas à agricultura são as mais propensas ao desenvolvimento da patologia.

No Brasil, têm-se os trabalhos pioneiros de Santos et al. (2011), que analisaram os impactos do uso da terra e a Hantavirose no Distrito Federal, e Brito (2012), que fez um estudo da distribuição espacial da Hantavirose no Estado de Minas Gerais e sua relação com o uso da terra naquela região. Ambos os trabalhos mencionaram que os desmatamentos ocasionados pela agricultura, a suburbanização e outros aspectos têm influenciado a dispersão de roedores, acarretando no surgimento de surtos esporádicos de Hantavirose naquelas localidades. 
Santos et al. (2012) abordaram os impactos da rodovia BR-163 (Cuiabá-Santarém) sobre o meio ambiente ao longo da rodovia e perceberam que as alterações espaciais relatadas colaboraram também no aumento dos casos de Hantavirose. Neste sentido, têm-se aí um esforço na compreensão dos processos espaciais que interferem no ciclo das doenças infecciosas transmitidas por animais vetores e reservatórios de patógenos dos hantavírus presentes no território nacional.

Santos (2008) abordou o fato de que os espaços naturais vêm sendo substituídos por ambientes artificiais que trazem consequências à saúde pública, uma vez que tais ambientes tornaram-se ambientes hostis. Trazendo para a questão da Hantavirose, é possível observar que para aquele autor, o espaço habitado alcançou uma situação-limite, onde o processo destrutivo pode se tornar irreversível. Neste sentido, na medida em que o uso do solo se torna especulativo, maiores serão os efeitos sobre o ambiente e, por sua vez, sobre a biodiversidade.

A partir das referidas considerações é possível notar a necessidade de compreender, a nível regional e local, as possíveis contribuições que as mudanças antrópicas trouxeram em relação à Hantavirose para o Distrito Federal e sua região de entorno, formada por alguns Municípios dos Estados de Goiás e Minas Gerais, pois, conforme trabalhos descritos por Santos et al. (2011) e Oliveira et al. (2013), aquela região apresenta o mesmo ecossistema, além de quantidade considerável de casos Hantavirose, fazendo com que o Ministério da Saúde (2005) considere de suma importância os estudos dos fatores ecoepidemiológicos e socioeconômicos, como, por exemplo, a ocupação humana recente de áreas de cerrado ou o aumento da população de roedores reservatórios nestas áreas.

Diante do exposto, o presente estudo teve como objetivo analisar as categorias de uso e cobertura da terra presentes na Região Integrada de Desenvolvimento do Distrito Federal e Entorno (RIDE-DF), período 2004-2010, tendo em vista avaliar espacialmente a influência destas categorias na dinâmica da Hantavirose e, assim, subsidiar as ações de saúde pública para o controle do agravo. 


\subsection{MATERIAIS E MÉTODOS}

\subsection{1 - Área de estudo}

A área analisada encontra-se entre os meridianos $47^{\circ} 00^{\prime}$ e $49^{\circ} 00^{\prime}$ de longitude oeste e os paralelos $15^{\circ} 00^{\prime}$ e $17^{\circ} 00^{\prime}$ de latitude sul, inserida na região conhecida como RIDE-DF, e abrange uma área de 55.402,2 $\mathrm{km}^{2}$. É constituída (Figura 1) pelo Distrito Federal, pelos Municípios de Abadiânia, Água Fria de Goiás, Águas Lindas de Goiás, Alexânia, Cabeceiras, Cidade Ocidental, Cocalzinho de Goiás, Corumbá de Goiás, Cristalina, Formosa, Luziânia, Mimoso de Goiás, Novo Gama, Padre Bernardo, Pirenópolis, Planaltina, Santo Antônio do Descoberto, Valparaíso de Goiás e Vila Boa, no Estado de Goiás, e pelas localidades de Unaí, Buritis e Cabeceira Grande, no Estado de Minas Gerais.

Segundo as informações provenientes do Ministério da Integração Nacional (MI) (2014), a RIDE-DF foi criada em 1998 pela Lei Complementar $n^{\circ}$ 94, de 19 de fevereiro de 1998, e regulamentada pelo Decreto $n^{\circ} 7.469$, de 04 de maio de 2011, com o objetivo de promover a articulação da ação administrativa da União, dos Estados de Goiás e de Minas Gerais e do Distrito Federal, a fim de reduzir as desigualdades regionais causadas pela alta concentração urbana decorrente do fluxo migratório entre o Distrito Federal e os municípios vizinhos, bem como a pressão existente em relação aos serviços públicos oferecidos pela capital do país.

Os recursos destinados a RIDE-DF visam promover o desenvolvimento global e destinam-se essencialmente a sistemas viários, transporte, geração de empregos, saneamento básico, educação, saúde, assistência social, cultura, entre outros. Porém, os resultados de suas políticas ainda não são notados e a realidade é que os problemas em sua área de abrangência têm se tornado cada vez mais graves (MINISTÉRIO DA INTEGRAÇÃO NACIONAL, 2014). 


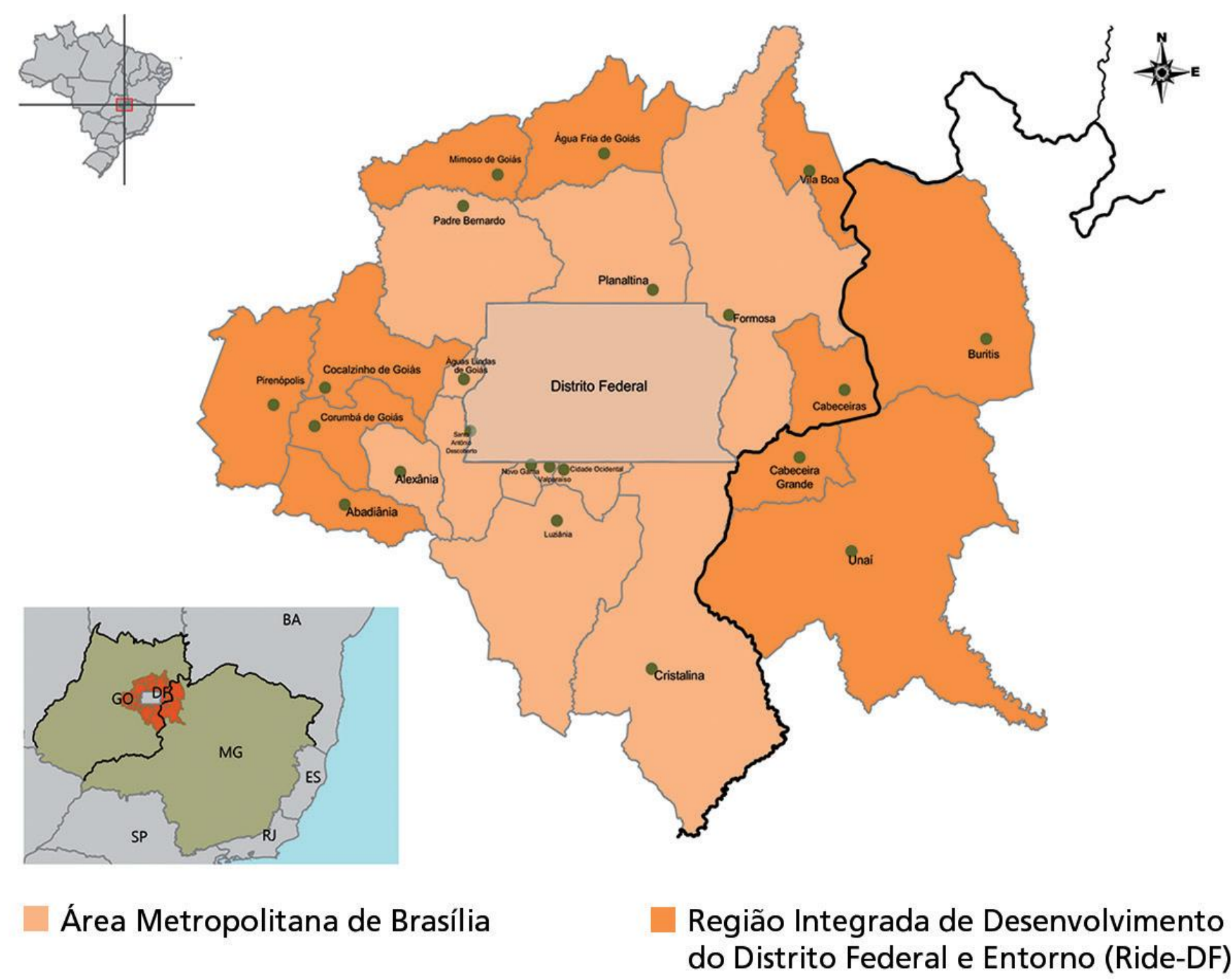

Figura 1 - Mapa de localização da Região Integrada de Desenvolvimento do Distrito Federal e Entorno (RIDE-DF). Fonte: Instituto Brasileiro de Geografia e Estatística (IBGE). Malha municipal 2010. Elaboração: Companhia de Planejamento do Distrito Federal (CODEPLAN). 
Para o Instituto de Pesquisas Econômicas Aplicadas (IPEA) (2014), em 2010, a RIDEDF possuía um grau de urbanização de $94,1 \%$. A população do município núcleo (Distrito Federal) desta correspondia, em 2010, a 69\% da população da região. A taxa de crescimento da população da RIDE-DF, entre 2000 e 2010, foi de 2,33\% ao ano.

Conforme o relatório da Companhia de Pesquisas de Recursos Minerais CPRM (2003), as atividades econômicas são fortemente influenciadas pela estrutura urbana do Distrito Federal. Assim, a indústria aparece de modo complementar e predominantemente de caráter terciário, com destaque para a indústria da construção civil como a maior responsável pela absorção da mão de obra local.

Ainda de acordo com o referido relatório, a agropecuária tem um papel relevante na economia da região do entorno do Distrito Federal. As maiores áreas de solo tem sua ocupação com a cultura de grãos e pastagem artificial, estando a fruticultura e a horticultura com áreas menores. Na pecuária, predomina a criação de bovinos, seguida por suínos e equinos, extensiva a toda a região, com destaque para os Municípios de Luziânia, Cristalina, Formosa e Pirenópolis. A agricultura varia desde a de subsistência até a de grandes culturas de cereais, em especial, soja, milho e feijão, bem como a produção de tomate. As grandes culturas comerciais são beneficiadas por irrigação do tipo pivô central, onde a lavoura tem se expandido em áreas anteriormente ocupadas por cerrado, em cujos solos se fazem uso de corretivos e fertilizantes para compensar as deficiências naturais (CPRM,2003).

Têm-se ainda a silvicultura: áreas de reflorestamentos com pinus, eucalipto e frutíferas (laranjas e bananas), que ocupam áreas desapropriadas e arrendadas por empresas. A extração mineral, concentrada no setor de materiais para a construção civil e insumos agrícolas, é modesta - além da exploração de argila, areia e brita para material de construção, o quartzito laminado constitui bem mineral largamente utilizado na construção civil como pedra de revestimento, pisos rústicos e fachada. 


\subsubsection{Procedimentos metodológicos}

O fluxograma esquemático apresentado na Figura 2, a seguir, detalha as etapas de realização do presente estudo. Neste sentido, têm-se a seleção de dados secundários provenientes de alguns bancos de dados governamentais que foram inseridos e analisados com o intuito de observar e compreender a dinâmica da Hantavirose na região analisada.

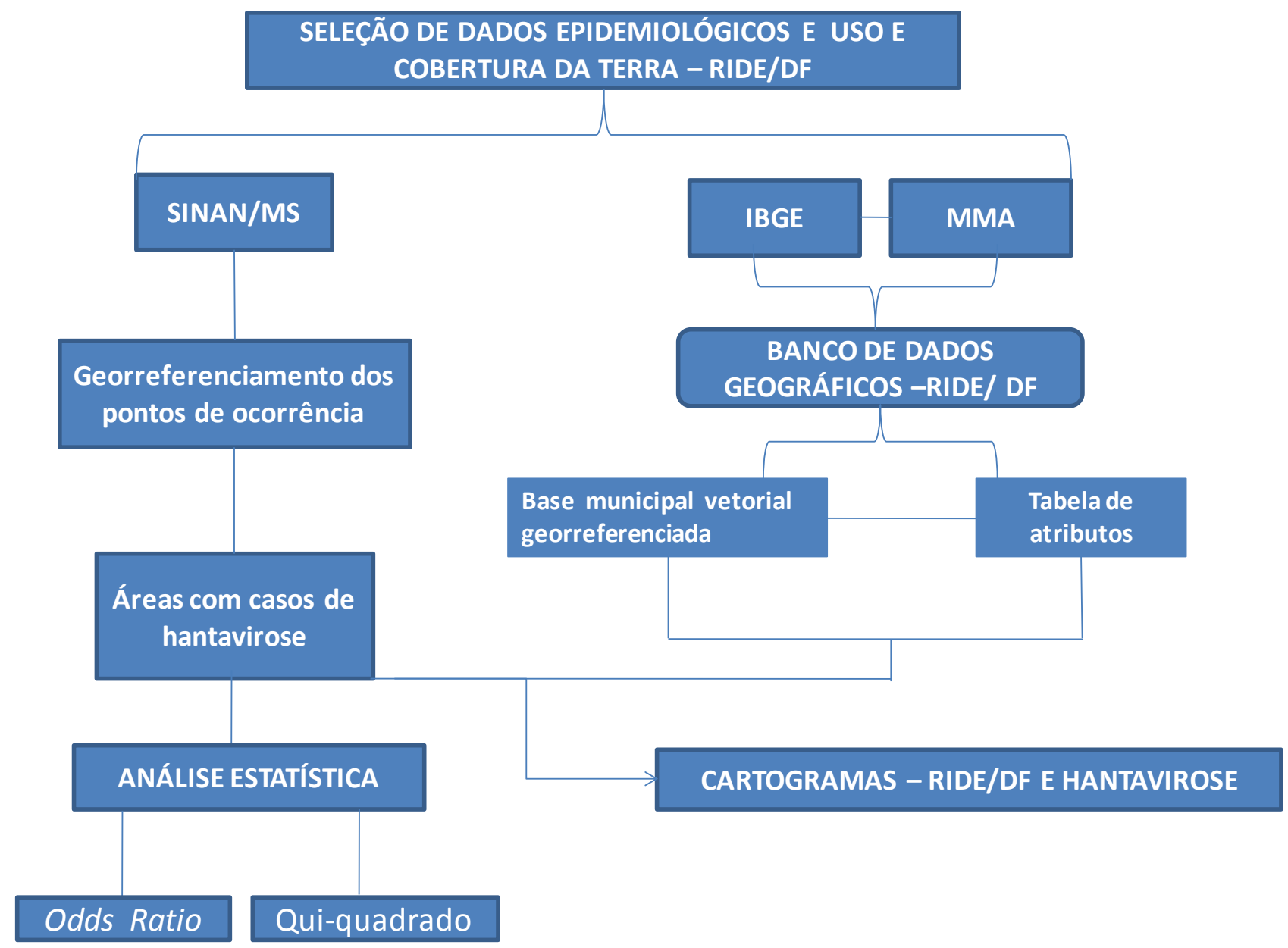

Figura 2 - Fluxograma dos procedimentos metodológicos do estudo. Elaboração: Janduhy Santos

Os dados epidemiológicos de casos de Hantavirose provenientes das fichas de notificação foram georreferenciados e sobrepostos nos mapas contendo a malha digital de uso e cobertura da terra da RIDE-DF com escala de 1:250.000, permitindo, assim, a elaboração de cartogramas, bem como a extração de informações de variáveis que foram analisadas por técnicas de estatística (odds ratio e o teste qui-quadrado), visando determinar a pressão que cada variável de uso ou cobertura da terra teve sobre a dispersão dos casos de Hantavirose. 


\subsubsection{Dados epidemiológicos}

A população do presente estudo foi constituída pela totalidade dos casos confirmados de Síndrome Cardiopulmonar por Hantavírus (SCPH) notificados ao MS dos Municípios integrantes (Entorno) da RIDE-DF e das Regiões Administrativas (RAs) do Distrito Federal no período 2004-2010 no Sistema de Informação de Agravos de Notificação (SINAN). As informações foram produzidas por um instrumento de coleta de dados, denominado de Ficha de Investigação Epidemiológica (FIE) de Hantavirose. Os dados do SINAN são gerados pelas Secretarias Municipais de Saúde (SMS), seguindo para as Secretarias Estaduais de Saúde (SES) e, posteriormente, enviadas para o âmbito nacional, para a área técnica das Hantaviroses, por meio eletrônico. Estes dados foram analisados em relação às possíveis duplicidades e incoerências, sendo que as tabulações foram efetuadas através do software Microsoft Office Excel $2007^{\circledR}$.

As fichas que tiveram todos os campos preenchidos foram aproveitadas com o intuito de determinar as áreas de ocorrências dos casos confirmados. Os dados reunidos foram organizados em planilhas do programa OpenOffice.org Calc ${ }^{\circledR}$ para georreferenciamento dos locais de ocorrência com as coordenadas latitude/longitude em graus decimais com o Datum World Geodetic System 84. A conversão no formato shapefile se deu pelo software ArcGIS, versão 10.2.2, desenvolvido pela Environmental System Research Institute ${ }^{\circledR}$.

Os dados obtidos analisaram 179 casos confirmados ocorridos nos Municípios dos Estados supramencionados, sendo possível determinar 66 áreas de ocorrência da infecção.

\subsubsection{Base cartográfica do uso e cobertura da Terra da Região Integrada de Desenvolvimento do Distrito Federal e Entorno.}

A base cartográfica digital do uso e da cobertura da terra foi obtida de 02 (dois) bancos de dados governamentais. Um dos bancos de dados utilizados foi o do Instituto Brasileiro de Geografia e Estatística (IBGE), que disponibilizou a malha digital (formato shapefile) dos Estados de Goiás, Minas Gerais e do Distrito Federal para composição do mapa da RIDE-DF, com sistema de coordenadas geográficas (latitude e longitude), escala de 1:1.000.000 e Datum em SIRGAS 2000 e posteriormente convertido para o Datum World Geodetic System 84. 
O outro banco de dados governamental foi obtido junto ao Ministério do Meio Ambiente (MMA), que realizou através do Departamento de Zoneamento Territorial a classificação de uso e da ocupação do solo através do diagnóstico físico-biótico do Zoneamento Ecológico e Econômico da RIDE-DF. O tema foi atualizado em 2007, a partir de imagens orbitais provenientes do sensor HRC (Câmera Pancromática de Alta Resolução) do satélite CBERS-2B do Instituto Nacional de Pesquisas Espaciais (INPE). As imagens no formato raster foram convertidas posteriormente no formato shapefile.

A malha digital possui um sistema de coordenadas geográficas (latitude e longitude), escala de 1:250.000 e Datum em South America 69 que posteriormente foi padronizado para o World Geodetic System 84.

Através da classificação supervisionada, foi possível a discriminação das seguintes classes: antrópicas (aeroporto, área urbana, estação de tratamento de esgoto, lavoura temporária, lavoura permanente, pastagem e vegetação secundária, pivô e reflorestamento) e não antrópicas (floresta galeria, lago, savana florestada, savana parque, savana parque/floresta sazonal montana, savana parque/gramínea-lenhosa, savana parque/savana arborizada, savana parque/savana floresta e solo exposto).

Para o tratamento, a organização e a interação dos dados numéricos e gráficos em ambiente de Sistemas de Informações Geográficas (SIG) foi utilizado o software ArcGIS, versão 10.2. ${ }^{\circledR}$, desenvolvido pela Environmental System Research Institute (ESRI).

\subsubsection{Análise estatística}

\section{Análise de Odds Ratio}

Para a análise estatística da associação das variáveis de cobertura da terra com os casos de Hantavirose na área de estudo optou-se pela análise de Odds Ratio ou Razão de Chances, cujo teste avalia as proporções dispostas em tabela de contingência 2 × 2 , ou seja, para 02 (duas) amostras dicotomizadas, mensuradas a nível nominal, onde se tem o cálculo da vantagem (ou desvantagem) de um dos eventos - sucesso - em relação ao outro (AYRES et al., 2007). 
Se as probabilidades de um evento em cada um dos grupos forem $p$ (primeiro grupo) e $q$ (segundo grupo), então, a razão de chances se dá como se segue:

$$
\frac{p /(1-p)}{q /(1-q)}=\frac{p(1-q)}{q(1-p)}
$$

Uma razão de chances de 1 indica que a condição ou evento sob estudo é igualmente provável de ocorrência nos dois grupos. Uma razão de chances maior do que 1 indica que a condição ou evento tem maior chance de ocorrer no primeiro grupo. Finalmente, uma razão de chances menor do que 1 indica que a probabilidade é menor no primeiro grupo do que no segundo grupo.

Análise de Odds Ratio no estudo de caso e controle entre a variável de uso e cobertura da terra com casos de hantavirose e a quantidade de áreas dessa variável e a variável de uso e cobertura da terra, com casos de hantavirose e sem a quantidade de áreas, no mesmo período. Para a realização desta análise, o software utilizado foi o BioEstat, versão $5.0^{\circledR}$, desenvolvido pela Universidade Federal do Pará (UFPA).

\section{Análise pelo teste de Qui-quadrado $\left(\chi^{2}\right)$}

É um teste não paramétrico, ou seja, os parâmetros média e desvio-padrão não são utilizados. Neste, as frequências de cada grupo são relacionadas em uma tabela de dupla entrada. O teste do Qui-Quadrado deve ser aplicado quando cada frequência for um número maior ou igual a 5. Se a frequência de alguma das células da tabela for menor que 5, esta deverá ser agrupada com outra classe (AYRES et al., 2007).

Esse teste deve ser aplicado quando as variáveis tiverem no mínimo 02 (duas) categorias. E a hipótese deste tipo de teste é dada por:

$\left\{\begin{array}{l}\mathrm{H}_{0}: \mathrm{y} \text { independe de } \mathrm{x} \\ \mathrm{H}_{1}: \mathrm{y} \text { não independe de } \mathrm{x}\end{array}\right.$

$$
X^{2}=\sum_{i=j}^{k=1} \frac{\left(f_{o}-f_{e}\right)^{2}}{f_{e}}
$$

$\mathrm{gl}=c-1 \times l-1$

Onde: $f_{\mathrm{o}}=$ frequência observada; $f_{\mathrm{e}}=$ frequência esperada . 
Para a realização das análises citadas, fez-se uso do software BioEstat, versão $5.0^{\circledR}$, desenvolvido pela UFPA.

\subsection{RESULTADOS}

Os levantamentos de uso e cobertura da terra fornecem subsídios para as análises e avaliações dos impactos ambientais (provenientes de desmatamentos, perda da biodiversidade, mudanças climáticas, doenças reincidentes) ou de inúmeros impactos gerados pelos altos índices de urbanização e pelas transformações rurais (IBGE, 2013).

A partir daí, é possível observar que a RIDE-DF apresenta uma diversidade ecológica e socioeconômica em seu espaço, pois as Unidades da Federação (UFs) compreendidas compartilham o mesmo bioma: o Cerrado. Contudo, ocorre que os espaços naturais vêm sendo alterados drasticamente.

De acordo com o MMA (2011), em termos históricos, o bioma Cerrado teve uma área suprimida de 43,6\% até o ano de 2002, e de 47,8\% até o ano de 2008. No período 2009-2010, a taxa anual de desmatamento foi de $0,3 \%$ - a maior taxa dentre os seis biomas brasileiros. Neste sentido, é importante frisar que não se tem dados sobre a taxa anual de desmatamento antes de 2002. Por sua vez, Marinho-Filho et al. (2010) mencionam que somente o Estado de Goiás perdeu $65 \%$ da sua cobertura vegetal.

Neste contexto, de acordo com Walter et al. (2008), a integridade da cobertura já estaria comprometida em 49,1\%, classificados como não-cerrado, sendo que $16,7 \%$ estariam cobertos por cerrado fortemente antropizado, $17,4 \%$ seriam cerrado antropizado e restariam somente $16,7 \%$ de áreas com cerrado não antropizado.

A Figura 3, a seguir, apresenta a sobreposição dos casos de Hantavirose no mapa de uso e cobertura da terra da região em estudo. Na região de entorno do Distrito Federal foram contabilizados 26 casos de Hantavirose no período 2004-2010. Foi possível determinar 14 locais de ocorrência do agravo e, assim, observar uma concentração dos casos no entorno sul, principalmente nos municípios goianos de Cidade Ocidental, Cristalina, Luziânia e Valparaíso de Goiás. 


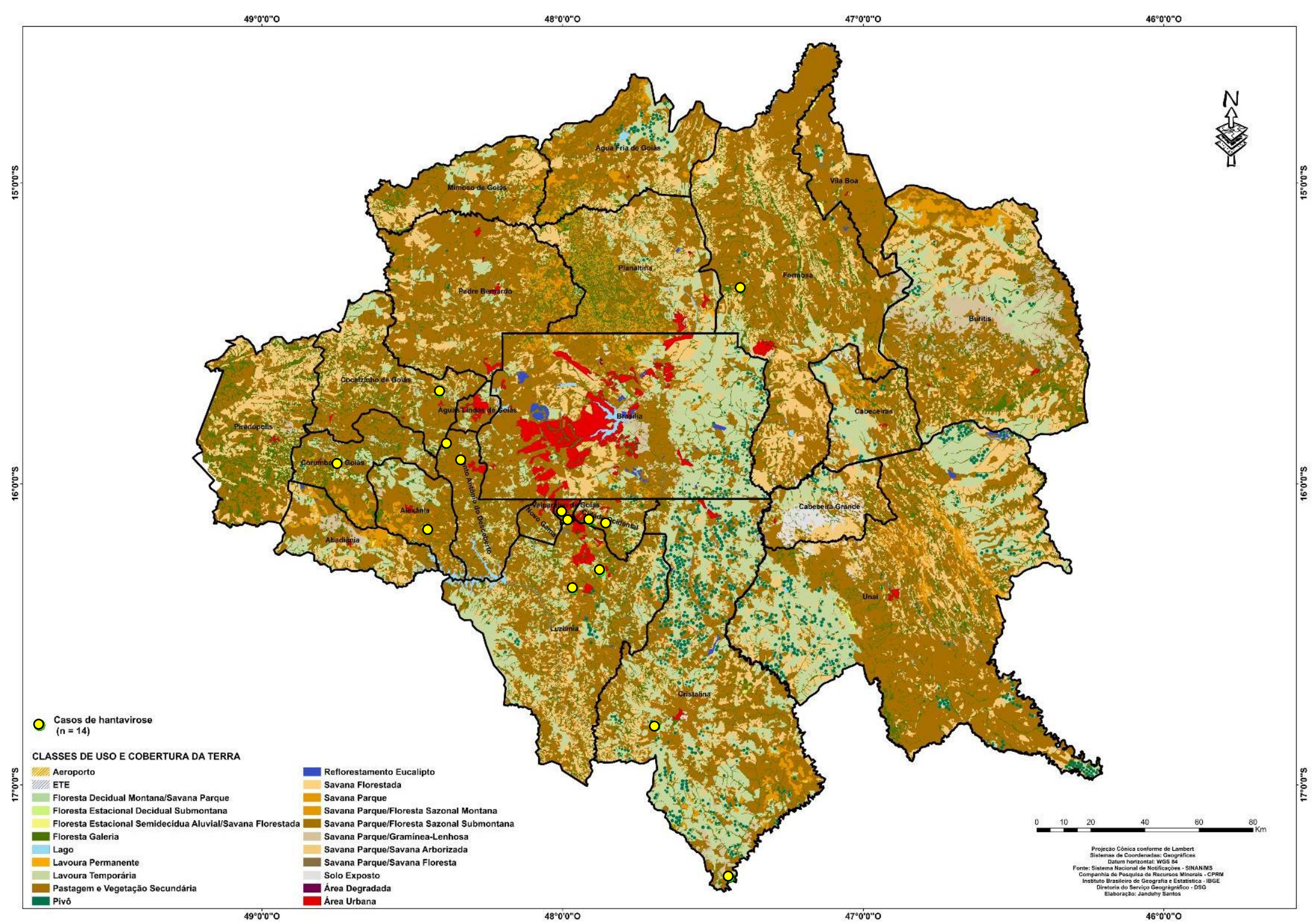

Figura 3 Mapa de uso e cobertura da terra da Região Integrada de Desenvolvimento do Distrito Federal e Entorno (RIDE-DF) e os casos de Hantavirose, período 2004-2010. 
O cartograma apresentado anteriormente (Figura 3) aponta a diversidade de uso da terra de acordo com o levantamento realizado pelo MMA (2007). Com o intuito de facilitar a compreensão daquele mapa, fez-se uma divisão em 02 (duas) categorias, quais sejam: 1) classes de uso; e, 2) cobertura da terra. A categoria antrópica apresenta as classes de uso da terra, ou seja, são aquelas que possuem suas estruturas espaciais modificadas pela ação humana, e a categoria não antrópicos refere-se às classes de cobertura da terra, isto é, as estrutura espaciais formadas por elementos naturais.

Neste sentido, conforme a organização dos dados nos SIG e o mapa apresentado na Figura 3, é possível observar as agregações (classes) de uso e cobertura da terra existentes na região e a quantidade de casos por classe na Tabela 1, que se segue:

Tabela 1 - Área total das classes de uso e cobertura da terra do Entorno e os casos de Hantavirose, período 2004-2010.

\section{Classe}

\section{Área coberta}

Casos de

$\left(\mathbf{K m}^{2}\right)$ hantavirose

Área degradada

\section{Antrópicos (Uso da terra)}

Área urbana 327,61

Lavoura permanente

Lavoura temporária

9.830 .73

Pastagem e vegetação secundária

Reflorestamento

100,52

\section{Não antrópicos (Cobertura da terra)}

Floresta decidual montana/savana parque

Floresta estacional decídua/submontana

Floresta estacional semidecídua aluvial/savana florestada

Floresta galeria

Lago

377,32

Savana florestada

149,46

Savana parque

875,52

1

Savana parque/floresta sazonal montana

$1.010,62$

Savana parque/floresta sazonal submontana

825,41

Savana parque/gramínea-lenhosa

$1.021,43$

Savana parque/savana arborizada

$8.706,84$

1 
Conforme a tabela 1 apresentada anteriormente, os espaços antropogênicos, como, por exemplo, as pastagens, apresentaram 49\% dos casos de Hantavirose na região analisada no período 2004-2010. Tais espaços são compostos por áreas destinadas ao pastoreio do gado, formados mediante plantio de forragens perenes ou aproveitamento e melhoria de pastagens naturais. Nestas áreas, o solo está coberto por vegetação de gramíneas e/ou leguminosas, cuja altura pode variar de alguns decímetros a alguns metros (IBGE, 2012). A Figura 3 também apresentou, em associação às pastagens, a vegetação secundária - formação resultante de processos naturais de sucessão, após supressão total ou parcial de vegetação primária por ações antrópicas ou causas naturais.

As áreas antrópicas agrícolas representadas pela lavoura temporária responderam por $21 \%$ dos casos de Hantavirose. A referida classe é formada por cultivo de plantas de curta ou média duração, em geral, com ciclo vegetativo inferior a um ano, que, após a produção, deixam o terreno disponível para novo plantio. Entre as culturas existentes destacam-se as de grãos e cereais, além de bulbos, raízes, tubérculos e hortaliças (IBGE, 2013). Já a classe lavoura permanente é compreendida pelo cultivo de plantas perenes, isto é, de ciclo vegetativo de longa duração. Estas plantas produzem por vários anos sucessivos sem a necessidade de novos plantios após colheita. Neste sentido, esta última classe não apresentou casos de Hantavirose plotados em suas áreas no mapa (Figura 3).

E ainda, os reflorestamentos, que na Tabela 1 são representados pelo plantio de espécies exóticas, tais como: eucalipto, pínus e acácia-negra. Em ambas as classes não foram observadas ocorrências de hantavírus. E o mesmo se dá para as áreas degradadas que sofreram processos de deterioração provocada pelas atividades humanas, como, por exemplo, a extração de minerais.

As coberturas florísticas existentes nos municípios integrantes do Entorno são caracterizadas por formações savânicas em razão dos solos areníticos lixiviados e ricos em alumínio. Já as formações florestais estacionais que se expandiram através da rede hidrográfica encontram-se em áreas como solos ígneos e logicamente mais férteis (IBGE, 2013). 
Em relação às coberturas que apresentaram ocorrências de Hantavirose foi possível observar que a cobertura representada pela floresta de galeria apresentou $14 \%$ das ocorrências. Tais florestas são fitofisionomias caracterizadas pela vegetação florestal que acompanha os rios de pequeno porte e córregos dos planaltos do Brasil Central, formando corredores fechados (galerias) sobre o curso de água (ICMBIO, 2014). Para Alho (1982), a floresta de galeria aparentemente oferece refúgio para algumas espécies de roedores silvestres que se deslocam para aquela formação vegetal em épocas de estiagem, quando se tem elevado número de incêndios florestais.

Com 7\% das ocorrências de Hantavirose, as formações campestres do tipo savana parque (campo sujo), savana parque/savana arborizada (cerrado stricto sensu) e savana parque/savana florestada (cerradão) foram as áreas que apresentaram tais ocorrências. A formação savana parque é uma formação fisionômica dominada por gramíneas e arbustos, com baixa cobertura de árvores (EMBRAPA, 2008). Em razão da escala utilizada (1:250.000), a Figura 3 apresentou a conjugação da savana parque com a savana arborizada, bem como a savana floresta ou florestada. A savana arborizada é um subtipo savana mais conhecido como campo cerrado ou cerrado stricto sensu, caracterizado pelo predomínio de vegetação herbácea, principalmente gramíneas, e pequenas árvores e arbustos bastante espaçados entre si; e a savana gramíneo-lenhosa (campo limpo) é constituída por uma vegetação herbácea, sem árvores. A savana floresta ou florestada é mais conhecida como cerradão, que exibe estrato arbóreo com indivíduos tortuosos e eretos (EMBRAPA, 2008). Poucas espécies com caducifolia (que perde as folhas no período de estiagem) resistem à estação seca.

As outras formações florestais, como, por exemplo, a floresta decidual Montana com a savana parque, floresta estacional decídua/submontana e floresta estacional semidecídua aluvial com savana florestada, são formações caracterizadas por 02 (duas) estações climáticas bem demarcadas, quais sejam: 1) chuvosa; e 2) longo período biologicamente seco. No caso da formação decidual montana, conforme a sua latitude, pode ser encontrada em áreas com até $2.000 \mathrm{~m}$ de altitude (IBGE, 2013).

A formação submontana caracteriza-se por uma formação florestal de porte médio composta por nanofoliadas deciduais com caules finos. A floresta estacional semidecídua aluvial é um tipo de formação marcada pela dupla estacionalidade climática; é constituída por fanerógamos com gemas foliares protegidas da seca por escamas, tem folhas esclerófilas deciduais e a perda de folhas do conjunto florestal (não das espécies) situa-se entre 20 e $50 \%$. 
Tal formação pode ser encontrada nas margens dos cursos d'água (IBGE, 2013). Nas formações florestais citadas, conforme a Tabela 1, não foram registrados casos de Hantavirose.

Os solos expostos podem ser de origem natural, como é o caso das áreas cobertas por rocha nua exposta, ou não, como, por exemplo, as áreas de extração abandonadas. Em relação àqueles espaços, não foram constatados casos de Hantavirose.

Seguindo os mesmos princípios do mapa da Figura 3, o mapa da Figura 4, a seguir, detalha os processos de uso da terra e os casos sobrepostos de Hantavirose no Distrito Federal na escala temporal do estudo. Dos 78 casos autóctones confirmados no Distrito Federal foram identificados 49 locais de ocorrência para a Hantavirose.

No Distrito Federal, a forma como o seu território vem sendo ocupado é resultado do comportamento de diferentes processos espaciais. Tal consideração atenta que aquela UF possui uma dinâmica territorial bastante dinâmica e, ao mesmo tempo, dialética em razão dos conflitos que ocorrem pela expansão de áreas urbanas e as estruturas espaciais existentes, que, conforme Anjos (2004), são denominadas de estruturas inibidoras da urbanização. Estas estruturas que inibem os processos de urbanização para todo o Distrito Federal são representadas pelos espaços destinados às lavouras temporárias, permanentes e pastagens. As áreas de preservação permanentes e as áreas com topografia bastante acidentada encontram-se no eixo norte-noroeste do Distrito Federal. Contudo, estes espaços servem também de habitat para várias espécies de roedores, em especial, o Necromys lasiurus - encontrado com abundância nestas áreas, segundo os trabalhos publicados de Mares et al. (1986), Vieira (1999), Alho (2005), Santos et al. (2011) e Rocha et al. (2011). 


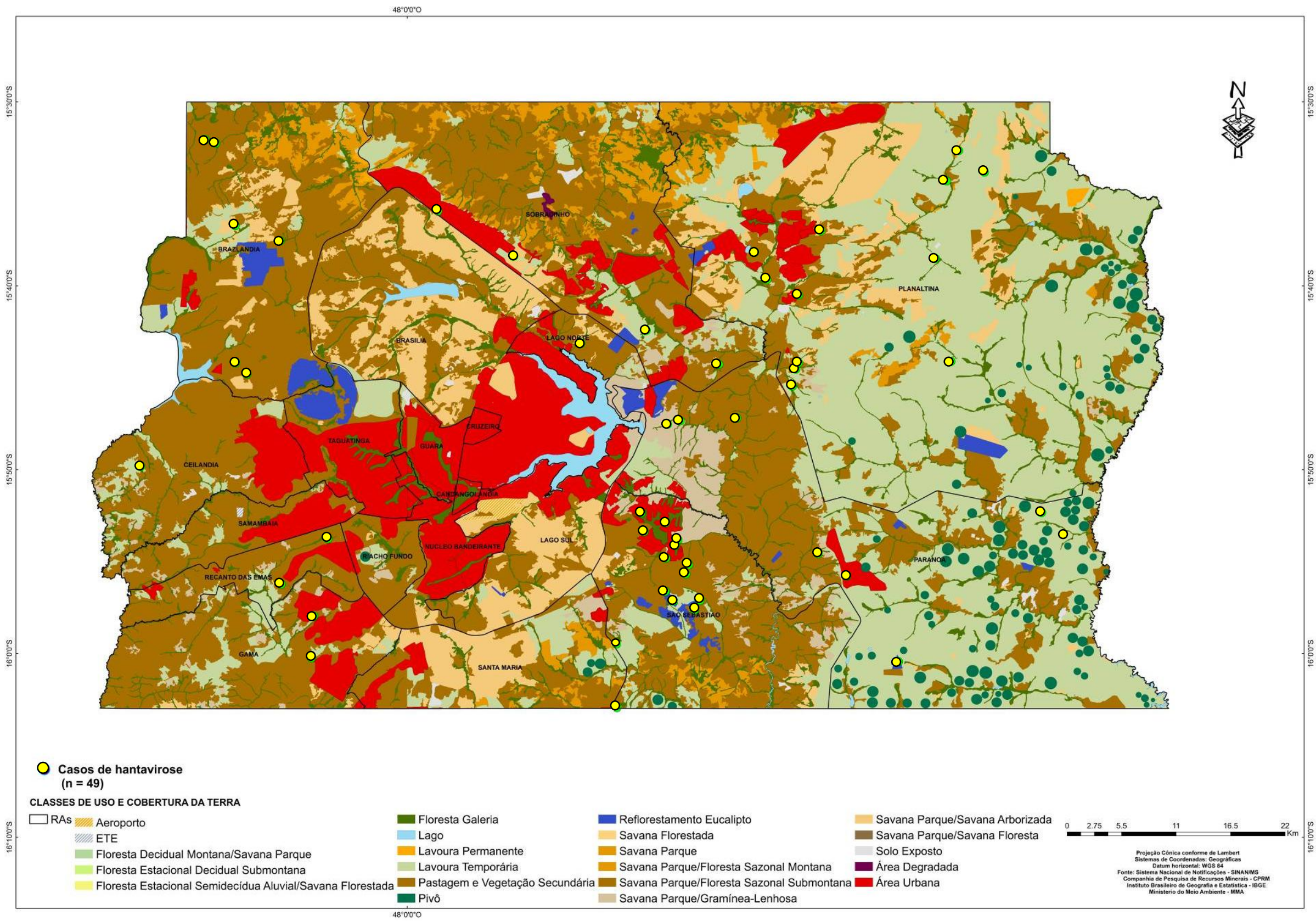

Figura 4 Mapa de uso e cobertura da terra do Distrito Federal e os casos de Hantavirose, período 2004-2010. 
Na Tabela 2, a seguir, têm-se as agregações de uso e ocupação da terra predominantes no Distrito Federal e representadas no mapa da Figura 4.

Tabela 2 - Área total das classes de uso e cobertura da terra no Distrito Federal e os casos de Hantavirose, período 2004-2010.

\begin{tabular}{|c|c|c|}
\hline Classe & $\begin{array}{c}\text { Área coberta } \\
\left(\mathrm{Km}^{2}\right)\end{array}$ & $\begin{array}{c}\text { Casos de } \\
\text { hantavirose }\end{array}$ \\
\hline \multicolumn{3}{|c|}{ Antrópicos (Uso da terra) } \\
\hline Área degradada & 1,8 & - \\
\hline Área urbana & 647,08 & 5 \\
\hline Lavoura permanente & 5,0 & - \\
\hline Lavoura temporária & $1.605,7$ & 14 \\
\hline Pastagem e vegetação secundária & 2.089 & 20 \\
\hline Reflorestamento & 70,7 & 2 \\
\hline \multicolumn{3}{|c|}{ Não antrópicos (Cobertura da terra) } \\
\hline Floresta decidual montana/savana parque & - & - \\
\hline Floresta estacional decídua/submontana & - & - \\
\hline Floresta estacional semidecídua aluvial/savana florestada & - & - \\
\hline Floresta galeria & 389,35 & 2 \\
\hline Lago & 60,8 & - \\
\hline Savana florestada & 0,31 & - \\
\hline Savana parque & 41,6 & - \\
\hline Savana parque/floresta sazonal montana & 162,20 & - \\
\hline Savana parque/floresta sazonal submontana & - & - \\
\hline Savana parque/gramínea-lenhosa & 148,66 & 2 \\
\hline Savana parque/savana arborizada & 550,22 & 4 \\
\hline Savana parque/savana floresta & 0,21 & - \\
\hline Solo exposto & 15,3 & - \\
\hline
\end{tabular}

Elaboração: Janduhy Santos

Conforme a tabela apresentada anteriormente é possível observar que $83 \%$ dos casos de Hantavirose no Distrito Federal se deram em áreas antrópicas. E ainda, as áreas destinadas para as pastagens e vegetação secundária representaram $41 \%$, e as lavouras temporárias 
apresentaram $28 \%$ do agravo. As áreas urbanas, por sua vez, corresponderam a $10 \%$ de presença do agravo em seus espaços. Em relação à classe urbana, o Ministério da Saúde (2013) detalha que a expansão das cidades tem trazido consigo a construção de moradias em regiões rurais, agrícolas e silvestres que circundam os Municípios. Neste sentido, vale ressaltar que casos associados a tal fator foram detectados, por exemplo, nos Estados de Minas Gerais, Mato Grosso, São Paulo e no Distrito Federal.

No Distrito Federal, os fatores de cobertura da terra (não antrópicos) não tiveram peso considerável e, assim, responderam somente $16 \%$ dos espaços onde se deram os casos de Hantavirose. Neste sentido, em relação às ilustrações e informações aqui apresentadas, a cobertura savana parque/savana arborizada, na Figura 4, são as fitofisionomias do campocerrado, e Tabela 2, destaca-se com $8 \%$ das ocorrências. As fitofiosionomias floresta de galeria e savana parque/gramínea-lenhosa apresentaram 8\% de ocorrências em suas áreas.

Para uma análise da associação das ocorrências de Hantavirose com as classes de uso da terra foi calculado o Odds Ratio (OR) das categorias envolvidas com aquela enfermidade, a fim de avaliar a intensidade de associação no Distrito Federal e no Entorno, conforme exposto na Tabela 3, a seguir.

Tabela 3 - Resultados da análise da relação do uso da terra e a ocorrência de Hantavirose no Distrito Federal e no Entorno, período 2007-2010.

Classe de uso e cobertura da terra

$\begin{array}{ccc}\mathrm{N}^{\circ} \text { de áreas } & \text { P value } & \text { OR }(95 \% \mathrm{CI})\end{array}$

\section{ENTORNO}

Lavoura temporária

Pastagem e vegetação secundária

Savana parque/savana floresta

Savana parque

Savana parque/savana arborizada

Floresta galeria

\section{DISTRITO FEDERAL}

Área urbana

Lavoura temporária

Pastagem e vegetação secundária

Reflorestamento

Floresta galeria

Savana parque/gramínea-lenhosa

Savana parque/savana arborizada
$2,90(0,80-10,4)$

$1,8(0,64-5,37)$

$7,31(0,96-56,5)$

$4,30(0,56-32,9)$

$0,22(0,03-1,75)$

$0,84(0,18-3,76)$
2,93 (1,14-7,54)

$2,30(1,22-4,31)$

$1,51(0,85-2,67)$

$4,15(0,96-17,8)$

$0,29(0,07-1,21)$

$0,57(0,13-2,38)$

$0,75(0,26-2,10)$

*OR = odds ratio $; \mathrm{CI}=$ intervalo de confiança

Elaboração: Janduhy Santos 
A análise exposta na Tabela 3 aponta que no entorno, nenhuma classe de cobertura e uso da terra apresentou resultados estatisticamente significativos para o Odds Ratio dentro do $p$-valor de $<0.05$. No Distrito Federal, as classes de uso - as áreas urbanas $(\mathrm{OR}=2.9)$ e as lavouras temporárias $(\mathrm{OR}=2.3)$ - que apresentaram medidas de associação significativas.

Com base em tais variações, a Tabela 4, a seguir, apresenta os resultados do teste do Qui-Quadrado $\left(\chi^{2}\right)$, a fim de avaliar se a Hantavirose do Distrito Federal e da RIDE-DF possui alguma dependência em relação a Hantavirose com $p$-valor de $<0.05$.

Tabela 4 - Resultados do teste do Qui-Quadrado $\left(\chi^{2}\right)$ para o Distrito Federal e no Entorno, período 2007-2010.

\begin{tabular}{lccc}
\hline Região & $\chi^{2}$ & $\chi^{2}$ Yates & $p$-valor \\
\hline Distrito Federal & 9,5 & 8,5 & 0,0034 \\
Entorno & 1,8 & 1,0 & 0,30 \\
\hline
\end{tabular}

Elaboração: Janduhy Santos

Para a os municípios que integram o entorno, os resultados do teste Qui-quadrado obtidos e devidamente corrigidos (Yates) não são estatisticamente significativos, ou seja, a análise sugere que a ocorrência de Hantavirose independe dos fatores de uso da terra. Já para o Distrito Federal, conforme a tabela apresentada anteriormente, se deu o inverso em relação ao entorno: o resultado do $\chi^{2}$ apresentou dados estatisticamente significativos, rejeitando, assim, a hipótese de nulidade e aceitando a alternativa de que a ocorrência da Hantavirose no Distrito Federal possui alguma dependência com o uso da terra para o período 2004-2010.

\subsection{DISCUSSÃO}

A circulação do hantavírus Araraquara (ARAV) depende da presença de seu respectivo reservatório. Apesar do reservatório do hantavírus Araraquara (o roedor Necromys lasiurus) ser uma espécie silvestre, observa-se que mais casos de Hantavirose se dão em paisagens antrópicas.

Com base na Figura 3 e na Tabela 1 apresentadas anteriormente, os espaços antropizados no entorno são os mais predominantes com as pastagens como a maior estrutura espacial da região. Estas paisagens antropizadas oferecem condições propícias para o contato do homem com o hantavírus - contato percebido através das atividades agrícolas, onde o roedor é atraído pela oferta de grãos que são consumidos principalmente na época da seca, quando se tem a diminuição de insetos e sementes em seu habitat. 
Observando os valores do Odds ratio e do qui-quadrado percebe-se que nos municípios que integram o entorno do Distrito Federal, tanto as classes de cobertura como as de uso não ofereceram valores que apresentassem significação estatística a um nível de 5\% para considerá-los como fator de importância na transmissão da Hantavirose. Tal fato se deve pela quantidade de ocorrências disponíveis que não permitiram fornecer informações conclusivas, sendo necessário o cruzamento com outras referências para a obtenção de outras complementações.

Em relação ao Distrito Federal, as áreas urbanas e as áreas destinadas às lavouras temporárias tiveram o maior Odds Ratio. As áreas urbanizadas no Distrito Federal vêm apresentando nos últimos anos uma grande expansão, o que aumenta a fragmentação dos espaços silvestres existentes no território. Tal expansão se dá com o aumento de empreendimentos imobiliários para todas as classes da população. Têm-se aí o surgimento de condomínios de luxo que, muitas vezes, se instalam em áreas próximas às matas em razão dos aspectos estéticos e de elevada qualidade ambiental; e ainda, têm-se a implantação de assentamentos urbanos regularizados ou surgimento de aglomerados subnormais (favela, invasão, grota, baixada, comunidade, vila, ressaca, mocambo, palafita e outros) em áreas periféricas próximas aos ambientes silvestres. A questão da expansão habitacional, sem dúvida, é um aspecto bem característico do Distrito Federal, e isso se dá em razão da diluição que ocorre das áreas rurais e silvestres em favor da criação de novos projetos urbanos, tornando difícil delimitar o que é área urbana e o que é área rural.

Ademais, a perda do habitat em virtude do desmatamento para o plantio de culturas temporárias ou permanentes e de pastagens desaloja aqueles roedores de seu habitat, fazendoos procurarem abrigo em tocas próximas às benfeitorias (paióis, galinheiros, silos e outros) dos estabelecimentos agropecuários; e ainda, sendo animais com comportamento oportunista, infiltram-se em tais ambientes para se alimentarem, eliminando, por sua vez, excrementos contaminados com o hantavírus que se misturam com a poeira.

O resultado do teste Qui-Quadrado (vide Tabela 4) apresentou um valor relativamente alto, ao contrário do entorno, que apresentou uma taxa relativamente baixa em razão da quantidade de locais de ocorrência disponíveis para avaliação. Neste sentido, através do resultado do teste de Qui-Quadrado, é possível observar que o antropismo tem contribuído na dinâmica espacial da Hantavirose no Distrito Federal. 


\subsection{CONSIDERAÇÕES FINAIS}

Após as análises dos dados epidemiológicos e espaciais dos casos de Hantavirose na no Distrito Federal e no seu entorno, constatou-se um arranjo espacial sui generis da doença na região.

Apesar de não terem apresentado resultados estatisticamente expressivos, as formações florísticas do bioma Cerrado: a savana parque (campo-sujo) e a savana parque/savana floresta (cerradão) são importantes habitats dos roedores reservatórios do hantavírus Araraquara (ARAV). Sendo assim, a importância da biodiversidade para o equilíbrio destes ambientes é essencial em razão da manutenção do equilíbrio ecossistêmico, o que evita o "transbordamento" de agentes patógenos para as populações humanas.

Conforme o teste Qui-Quadrado, os resultados do Distrito Federal foram mais expressivos em relação aos impactos antropogênicos e o agravo. A razão disto está no fato de que o espaço do Distrito Federal apresenta um forte dinamismo em sua estrutura, que sugere a criação de um ambiente favorável à enfermidade.

Assim, a criação e preservação de espaços voltados à conservação da biodiversidade do cerrado são mecanismos que colaboram no equilíbrio das populações de roedores silvestres, como, por exemplo, no caso do Necromys lasiurus. As manchas de áreas silvestres situadas em áreas urbanas merecem também atenção especial para sua conservação, bem como uma ação de conscientização dos habitantes em relação à deposição de resíduos que possam atrair os roedores, quando da probabilidade de contato com os excrementos daqueles animais.

Para as populações rurais, o mais importante para a prevenção da Hantavirose é seguir as recomendações preconizadas pelos órgãos de saúde e de extensão rural com a finalidade de que os locais destinados ao armazenamento de insumos e grãos sejam preservados da entrada de roedores sinantrópicos e silvestres. E ainda, faz-se importante a utilização de equipamentos de segurança individual, como, por exemplo, máscaras e luvas - que ajudam a realizar atividades laborais de limpeza naqueles ambientes.

De fato, estudos destinados à verificação da densidade de roedores com anticorpos de hantavírus se fazem extremamente necessários no sentido de correlacionar com maior acurácia os locais com a presença de roedores contaminados e, consequentemente, as classes de uso e cobertura da terra que apresentam condições ideais para o desenvolvimento da Hantavirose. Seria de grande importância que este tipo de estudo fosse conduzido de forma 
contínua nas periferias de áreas urbanas tanto do Distrito Federal bem como em sua região de entorno, nas regiões de espaços silvestres.

Finalmente, o presente estudo buscou resgatar a importância do espaço no estudo das doenças infectocontagiosas transmitidas por animais vetores e reservatórios de patógenos, uma vez que as doenças ali advindas possuem um elo com atividades humanas e necessitam de abordagem e análise que perpassam a Epidemiologia.

\subsection{REFERÊNCIAS BIBLIOGRÁFICAS}

ALHO J.R.C, Brazilian rodents: their habitats and habits. Pymatuning Laboratory of Ecology Special Publications. Nº 06, 1982.

, Intergradation of habitats of non-volant small mammals in the patchy cerrado landscape. Arquivos do Museu Nacional, Vol. 63, nº 1. 2005.

ACUNA-SOTO R., STAHLE D.W, CLEAVELAND M.K, THERRELL M.D. Megadrought and Megadeath in 16th Century Mexico. Emerging Infectious Diseases. 2002.

ANJOS, R. S. A. Estruturas Básicas da Dinâmica Territorial no DF. In: PAVIANI, A \& GOUVÊA, L. A. C.. (Org.). Brasília: Controvérsias Ambientais. Brasília: Editora Universidade de Brasília, 2004, v. 1, p. 199-215.

AYRES, M. et al. BioEstat 5.3: Aplicações Estatísticas nas Áreas das Ciências Biológicas e Médicas. Belém-PA. Publicações Avulsas do Mamirauá, 2007.

BECKER, R. G. et al. Estrutura de comunidades de pequenos mamíferos e densidade de Necromys lasiurus (Rodentia, Sigmodontinae) em áreas abertas de cerrado no Brasil Central. Mastozool. neotrop., Mendoza, v. 14, n. 2, dic. 2007.

BREARLEY, G. et al. Wildlife disease prevalence in human-modified landscapes. Biological Reviews, v. 88, n. 2, p. 427-442, 2013.

BRITO, M.G. Uso da terra e a distribuição espacial de casos humanos da síndrome cardiopulmonar por hantavírus em Minas Gerais, 1996 a 2007. Tese (doutorado) Universidade Federal de Minas Gerais. 81p.

COMPANHIA DE PESQUISAS DE RECURSOS MINERAIS (CPRM). Zoneamento ecológico-econômico da região integrada de desenvolvimento do Distrito Federal e entorno: fase I. Rio de Janeiro: Serviço Geológico do Brasil; Embrapa. 2003.

EMPRESA BRASILEIRA DE PESQUISA AGROPECUÁRIA. Cerrado: ecologia e flora, v. 1, 2008.

ESTRADA-PEÑA, A. et al. Effects of environmental change on zoonotic disease risk: an ecological primer. Trends in parasitology, v. 30, n. 4, p. 205-214, 2014.

FOLEY. J.A. et al. Global Consequences of Land Use. Science. Vol. 309, 2005, pp. 570-573.

GLASS G.E. et al. Persistently Highest Risk Areas for Hantavirus Pulmonary Syndrome: Potential Sites for Refugia. Ecological Applications, 17(1), 2007, pp. 129-139. 
GOODIN, D.G. et al. Land cover associated with hantavirus presence in Paraguay. Global Ecology and Biogeography. Vol. 12, nº 5. Blackwell Publishing, 2006.

GOTTDENKER, N. L. et al. Anthropogenic Land Use Change and Infectious Diseases: A Review of the Evidence. EcoHealth, p. 1-14, 2014.

INSTITUTO BRASILEIRO DE GEOGRAFIA E ESTATÍSTICA - IBGE. Manual técnico da vegetação do Brasil. $2^{a}$ edição. Rio de Janeiro: 2012, 271p.

INSTITUTO BRASILEIRO DE GEOGRAFIA E ESTATÍSTICA - IBGE. Manual técnico de uso da terra. $3^{\text {a }}$ edição. Rio de Janeiro: 2013, 171p.

INSTITUTO CHICO MENDES DE CONSERVAÇÃO DA BIODIVERSIDADE - ICMBIO. Cerrado. Disponível em: <http://www.icmbio.gov.br/portal/biodiversidade// >. Acesso em: 01 nov. 2014.

INSTITUTO DE PESQUISA ECONÔMICA APLICADA (IPEA). Atlas do Desenvolvimento Humano nas Regiões Metropolitanas Brasileiras. Disponível em: <http://www.integracao.gov.br/ >. Acesso em: 11 dez. 2014.

LAMBIN, E.F. et al. Pathogenic landscapes: interactions between land, people, disease vectors, and their animal hosts. International journal of health geographics, v. 9, n. 54, p. $1-13,2010$.

MARES, M.A; ERNEST, K.A; GETTINGER, D.D. Small mammal community structure and composition in the Cerrado Province of central Brazil. Laboratory of Parasitilogy. Vol. 2, 1986.

MARINHO-FILHO, J.; MACHADO, R.B.; HENRIQUES, R.P.B. Evolução do conhecimento e da conservação do Cerrado brasileiro. In: Cerrado: conhecimento científico quantitativo como subsídio para ações de conservação. Editora Thesaurus. 2010.

MINISTÉRIO DA INTEGRAÇÃO NACIONAL. Região Integrada de Desenvolvimento do Distrito Federal e Entorno - RIDE-DF. Disponível em: 〈http://www.integracao.gov.br/ >. Acesso em: 09 dez. 2014.

MINISTÉRIO DA SAÚDE. Manual de vigilância, prevenção e controle das hantaviroses. Departamento de Vigilância Epidemiológica. - Brasília : Ministério da Saúde, 2013. 94 p.

MINISTÉRIO DA SAÚDE. Surto da síndrome cardiopulmonar por hantavírus no Distrito Federal e Goiás - maio a setembro de 2004. Boletim eletrônico epidemiológico. $\mathrm{n}^{\circ}$ 01, 2005.

MINISTÉRIO DO MEIO AMBIENTE. Relatório técnico de monitoramento do desmatamento no cerrado - Bioma Cerrado, 2002 a 2010: Dados Revisados. Centro de Sensoriamento Remoto - CSR/IBAMA. 2011.

MINISTÉRIO DO MEIO AMBIENTE. Uso e Ocupação do Solo RIDE - 2007. Disponível em: <http:// http://mapas.mma.gov.br// >. Acesso em: 09 dez. 2014.

OLIVEIRA S.V.; ESCOBAR L.E.; PETERSON A.T.; GURGEL-GONÇALVES, R.; Potential Geographic Distribution of Hantavirus Reservoirs in Brazil. PLoS ONE, v. 8, n.12, 2013. 
PATZ, J.A. et al. Disease emergence from global climate and land use change. Medical Clinics of North America, v. 92, n. 6, p. 1473-1491, 2008.

ROCHA, C.C; RIBEIRO, R; TAKAHASHI, F.S.C; MARINHO-FILHO, J. Micrvohabitat use by rodent species in a central Brazilian cerrado. Mammalian Biology. Vol. 76. 2011.

SANTOS, J.P et al. A dinâmica do uso da terra e a hantavirose. Hygeia, v. 8, n. 15, 2012.

SANTOS, J.P.; STEINKE, E.T.; GARCÍA-ZAPATA, M.T.A. Uso e Ocupação do Solo ea Disseminação da Hantavirose no Distrito Federal, Estudo de Caso: São Sebastião, 2004-2008. Revista da Sociedade Brasileira de Medicina Tropical, v. 44, n. 1, 2011.

SANTOS, M. Metamorfoses do Espaço Habitado: Fundamentos Teóricos e Metodológicos da Geografia. São Paulo: EDUSP, 2008. 136 p.

TALAMONI, S.A; COUTO, D; JÚNIOR D.A.C; DINIZ, F.M. Diet of some species of Neotropical small mammals. Mammalian Biology. Vol. 73. 2008.

VAZQUEZ-PROKOPEC, G.M. et al. Seasonal variations in active dispersal of natural populations of Triatoma infestans in rural north-western Argentina. Medical and veterinary entomology, v. 20, n. 3, p. 273-279, 2006.

VIEIRA, E. M. Small mammal communities and fire in the Brazilian Cerrado. Journal of Zoology, v. 249, p. 75-81, 1999.

WALTER, B.M.T. et al. O Conceito de Savana e de seu Componente Cerrado. Cerrado: Ecologia e Flora. Embrapa Informação Tecnológica, 2008.

WU, X.X. et al. Impact of global change on transmission of human infectious diseases. Science China Earth Sciences, v. 57, n. 2, p. 189-203, 2014. 


\section{CAPÍTULO 6 CONSIDERAÇÕES FINAIS E RECOMENDAÇÕES}

A partir das análises aqui sistematizadas em formato de artigos científicos, a seguir, têm-se algumas conclusões que permitiram a elaboração de recomendações finais sobre a temática abordada, tendo em vista colaborar com os órgãos públicos de saúde e de meio ambiente para o êxito nas ações de controle da Hantavirose.

Em relação à abordagem da dimensão do espaço na Geografia da Saúde, as teorias desenvolvidas por Pavlovsky (da nidalidade e dos focos antropúrgicos) ainda tem um peso significativo na compreensão das zoonoses. Atualmente, é possível observar que em vários lugares, o aparecimento de doenças que antes tinham sido controladas, hoje estão retornando vivazmente, bem como o surgimento de novos agravos que continuam a desafiar a comunidade internacional e colocar os serviços de saúde pública em permanente estado de alerta.

A compreensão das estruturas espaciais tanto na sua dimensão abiótica como na biótica é de suma importância para os gestores que planejam políticas públicas voltadas aos empreendimentos de infraestrutura. Pois, as mudanças realizadas em ambientes naturais causam impactos aos ciclos biogeoquímicos e à biodiversidade. E as mudanças na biodiversidade trazem também, de per si, alterações nos perfis epidemiológicos, conforme aqueles aqui demonstrados em relação à Hantavirose. Portanto, a teoria da nidalidade e a dos focos antropúrgicos são relevantes na compreensão das doenças zoonóticas.

Nesta perspectiva, com o interesse em conhecer a distribuição do Necromys lasiurus - o reservatório do hantavírus Araraquara, que se faz presente nos casos de Hantavirose no Estado de Goiás e no Distrito Federal - realizou-se a Modelagem de Nicho Ecológico (MNE) para o referido roedor reservatório. Neste sentido, foi possível notar uma ampla distribuição daquele roedor e, contudo, o que mais chamou a atenção é que em áreas onde existe uma adequabilidade ambiental não foram registrados nenhum caso de hantavirose.

Tal fato exige uma reflexão a respeito das "áreas silenciosas", pois, questiona-se: é possível que naquelas áreas que não apresentam uma circulação viral ou que realmente ocorram casos de Hantavirose, a situação não esteja sendo corretamente diagnosticada? Neste sentido, várias áreas das regiões Nordeste e Centro-Oeste apresentaram adequabilidade ambiental para o roedor, mas até agora não se tem o registro de qualquer caso da enfermidade em questão. 
Apesar da MNE apresentar somente uma simulação da presença da espécie, esta permite a continuidade da realização de inventários da fauna de pequenos mamíferos e principalmente daqueles de interesse médico em lugares que apresentam alterações em seus espaços em razão do uso da terra.

Sobre a MNE, é possível sugerir a todos aqueles que pretendem utilizar a modelagem para o estudo da distribuição potencial de espécies da fauna e da flora que deem importância ao uso da camada de uso e cobertura da terra. A razão desta sugestão se dá em virtude que a camada oferece uma aproximação da real situação daquele espaço onde a modelagem está sendo desenvolvida. Pois, as alterações ambientais advindas dos processos de uso da terra interferem na distribuição das espécies, e como a MNE tem como objetivo principal demonstrar as áreas que apresentam uma adequabilidade ambiental para a espécie estudada, o referido dado melhora a sensibilidade da modelagem.

Através da análise espacial da incidência de Hantavirose no Estado de Goiás foram detectados agrupamentos espaciais significativos em municípios próximos ao Distrito Federal. Apesar de que no índice de Moran não houve correlação, a análise através do algoritmo Getisord Gi demonstrou que municípios próximos à capital goiana e ao Distrito Federal tiveram pesos espaciais semelhantes, o que sugere alguma conectividade na incidência da Hantavirose na região. Dentro do território do Distrito Federal, a análise apontou uma correlação espacial indicando que a incidência de Hantavirose apresentava dependência espacial do fenômeno, além de expressar clusters significativos no seu território.

A análise espacial da incidência da Hantavirose trouxe como principal contribuição uma visão espacial da incidência da doença e a espacialidade que tal agravo possui. Assim, os produtos originados pela abordagem contribuem com eficiência na vigilância epidemiológica.

A partir desta visão global da incidência da Hantavirose nas Unidades da Federação (UFs) analisadas, buscou-se em maior escala um estudo que abrangesse os impactos do uso do solo na disseminação da Hantavirose na Região Integrada de Desenvolvimento do Distrito Federal e Entorno (RIDE/DF). Dentro desta perspectiva foram detectados que certos usos da terra, como, por exemplo, no caso das pastagens, do reflorestamento e das áreas agrícolas, tiveram resultados estaticamente representativos. Também tiveram resultados que merecem atenção algumas fitofisionomias, o que traz a importância da preservação destes ambientes para o equilíbrio da biodiversidade. 
O Distrito Federal apresentou os resultados mais significativos em razão das informações disponíveis da ocorrência de casos de Hantavirose, o que leva à necessidade de uma reflexão a respeito da dinamização que se dá no território daquela UF, que cada vez mais apresenta mudanças agressivas em seus espaços, resultando, assim, em uma perda ainda maior de áreas silvestres.

Diante da presente situação, as linhas que se seguiram trouxeram também informações que permitiram propor recomendações que pudessem subsidiar as ações governamentais e particulares que possam servir como auxílio na prevenção da Hantavirose.

Neste sentido, faz-se necessário o estímulo e a continuidade das ações de controle da Hantavirose através de programas de educação em saúde e ambiental. Tais ações - constantes e dirigidas para as populações-alvo - podem ser feitas via material informativo (posters, panfletos, folders e outros), mídia (jornais, TV, rádio e internet) e manifestações artísticas (teatro).

O incentivo do uso dos Equipamentos de Proteção Individual (EPIs) para a proteção de pessoas que executam atividades agrícolas, agroindustriais e tantas outras se encontra no Manual de Vigilância, Prevenção e Controle da Hantavirose do Ministério da Saúde (MS). Este tem uma enorme importância na compreensão da Hantavirose e precisa ser divulgado com mais veemência para os profissionais de vigilância em saúde, em especial àqueles profissionais de áreas consideradas "silenciosas", mas que constam a presença do roedor Necromys lasiurus e de outras espécies de roedores silvestres - reservatórios de outros tipos de hantavírus.

Em relação às áreas silenciosas, os estudos de densidade de roedores infectados são necessários para a manutenção das vigilâncias epidemiológicas informadas da presença dos roedores contaminados. Portanto, a fim de evitar o aumento das taxas de mortalidade de pessoas que habitam em regiões que são distantes de centros de referência para o tratamento da Hantavirose, seria adequado que as Secretarias Estaduais de Saúde (SESs) realizassem tais levantamentos. E ainda, que estes levantamentos fossem executados em áreas periféricas aos assentamentos aonde foram detectados os casos de Hantavirose autóctones. Neste sentido, vale recordar que a presente pesquisa atentou-se para a questão do avanço das áreas urbanas sobre os espaços silvestres. Através dos mapas apresentados anteriormente, tem-se ali os locais onde poderiam ser desenvolvidos os estudos a respeito da diversidade e distribuição de roedores hospedeiros de hantavírus. 
Por último, têm-se a participação de geógrafos em estudos de distribuição destes roedores e no apoio nos levantamentos dos locais prováveis de infecção (LPI) para a elaboração em conjunto de medidas de controle do agravo. Tal sugestão se dá em razão do fornecimento de análises espaciais que permitam a detecção de agrupamentos espaciais nas áreas impactadas pela Hantavirose - parceria esta que poderia ser feita em conjunto com os Departamentos acadêmicos de Geografia, que poderiam capacitar os servidores das Secretarias Estaduais e Municipais de Saúde em tecnologias espaciais, com a utilização de sistemas de posicionamento global e na realização de atividades em softwares de sistemas de informações geográficas.

Atentando-se para o fato de que o presente estudo teve como objetivo realizar a análise espacial da dispersão do Necromys lasiurus, por meio da MNE, além de avaliar a dependência espacial e a correlação dos casos de Hantavirose com a cobertura e o uso da terra no Estado de Goiás e no Distrito Federal, convém ressaltar que a pesquisa cumpriu a sua meta, uma vez que o resultado geral apresentou a Hantavirose como uma doença que possui conexões com as alterações ambientais que ocorrem nas áreas estudadas.

No que diz respeito aos objetivos específicos, todos aqueles que foram elencados no projeto da tese foram cumpridos de maneira satisfatória, pois, considerando a amplitude da discussão, a partir da questão do espaço geográfico e a saúde pública até ao nível mais regional do estudo - o Distrito Federal e sua região de entorno - permitiu-se que o trabalho fosse executado com uma abordagem interdisciplinar em diferentes escalas geográficas.

Como resultado mais significativo das linhas que se seguiram, têm-se a possibilidade da aplicação das técnicas desenvolvidas para outras doenças, em especial, para aquelas de origem zoonótica, sendo possível aprimorar o que foi aqui indicado, no sentido de apoiar cada vez mais a sociedade na gestão dos programas de vigilância em saúde pública. 


\section{BIBLIOGRAFIA GERAL}

AB'SABER, A.N. A formação Boa Vista: significado geomorfológico e geoecológico no contexto do relevo de Roraima. In: A Obra de Aziz Nacib de Ab'Saber. Beca Editora. 2010 .

AB'SABER, A.N. Os Domínios de Natureza no Brasil: Potencialidades Paisagísticas. Ed. Ateliê Editorial. 2003.

AB'SABER, A.N.; JÚNIOR, M. Costa. Contribuição ao estudo do Sudoeste Goiano. In: MODENESI-GAUTTIERI et al. (ORG.). A Obra de Aziz Nacib Ab'Saber. São Paulo: Ed. BECA, 2010.

ACUNA-SOTO, R. et al. Megadrought and megadeath in 16th century Mexico. Revista Biomédica, v. 13, p. 289-292, 2002.

ADAMI, M.; MELlO, M. P.; AGUIAR, D. A.; RUDORFF, B. F. T.; SOUZA, A. F. A Web platform Development to Perform Thematic Accuracy Assessment of Sugarcane Mapping in South-Central Brazil. Remote Sensing. 2012, 4, 3201-3214. doi: <10.3390/rs4103201>.

ALHO J.R.C, Brazilian rodents: their habitats and habits. Pymatuning Laboratory of Ecology Special Publications. No 06, 1982.

ALHO J.R.C, Intergradation of habitats of non-volant small mammals in the patchy cerrado landscape. Arquivos do Museu Nacional, Vol. 63, $\mathrm{n}^{\circ} 1.2005$

ALHO, C.J.R. Importância da biodiversidade para a saúde humana: uma perspectiva ecológica. Estudos Avançados, v. 26, n. 74, p. 151-166, 2012.

ALHO, J.R.C, Brazilian rodents: their habitats and habits. Pymatuning Laboratory of Ecology Special Publications. No 06, 1982.

ANDRADE, M.E.B. Geografia médica: origem e evolução. In: BARATA, R.B.; BRICEÑOLEÓN, R.E., orgs. Doenças endêmicas: abordagens sociais, culturais e comportamentais. Rio de Janeiro: Editora FIOCRUZ, 2000. p. 151-166.

ANJOS, R. S. A. Estruturas Básicas da Dinâmica Territorial no DF. In: PAVIANI, A \& GOUVÊA, L. A. C.. (Org.). Brasília: Controvérsias Ambientais. Brasília: Editora Universidade de Brasília, 2004, v. 1, p. 199-215.

ÁVILA-PIRES, F.D. Princípios de Ecologia Médica. Florianópolis: Editora UFSC, 2000. $328 \mathrm{p}$.

AYRES, M. et al. BioEstat 5.3: Aplicações Estatísticas nas Áreas das Ciências Biológicas e Médicas. Belém-PA. Publicações Avulsas do Mamirauá, 2007.

BALASHOV, Y.S. The $70^{\text {th }}$ aniversary of E.N. Pavlovsky's concept of natural nidality of human diseases. Entomological Review, vol 90, nº 4, 2010, pp. 533-536.

BARCELLOS, C. et al. Mudanças climáticas e ambientais e as doenças infecciosas: cenários e incertezas para o Brasil. Epidemiol. Serv. Saúde, Brasília , v. 18, n. 3, set. 2009 
BECKER, R. G. et al. Estrutura de comunidades de pequenos mamíferos e densidade de Necromys lasiurus (Rodentia, Sigmodontinae) em áreas abertas de cerrado no Brasil Central. Mastozool. neotrop., Mendoza, v. 14, n. 2, dic. 2007.

BONVICINO C.R; OLIVEIRA J.A; D'ANDREA P.S. Guia dos roedores do Brasil, com chaves para gêneros baseadas em caracteres externos. Organização Pan-Americana da Saúde. Rio de Janeiro, 2008.

BREARLEY, G. et al. Wildlife disease prevalence in human-modified landscapes. Biological Reviews, v. 88, n. 2, p. 427-442, 2013.

BRITO, M.G. O uso da terra e a distribuição espacial de casos humanos da síndrome cardiopulmonar por hantavírus em Minas Gerais, 1996 a 2007. 2012. 81 p., enc. Tese (doutorado) - Universidade Federal de Minas Gerais.

CÂMARA, G. et al. Análise espacial de áreas. In: DRUCK, S. et al. (Org.). Análise espacial de dados geográficos. Embrapa. 2004, pp. 206.

CARMIGNOTTO, A.P; AIRES, C.C. Mamífeors não voadores (Mammalia) da Estação Ecológica Serra Geral do Tocantins. Biota Neotropica., 11(1): 313-328. 2011.

CASTRO, M. C.; SINGER, B. H. Environment and Health: a methodological approach for spatial assessment of malaria transmission in colonization projects in the Brazilian Amazon. Revista Brasileira de Estudos de População, v. 24, n. 2, p. 247-262, 2007.

CENTRO DE REFERÊNCIA EM INFORMAÇÃO AMBIENTAL. Rede SpeciesLink. Disponível em: <http://www.cria.org.br>. Acesso em: 26 set. 2013.

CENTRO UNIVERSITÁRIO DE ESTUDOS E PESQUISAS SOBRE DESASTRES. Atlas brasileiro de desastres naturais 1991 a 2010. Volume Brasil. 2012.

CHILDS, J.E. et al. Serologic and Genetic Identification of Peromyscus maniculatus as the Primary Rodent Reservoir for a New Hantavirus in the Southwestern United States. Journal Infectious Diseases. Vol. 169 (6): 1994. 1271-1280.

COLACICCO-MAYHUGH, M.G.; MASUOKA, P.M.; GRIECO, J. P. Ecological niche model of Phlebotomus alexandri and P. papatasi (Diptera: Psychodidae) in the Middle East. Int J Health Geogr, v. 9, n. 2, 2010.

COMPANHIA DE PESQUISAS DE RECURSOS MINERAIS (CPRM). Zoneamento ecológico-econômico da região integrada de desenvolvimento do Distrito Federal e entorno: fase I. Rio de Janeiro: Serviço Geológico do Brasil; Embrapa. 2003.

CONFALONIERI, U. E. C. Saúde na Amazônia: um modelo conceitual para a análise de paisagens e doenças. Estudos Avançados, v. 19, n. 53, p. 221-236, 2005.

CRISTOFELLETI, A. Modelagem de Sistemas Ambientais. Editora Edgard Blücher, São Paulo, 1999.

CROMLEY, E.K; McLAFFERTY, S.L. GIS and Public Health. In: Analyzing Sptail Clustering of Health Events. The Guilford Press. 2002, pp. 340.

DEARING, MD ; DIZNEY, L. Ecology of hantavirus in a changing world. Year In Ecology And Conservation Biology. Vol.1195, 2010. pp.99-112. 
DISTRITO FEDERAL. Plano Diretor de Ordenamento Territorial do Distrito Federal PDOT. Secretaria de Estado de Desenvolvimento Urbano e Meio Ambiente do Distrito Federal. Brasília, 2009.

DONALÍSIO M.R; PETERSON, A.T. Environmental factors affecting transmission risk for hantaviruses in forested portions of southern Brazil. Acta Tropica. Vol. 119. 2011.

DONALÍSIO, M.R et al. Aspectos climáticos em áreas de transmissão de hantavirose no estado de São Paulo, Brasil. Cadernos de Saúde Pública, Rio de Janeiro, 24(5): 2008, pp 1141-1150.

DRUCK, S; CARVALHO, M.S; CÂMARA, G; MONTEIRO, A.M.V. Análise espacial de dados geográficos. Embrapa. 2004, pp. 206.

EISEN R. J. et al. A Spatial Model of Shared Risk for Plague and Hantavirus Pulmonary Syndrome in the Southwestern United States. American Journal Tropical Medicine Hygiene. 77(6), 2007, pp. 999-1004.

ELTON, C. S. The Animal Community. In___Animal ecology. University of Chicago Press, 1927.

EMPRESA BRASILEIRA DE PESQUISA AGROPECUÁRIA. Cerrado: ecologia e flora, v. $1,2008$.

ENVIRONMENTAL SYSTEMS RESEARCH INSTITUTE. Documentation Manual. Redlands, 2011.

ESTRADA-PEÑA, A. et al. Effects of environmental change on zoonotic disease risk: an ecological primer. Trends in parasitology, v. 30, n. 4, p. 205-214, 2014.

FANG, L.Q. et al. Spatiotemporal Dynamics of Hemorragic Fever with Renal Syndrome, Beijing, People's Republic of China. Emerging Infectious Disease. Vol. 15, nº 12, 2009.

FERREIRA, M.U. Epidemiologia e geografia: o complexo patogênico de Max. Sorre. Cadernos de Saúde Pública, v. 7, n. 3, p. 301-309, 1991.

FIGUEIREDO L.T.M. et al. Hantavirus Pulmonary Syndrome, Central Plateau, Southeastern, and Southern Brazil. Emerging Infectious Diseases. Vol. 15, nº 04, 2009.

FOLEY, J.A. et al. Global consequences of land use. Science, vol. 309, p. 570-573, 2005.

FOOD AND AGRICULTURAL ORGANIZATION OF THE UNITED NATIONS. Mapping Land Use Systems at global and regional scales for Land Degradation Assessment Analysis. Technical report $\mathrm{n}^{\circ}$ 08, version 1.1. 2010.

GETIS, A; ORD, J. K. The analysis of spatial association by use of distance statistics. Geographical analysis, v. 24, n. 3, p. 189-206, 1992.

GIANNINI, T. C. et al. Desafios atuais da modelagem preditiva de distribuição de espécies. Rodriguésia, Rio de Janeiro, v. 63, n. 3, 2012. Disponível em <http://www.scielo.br/scielo>. Acesso em: 01 abr. 2014.

GLASS G.E. et al. Persistently Highest Risk Areas for Hantavirus Pulmonary Syndrome: Potential Sites for Refugia. Ecological Applications, 17(1), 2007, pp. 129-139. 
GOODIN, D.G. et al. Land cover associated with hantavirus presence in Paraguay. Global Ecology and Biogeography. Vol. 12, n 5. Blackwell Publishing, 2006.

GOTTDENKER, N. L. et al. Anthropogenic Land Use Change and Infectious Diseases: A Review of the Evidence. EcoHealth, p. 1-14, 2014.

GRINNELL, J. Geography and Evolution. Ecological Society of America. Vol. 5, No 3, pp. 225-229. 1924.

GRINNELL, J. The Niche-Relationships of the California Thrasher. American Ornithologists' Union. Vol. 34, No. 4, pp. 427-433. 1917.

GUISAN, A; THUILLER, W. Predicting species distribution: offering more than simple habitat models. Ecology letters, v. 8, n. 9, p. 993-1009, 2005.

HUTCHINSON, G.E. Concluding remarks. Cold Spring Harbor Symposia on Quantitative Biology. 22 (2): 415-427. 1957.

INSTITUO MAURO BORGES DE ESTATÍSTICAS E ESTUDOS SOCIOECONÔMICOS. Goiás em Dados 2012. Goiânia. Disponível em: 〈http://www.imb.go.gov.br/>. Acesso em 05 dez. 2013.

INSTITUTO BRASILEIRO DE GEOGRAFIA E ESTATÍSTICA - IBGE. Manual técnico da vegetação do Brasil. $2^{a}$ edição. Rio de Janeiro: 2012, 271 p.

INSTITUTO BRASILEIRO DE GEOGRAFIA E ESTATÍSTICA - IBGE. Manual técnico de uso da terra. $3^{\text {a }}$ edição. Rio de Janeiro: 2013, 171p.

INSTITUTO BRASILEIRO DE GEOGRAFIA E ESTATÍSTICA. Censo demográfico 2010. Rio de Janeiro: IBGE, 2012.

INSTITUTO CHICO MENDES DE CONSERVAÇÃO DA BIODIVERSIDADE - ICMBIO. Cerrado. Disponível em: <http://www.icmbio.gov.br/portal/biodiversidade// >. Acesso em: 01 nov. 2014.

INSTITUTO DE PESQUISA ECONÔMICA APLICADA (IPEA). Atlas do Desenvolvimento Humano nas Regiões Metropolitanas Brasileiras. Disponível em: <http://www.integracao.gov.br/ >. Acesso em: $11 \mathrm{dez} .2014$.

INSTITUTO NACIONAL DE PESQUISAS ESPACIAIS. O projeto Terraview. São José dos Campos, 2008.

INSTITUTO NACIONAL DE PESQUISAS ESPACIAIS. Variáveis Ambientais para Modelagem de Distribuição de Espécies. Grupo de Modelagem para Estudos da Biodiversidade. 2013.

JONES, $\mathrm{K}$ E. et al. Zoonosis emergence linked to agricultural intensification and environmental change. Procceding National Academic Sciences, v. 451, n. 7181, p. 990993, 2008.

JONSSON C.B.; FIGUEIREDO L.T.; VAPALAHTI O. A global perspective on hantavirus ecology, epidemiology and disease. Clin Microbiol Rev. 2010; 23:412-41. 
KAMINO, L.H.Y. Modelos de distribuição geográfica potencial: aplicação com plantas ameaçadas de extinção da Floresta Atlântica. Tese (doutorado) - Universidade Federal de Minas Gerais. 2009. 133f.

LAI, P.C.; SO, FM.; CHAN, KW. Spatial Epidemiological Approaches in Disease Mapping and Analysis. In: Areal Methods of Disease Analysis. CRC press. 2009.

LAMBIN, E.F. et al. Pathogenic landscapes: Interactions between land, people, disease vectors, and their animal hosts. International Journal of Health Geographics, v. 9, n. 54, p. $2-13,2010$.

LAYME, V.M.G.; LIMA, A.P.; MAGNUSSON, W.E. Effects of fire, food availability and vegetation on the distribution of the rodent Bolomys lasiurus in an Amazonian savanna. Journal of Tropical Ecology, 20, 2004. pp 183-187.

LEE, H. W.; LEE, P.W.; JOHNSON, K.M. Isolation of the etiologic agent of Korean hemorrhagic fever. Journal Infectious Diseases, 137:298-308. 1978.

LIMA, D. M. et al . Hantavirus infection in suspected dengue cases from State of Ceará, Brazil. Rev. Soc. Bras. Med. Trop., Uberaba, v. 44, n. 6, 2011. Disponível em <http://www.scielo.br >. Acesso em: 26 set. 2014.

LUSTOSA,G.S LEITE, F.H.R, MARQUES-OLIVEIRA, F.N. SANTOS, M.P.D. Análise da composição e riqueza de pequenos mamíferos em três fitofisionomias na Fazenda Bonito, município de Castelo do Piauí. Anais do VIII Congresso de Ecologia do Brasil. Caxambu, 2007.

MARCO JÚNIOR, P.; SIQUEIRA, M. F. Como determinar a distribuição potencial de espécies sob uma abordagem conservacionista. Megadiversidade, v. 5, p. 65-76, 2009.

MARES, M.A; ERNEST, K.A; GETTINGER, D.D. Small mammal community structure and composition in the Cerrado Province of central Brazil. Laboratory of Parasitilogy. Vol. 2. 1986.

MARINHO-FILHO, J.; MACHADO, R.B.; HENRIQUES, R.P.B. Evolução do conhecimento e da conservação do Cerrado brasileiro. In: Cerrado: conhecimento científico quantitativo como subsídio para ações de conservação. Editora Thesaurus. 2010.

MARQUES, A.P.S. et al. Análise exploratória de dados de área para índices de furto na mesorregião de Presidente Prudente-SP. In: III Simpósio Brasileiro de Ciências Geodésicas e Tecnologias da Geoinformação. Recife - PE, 27-30 de Julho de 2010. pp. 001 - 008.

MEADE, M. S.; EARICKSON, R.J. Medical Geography. $2^{\mathrm{a}}$ ed. New York: Guilford Press, 2005. 500 p.

MEHERETU Y. et al. High diversity of RNA viruses in rodents, Ethiopia. Emerg Infect Dis. Vol. 18, n. 12. 2012.

METZ, C. E. ROC methodology in radiologic imaging. Investigative Radiology, v. 21, n. 9, p. $720-733,1986$.

MILLS, J.N. Regulation of rodent-borne viruses in the natural host:implications for human disease. Arch. Virol. Suppl. 2005:45-57. 2005. 
MILLS, J.N.; AMMAN, B. R.; GLASS, G. E.; Ecology of hantaviruses and their hosts in North America. Vector-Borne and Zoonotic Diseases, v. 10, n. 6, p. 563-574, 2010.

MINISTÉRIO DA INTEGRAÇÃO NACIONAL. Região Integrada de Desenvolvimento do Distrito Federal e Entorno - RIDE-DF. Disponível em: 〈http://www.integracao.gov.br/ > Acesso em: 09 dez. 2014.

MINISTÉRIO DA SAÚDE, Hantaviroses: Situação Epidemiológica - Dados. Disponível em: 〈http://portal.saude.gov.br/>. Acesso em: 09 jan. 2014.

MINISTÉRIO DA SAÚDE. Manual de vigilância, prevenção e controle das hantaviroses. Departamento de Vigilância Epidemiológica. - Brasília : Ministério da Saúde, 2013. 94 p.

MINISTÉRIO DA SAÚDE. Secretaria de Vigilância em Saúde. Introdução à Estatística Espacial para a Saúde Pública. Texto Básicos de Saúde. Brasília, 2007.

MINISTÉRIO DA SAÚDE. Surto da síndrome cardiopulmonar por hantavírus no Distrito Federal e Goiás - maio a setembro de 2004. Boletim eletrônico epidemiológico, $\mathrm{n}^{\circ}$ 01, 2005. Disponível em: <http://portalsaude.saude.gov.br/images/pdf/2014/julho/15/Ano05n01-surto-scp-hantavirus-df-completo.pdf $>$ Acesso em: 10 abr. 2014.

MINISTÉRIO DO MEIO AMBIENTE. Relatório técnico de monitoramento do desmatamento no cerrado - Bioma Cerrado, 2002 a 2010: Dados Revisados. Centro de Sensoriamento Remoto - CSR/IBAMA. 2011.

MINISTÉRIO DO MEIO AMBIENTE. Uso e Ocupação do Solo RIDE - 2007. Disponível em: <http:// http://mapas.mma.gov.br// >. Acesso em: 09 dez. 2014.

MOORE, D. A; CARPENTER, T.E. Spatial analytical methods and geographic information systems: use in health research and epidemiology. Epidemiologic reviews, v. 21, n. 2, p. 143$161,1999$.

MURRAY, K.A.; DASZAK, P. Human ecology in pathogenic landscapes: two hypotheses on how land use change drives viral emergence. Current Opinion in Virology, v. 3, n. 1, p. 7983, 2013.

MYERS, S.S. Human health impacts of ecosystem alteration. Proccedings of the National Academic Sciences, v. 110, n.47, p. 18753-18760, 2013.

NICHOL S.T et al. Genetic identification of a hantavirus associated with an outbreak of acute respiratory illness. Science: Vol. 262 (5135), 1993. 914-917.

NUNES, F. G. Análise exploratória espacial de indicadores de desenvolvimento socioambiental das regiões de planejamento do norte e nordeste goiano. Ateliê Geográfico, v. 7, n. 1, 2013.

NUNES, M.L; MAIA-ELKHOURY, A.N.S; PELISSARI, D.M. Caracterização clínica e epidemiológica dos casos confirmados de hantavirose com local provável de infecção no bioma Cerrado Brasileiro, 1996 a 2008. Epidemiol. Serv. Saúde, vol.20, no.4, 2011. p.537545 .

OAK RIDGE NATIONAL LABORATORY. Vegetation Cover Types from MODIS, 500m, South America: 2000-2001. 2012. 
OLIVEIRA S.V.; ESCOBAR L.E.; PETERSON A.T.; GURGEL-GONÇALVES, R.; Potential Geographic Distribution of Hantavirus Reservoirs in Brazil. PLoS ONE, v. 8, n.12, 2013.

OLIVEIRA, S.V. Análise preditiva da distribuição geográfica de hantavírus no Brasil. Dissertação (mestrado) - Universidade de Brasília, Faculdade de medicina, Pós-Graduação em Medicina Tropical, 2013. 129 pp.

OLIVEIRA, S.V. et. al. Conhecimentos, atitudes e práticas sobre hantavirose em um assentamento rural de Planaltina-Distrito Federal. Sciencia Plena. Vol 8, 2012.

ORGANIZAÇÃO PAN-AMERICANA DE SAÚDE. Organización Panamericana de la Salud. Hantavírus en las Americas: guía para el diagnóstico, el tratamiento, la prevención y el control. Cuaderno Técnico. Washington, 1999. 66p.

OSTEFELD, R. S.; GLASS, G. E.; KESSING, F. Spatial epidemiology: an emerging (or reemerging) discipline, Trends in Ecology \& Evolution, v. 20, n. 6, p. 328-326, 2005.

PATZ, J.A. et al. Disease emergence from global climate and land use change. Medical Clinics of North America, v. 92, n. 6, p. 1473-1491, 2008.

PAVLOVSKY, E.N. Natural nidality of transmissible diseases in relation to landscape. Epidemiology of zooanthroponoses. Moscow: Ed. Peace Publishers, 1966. 249p.

PEARCE, J. L.; BOYCE, M. S. Modelling distribution and abundance with presence-only data. Journal of Applied Ecology, v. 43, n. 3, p. 405-412, 2006.

PEARSON, R. G. et al. Predicting species distributions from small numbers of occurrence records: a test case using cryptic geckos in Madagascar. Journal of Biogeography, v. 34, n. 1, p. 102-117, 2007.

PEARSON, R. G; DAWSON, T. P; LIU, C. 2004. Modelling species distributions in Britain: a hierachical integration of climate and landcover data. Ecography 27: 285-298. 2004.

PETERSON, A.T et al. The Geography of Disease Transmission. In__Ecological Niches and Geographic Distributions. Princenton University Press. 2011.

PHILLIPS, S. J. et al. Maximum entropy modeling of species geographic distributions. Ecol. Model. 190: 231-259. 2006.

PULLIAM, H. R. On the relationship between niche and distribution. Ecology Letters, v. 3, $n^{\circ} .4$, p. 349-361, 2000.

QUADROS, J; MONTEIRO-FILHO, E.L.A. Revisão conceitual, padrões e microestruturais proposal nomenclatura. Rev. Bras. Zool. vol 23, nº 1, pp. 279-292. 2006

REIS, N.R.; PERACCHI, A.L.; PEDRO, W.A.; LIMA, I.P. Mamíferos do Brasil. Editora UEL. 2006.

RILEY, J.C. The Eighteenth-Century Campaign to Avoid Disease. New York: St Martin's Press, 1987.

ROCHA, C.C; RIBEIRO, R; TAKAHASHI, F.S.C; MARINHO-FILHO, J. Microhabitat use by rodent species in a central Brazilian cerrado. Mammalian Biology. Vol. 76. 2011 
RODRIGUEZ J.M.M.; SILVA, E.V.; CAVALCANTI, A.P.B. Geoecologia das Paisagens: uma visão geossitêmica da análise ambiental. Fortaleza: Ed. UFC, 2007.

ROSS, J.L.S. Ecogeografia do Brasil. Subsídios para Planejamento Ambiental. Ed. Oficina de Textos. São Paulo, 2006.

ROUQUAYROL, M.Z. Medidas de Saúde Coletiva. In: Epidemiologia e Saúde. $7^{\text {a }}$ Ed. Editora Med Book. Rio de Janeiro. 736p.

SANTOS, J. P. et al. Análise da distribuição espacial da hantavirose no Distrito Federal, Brasil, 2004-2010. Hygeia, v. 10, n. 18, p. 98-109, 2014.

SANTOS, J. P. Aspectos geoambientais e epidemiológicos em áreas de transmissão da Hantavirose no Distrito Federal, 2009. p.89. Dissertação de Mestrado. Universidade de Brasília, Brasília.

SANTOS, J.P et al. A dinâmica do uso da terra e a hantavirose. Hygeia, v. 8, n. 15, 2012.

SANTOS, J.P.; STEINKE, E.T.; GARCIA-ZAPATA, M.T.A. Uso e ocupação do solo e a disseminação da hantavirose na região de São Sebastião, Distrito Federal: 2004 - 2008. Rev. Soc. Bras. Med. Trop., Uberaba, v. 44, n. 1, 2011.

SANTOS, M. Metamorfoses do Espaço Habitado: Fundamentos Teóricos e Metodológicos da Geografia. São Paulo: EDUSP, 2008. 136 p.

SCHMALJOHN, C.; HJELLE, B. Hantaviruses: a global disease problem. Emerg Infect Dis. Vol. 3(2): 1997.

SECRETARIA DE ESTADO DE SAÚDE DE GOIÁS. Mapa da saúde de Goiás. Goiânia, 2014.

SECRETARIA DE VIGILÂNCIA EM SAÚDE. Dados de Hantavirose. Brasília, 2010.

SECRETARIA DE VIGILÂNCIA EM SAÚDE. Guia de Vigilância Epidemiológica. Caderno 8, Brasília, 2010.

SILVA, L. J. Ocupação do espaço e doenças endêmicas. In: BARATA, R.B.; BRICEÑOLEÓN, R.E., orgs. Doenças endêmicas: abordagens sociais, culturais e comportamentais. Rio de Janeiro: Editora FIOCRUZ, 2000.

SILVA, L.J. O conceito de espaço na epidemiologia das doenças infecciosas. Caderno Saúde Pública, v. 13, n. 4, p. 585-593. 1997.

SOBERÓN, J. Grinnellian and Eltonian niches and geographic distributions of species. Ecology Letters. V. 10:1115-1123. 2007.

SOBERÓN, J; PETERSON, A.T. Interpretation of models of fundamental ecological niches and species distributional areas. Biodiversity informatics. 2005. 2:1-10.

SORRE, M. Complexes pathogènes et géographie médicale. Hygeia, Revista Brasileira de Geografia Médica e da Saúde, v. 2, n. 2, p. 2-14, 2006.

SUSUKI, A. et al. Identifying Rodent Hantavirus Reservoirs, Brazil. Emerging Infectious Diseases. Vol. 10, $\mathrm{n}^{\mathrm{o}}$ 12, 2004. 
TALAMONI, S.A; COUTO, D; JÚNIOR D.A.C; DINIZ, F.M. Diet of some species of Neotropical small mammals. Mammalian Biology. Vol. 73. 2008.

UJVARI, S.C. Meio ambiente \& epidemia. In: Meio abiótico. São Paulo: Ed. Senac. 2004.

UNIVERSITY OF ILLINOIS. GeoDa 0.9 user's guide. v. 51, p. 618, 2003.

VALENCIUS, C.B. Histories of Medical Geography. Journal Medical History, v. 20. 2000.

VAZQUEZ-PROKOPEC, G.M. et al. Seasonal variations in active dispersal of natural populations of Triatoma infestans in rural north-western Argentina. Medical and veterinary entomology, v. 20, n. 3, p. 273-279, 2006.

VERDADE, L.M; GHELER-COSTA, C; PENTEADO, M; DOTTA, G. The impacts of sugarcane expansion on wildlife in the state of São Paulo, Brazil. Journal of Sustainable Bioenergy Systems, v. 2, n. 4, p. 134-138, 2012.

VIEIRA, E. M. Small mammal communities and fire in the Brazilian Cerrado. Journal of Zoology, v. 249, p. 75-81, 1999.

WALTARI, E; PERKINS, S.L. In the hosts' footsteps? Ecological niche modelling and its utility in predicting parasite distributions. In:_The biogeography of host-parasite interactions. pp. 145- 157. Oxford University Press, Oxford. 2010.

WALTER, B.M.T. et al. O Conceito de Savana e de seu Componente Cerrado. Cerrado: Ecologia e Flora. Embrapa Informação Tecnológica, 2008.

WEI, L. et al. Using Geographic Information System-based Ecologic Niche Models to Forecast the Risk of Hantavirus Infection in Shandong Province, China. American Journal Tropical Medicine Hygiene, Vol 84, 2011.

WEI, L. et al. Using Geographic Information System-based Ecologic Niche Models to Forecast the Risk of Hantavirus Infection in Shandong Province, China. American Journal Tropical Medicine Hygiene, vol. 84, 2011.

WEISS,S. et al. Hantavirus in Bat, Sierra Leone. Emerg Infect Dis. 2012 January; 18(1): $159-161$.

WINTERS A. M. et al. Spatial Risk Models for Human Plague in the West Nile Region of Uganda. American Journal Tropical Medicine Hygiene. 80(4), 2009, pp. 1014-1022.

WORLD HEALTH ORGANIZATION. Ecosystems and Human Well-beig: Current State and Trends. New York: Island Press, 2005.

WU, X.X. et al. Impact of global change on transmission of human infectious diseases. Science China Earth Sciences, v. 57, n. 2, p. 189-203, 2014.

YAN, L. et al. Landscape Elements and Hantaan Virus-related Hemorrhagic Fever with Renal Syndrome, People's Republic of China. Emerging Infectious Diseases. Vol, 13, nº 9, 2007.

YAN, L. et al. Landscape Elements and Hantaan Virus-related Hemorrhagic Fever with Renal Syndrome, People's Republic of China. Emerging Infectious Diseases. vol, 13, nº 9, 2007. 
YOUNG J.C et al. The incubation period of hantavírus pulmonary syndrome. American Journal Tropical Medicine Hygiene. Vol. 62, 2000. Pág. 714-7.

ZEIER, M. et. al. New Ecological Aspects of Hantavirus Infection: A Change of A Paradigm and a Challenge of Prevention- A Review. Virus Genes. Volume 30, Issue 2, 2005. pp 157180.

ZHANG W. Y. et al. Predicting the Risk of Hantavirus Infection in Beijing, People's Republic of China. American Journal Tropical Medicine Hygiene. 80(4), 2009, pp. 678683. 


\section{ANEXO 1}

Coordenadas geográficas dos roedores Necromys lasiurus.

LATITUDE LONGITUDE

$-18.6667$

$-16.0093$

$-15.4333$

$-15.9111$

$-15.9641$

$-07.5166$

$-07.2451$

$-11.4300$

$-14.7900$

$-19.7167$

$-19.6986$

$-19.9712$

$-19.7167$

$-11.7167$

$-01.4363$

$-13.0167$

$-23.6416$

$-07.9025$

$-00.9953$

$-17.8435$

$-22.3640$

$-19.1917$

$-15.4333$

$-07.2266$

$-02.4000$

$-01.9000$

$-20.3519$

$-20.6128$

$-19.3072$

$-20.6231$

$-18.9189$

$-19.9256$

-45.2500
-47.9167
-55.7500
-48.0486
-47.9167
-39.7167
-39.7607
-40.6000
-39.0300
-42.6500
-43.8646
-40.5238
-42.6500
-39.0833
-48.4111
-54.0015
-48.1919
-35.0465
-46.7043
-57.5788
-47.0268
-57.8783
-55.7500
-39.4501
-54.7000
-48.5000
-46.8439
-46.3208
-46.0558
-46.5231
-48.2778
-40.5964
-50

LATITUDE

LONGITUDE

$-22.2828$

$-22.4122$

$-21.9414$

$-22.8903$

$-22.0131$

$-23.3936$

$-23.9325$

$-21.3819$

$-17.6158$

$-17.5697$

$-25.4908$

$-23.3103$

$-10.4957$

$-02.51724$

$-16.3824$

$-03.2624$

$-13.3834$

$-09.37860$

$-15.3328$

$-04.3090$

$-08.8855$

$-24.2706$

$-18.974$

$-15.4528$

$-09.5980$

$-27.8256$

$-19.7740$

$-06.7237$

$-29.5228$

$-05.3192$

$-19.0591$

$-26.0898$
$-42.5342$

$-42.9664$

$-42.8772$

$-48.4553$

$-51.2347$

$-49.5150$

$-47.0667$

$-51.5708$

$-47.7785$

$-52.5508$

$-49.6242$

$-51.1628$

$-46.3850$

$-54.9503$

$-48.9438$

$-44.6422$

$-48.1494$

$-36.6040$

$-43.5850$

$-40.7127$

$-42.7064$

$-49.6566$

$-51.9371$

$-58.3607$

$-42.1201$

$-52.9336$

$-42.0945$

$-35.1721$

$-50.0564$

$-41.5694$

$-35.3060$

$-48.6426$ 


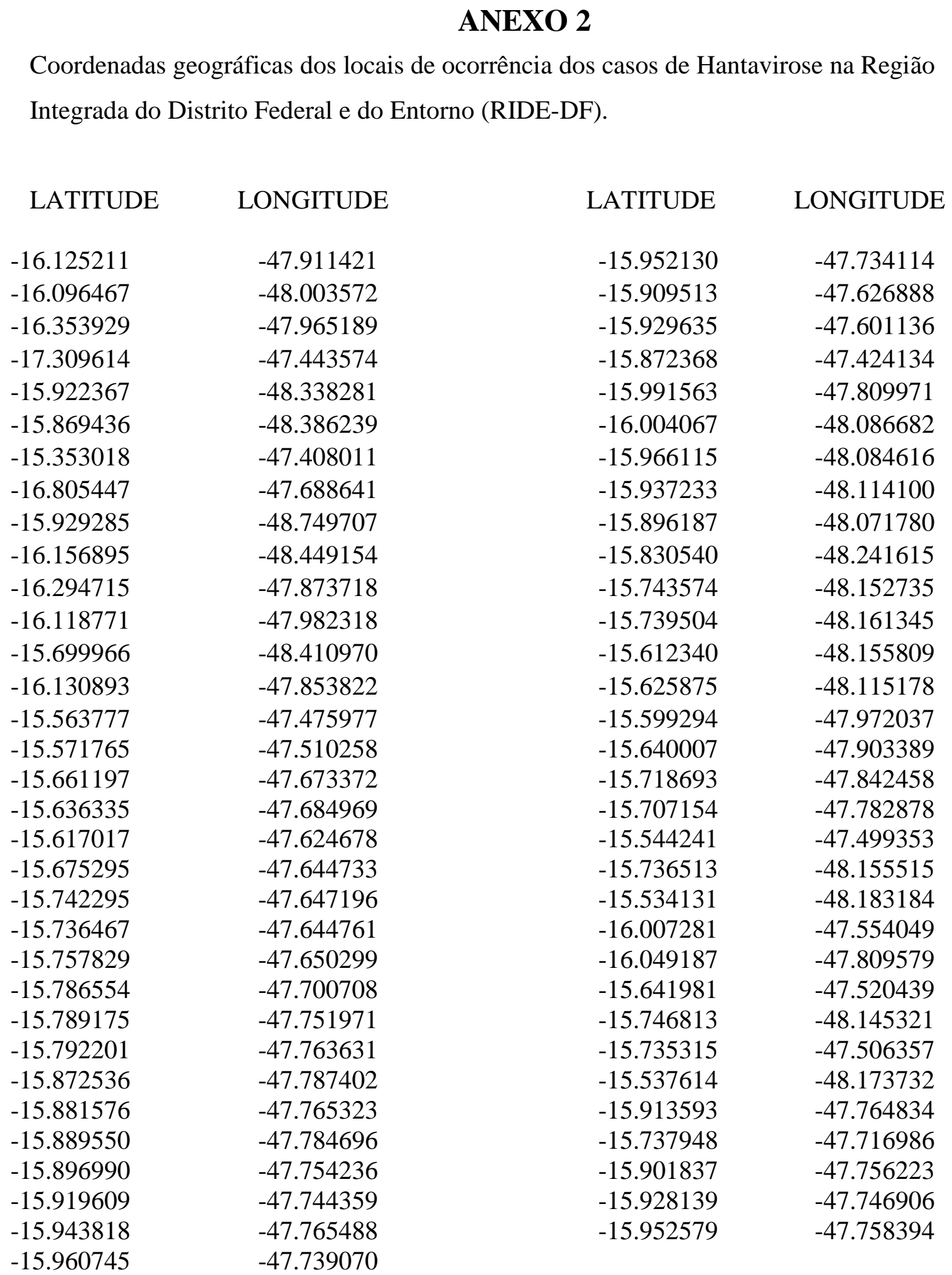




\section{ANEXO 3}

República Federativa do Brasil Ministério da Saúde

SINAN

SISTEMA DE INFORMACÃo DE AGRAVOS DE NOTIFICACÃO

FICHA DE INVESTIGACĀO HANTAVIROSE

CASO SUSPEITO: Paciente com febre, mialgia, cefaléia e insuficiência respiratória aguda de etiologia não determinada, na 1

semana da doença OU paciente com enfermidade aguda e insuficiência respiratória aguda, com evolução para o óbito na 1

semana da doença OU paciente com febre, mialgia, cefaléia e exposição a pelo menos uma situação de risco* até 60 dias

anteriores ao início dos sintomas ( ${ }^{*} 1$. atividades de risco para a infecção por hantavírus ou 2 . locais com roedores silvestres ou

com condições ambientais favoráveis ao seu estabelecimento).
1 Tipo de Notificação
2 - Individual

2

HANTAVIROSE

Código (CID10) 3 Data da Notificação

4

UF 5 Município de Notificação

A 98.8

ódigo (IBGE)

6 Unidade de Saúde (ou outra fonte notificadora)

8 Nome do Paciente

Código

$+\quad+\quad \mid$

10 (ou) Idade $\square_{3}^{2}$.

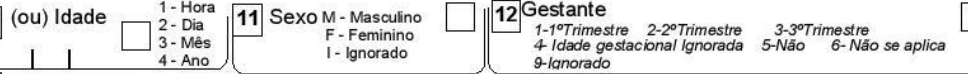

14 Escolaridade ${ }_{0}$-Analfabeto $\quad 11^{\mathrm{a}}$ a $4^{\mathrm{a}}$ série incompleta do $\mathrm{EF}$ (antigo primário ou $1^{\circ} \mathrm{grau}$ ) $2-4^{\mathrm{a}}$ série completa do $\mathrm{EF}$ (antigo primário ou $1^{\circ} \mathrm{grau}$ )

${ }^{3-5^{a}}$ a $8^{a}$ serie incompleta do EF (antigo ginásio ou $1^{\circ} \mathrm{grau}$ ) 4 -Ensino fundamental completo (antigo ginasio ou $1^{\circ} \mathrm{grau}$ ) 5 -Ensino médio incompleto (antigo colegial ou $2^{\circ} \mathrm{grau}$ ) (a)

15 Número do Cartão SUS 16 Nome da mãe

17 UF 18 Município de Residência

10

20 Bairro

rencicio de Residencia

110

Código (IBGE)

Código (IBGE) 19 Distrito

22 Número 23 Complemento (apto., casa, ...) 24 Geo campo 1

25

25 Geo campo 2

26

28 (DDD) Telefone

29 Zona 1 - Urbana 2 - Rural 3 - Periurbana 9 - Ignorado

30 Pais (se residente fora do Brasil)

\section{CEP}

\section{Dados Complementares do Caso}

\begin{tabular}{|c|c|c|}
\hline \multirow{11}{*}{ 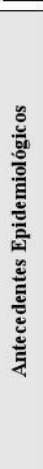 } & 1 Data da Investigação & 32 Ocupação \\
\hline & \multicolumn{2}{|c|}{33 Nas últimas 8 semanas ( 60 dias antes do início dos sintomas), desenvolveu elou expôs-se a atividades ligadas a: } \\
\hline & \multirow{9}{*}{$\begin{array}{l}\text { 1- Sim } \\
\text { 2- Não } \\
\text { 9- Ignorado }\end{array}$} & Treinamento militar em área rural ou silvestre \\
\hline & & Desmatamento, aragem de terra, plantio agricola, colheita agricola, corte de lenha e outros semelhantes \\
\hline & & Exposição e/ou limpeza de casa, despensa, galpão, depósitos, sótão, porão e outros semelhantes \\
\hline & & Moagem e/ ou armazenamento de grãos, arrumou ou moveu fardos de lenha, capim ou outros semelhantes \\
\hline & & Dormiu/descansou em barracas, galpão, paiol e outros locais semelhantes \\
\hline & & Transporte e ou carregamento (em veiculos motorizados) de cargas em geral \\
\hline & & Pescou, caçou, realizou turismo rural ou participou de atividades de ecoturismo ou similares. \\
\hline & & $\begin{array}{l}\text { Teve contato direto e/ ou viu rato silvestre ou do mato vivo ou morto ou suas excretas/vestigios (fezes, urina e/ou } \\
\text { cheiro da urina, sangue, saliva, roeduras, pegadas, trilhas, manchas e outros sinais de ratos) }\end{array}$ \\
\hline & & $\begin{array}{l}\text { Outras atividades/ exposições (outros animais ou suas instalações/ outros casos humanos de hantavirus ou } \\
\text { outras). Especifique_. }\end{array}$ \\
\hline
\end{tabular}

34 Data do $1^{\circ}$ Atendimento 35 Local $1^{\circ}$ Atendimento (US ou clínica ou hospital - Município/UF)

36 Manifestaçőes Clínicas (sinais e sintomas) 1 - Sim 2 - Não 9 - Ignorado

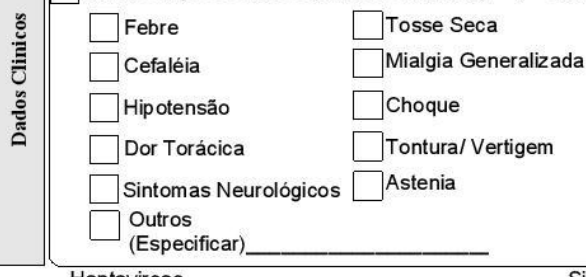

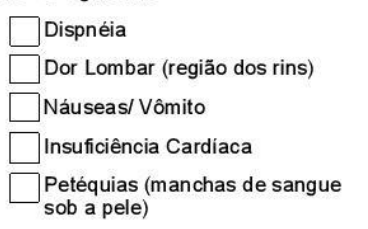

sob a pele)
Insuficiência Respiratória Aguda

Dor Abdominal

Diarréia

Insuficiência Renal

Outros manifestaçőes hemorrágicas (Especificar)

Hantavirose 


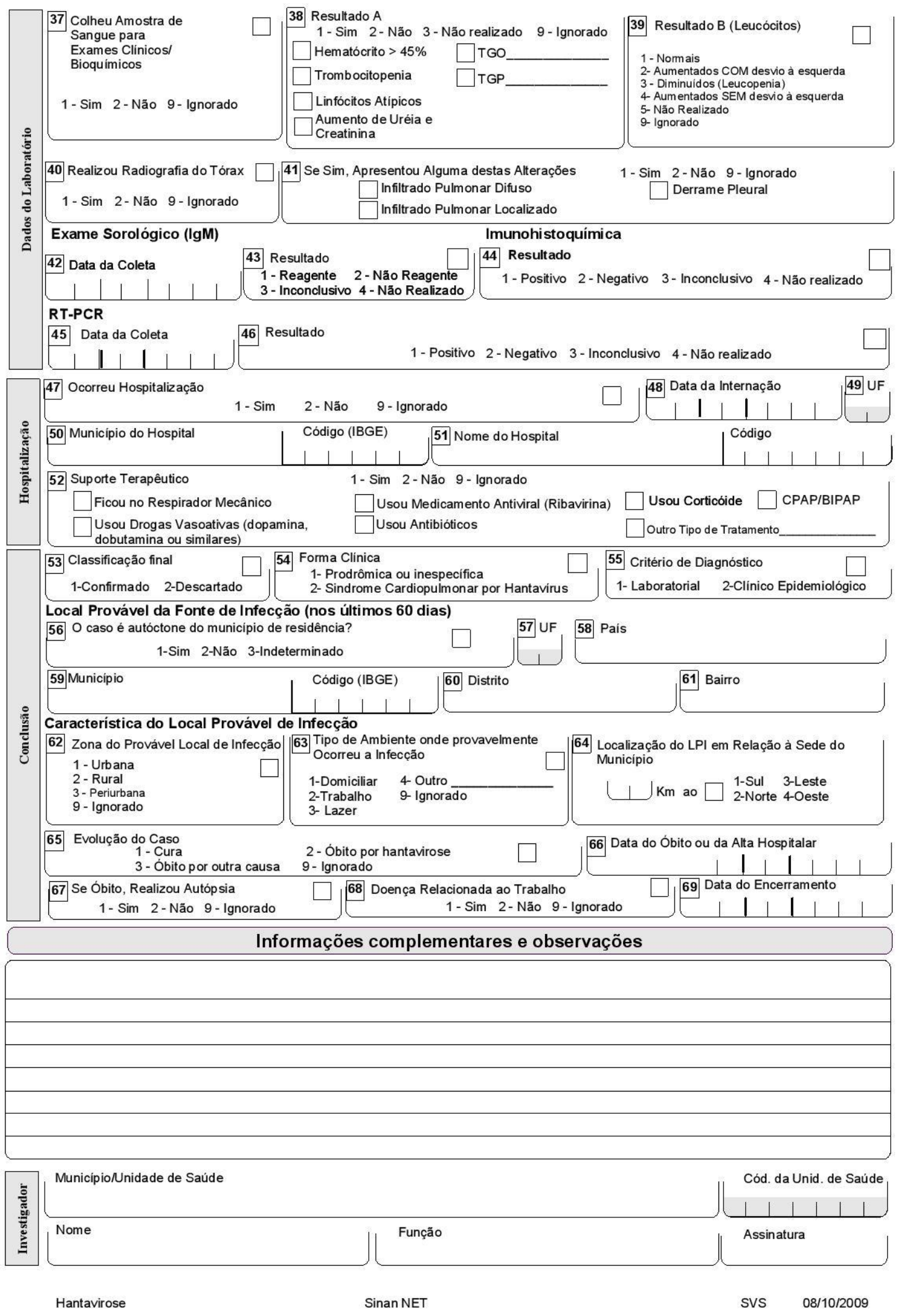

